\title{
COAGULATION OF SUBMICRON COLLOIDS BY SUPRAMICRON SILICA PARTICLES
}

\author{
by \\ David George Kebler
}

\begin{abstract}
A Thesis Submitted to the Faculty of the DEPARTMENT OF HYDROLOGY AND WATER RESOURCES In Partial Fulfillment of the Requirements For the Degree of MASTER OF SCIENCE WITH A MAJOR IN HYDROLOGY

In the Graduate college THE UNIVERSITY OF ARIZONA
\end{abstract}

$\begin{array}{llll}1 & 9 & 8 & 8\end{array}$ 


\section{STATEMENT BY AUTHOR}

This thesis has been submitted in partial fulfillment of requirements for an advanced degree at the University of Arizona and is deposited in the University Library to be made available to borrowers under rules of the Library.

Brief quotations from this thesis are allowable without special permission, provided that accurate acknowledgment of source is made. Requests for permission for extended quotation from or reproduction of this manuscript in whole or in part may be granted by the head of the major department or the Dean of the Graduate when in his or her judgement the proposed use of the material is in the interests of scholarship. In all other instances, however, permission must be obtained from the author.

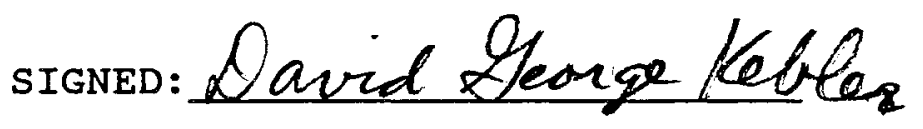

\section{APPROVAL BY THESIS DIRECTOR}

This thesis has been approved on the date shown below:

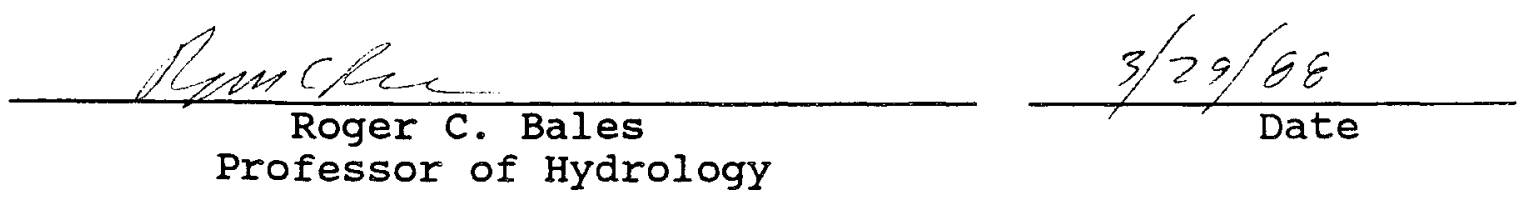




\section{ACKNOWLEDGEMENTS}

The author would like to thank both Dr. Gary I. Amy and Dr. Roger C. Bales for their input and guidance concerning my research. In particular, I want to thank Dr. Bales for initially recognizing my abilities, and finally, sending me off to the mountains of Wyoming to work.

I am indebted to Zaid Chowdhury for his assistance and input, and also to Jim Scezcody for running BET samples for me.

Finally, I want to give my thanks and love to Kathy who motivated me to finally complete writing this thesis by relentlessly standing over me with a large ruler.

Financial support for this research was provided by the U.S. Environmental Protection Agency grant R-81232501-0. The contents of this thesis do not necessarily reflect the views and opinions of the USEPA. 
LIST OF ILLUSTRATIONS....................

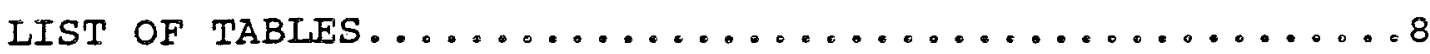

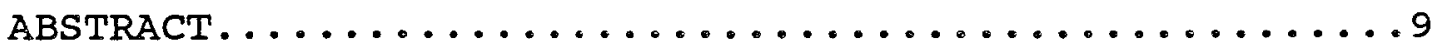

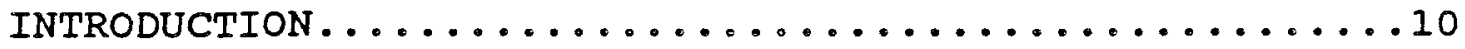

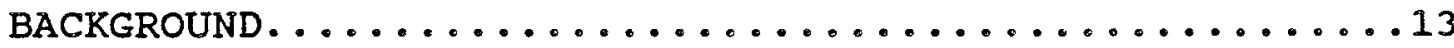

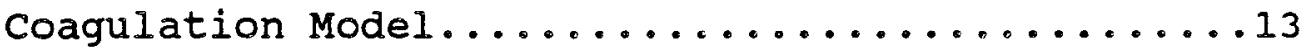

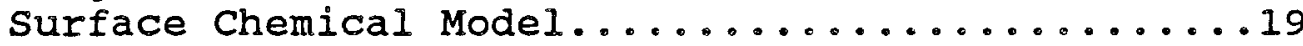

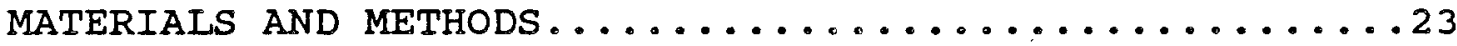

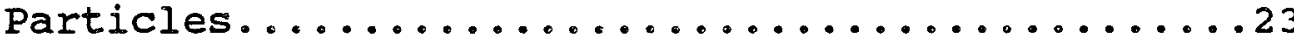

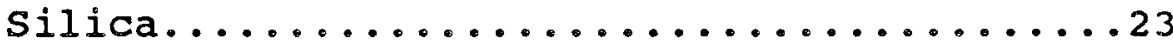

Aluminum (Hydr)oxide Colloids............24

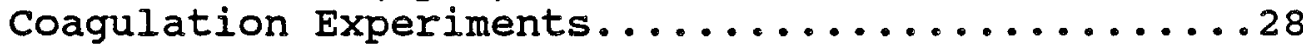

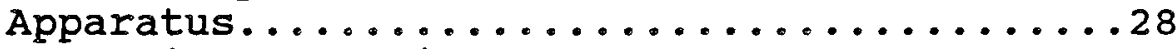

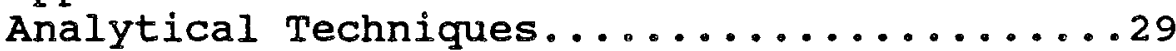

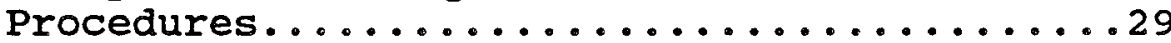

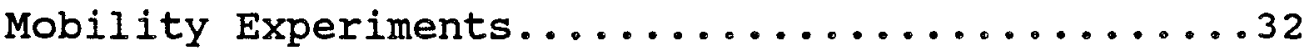

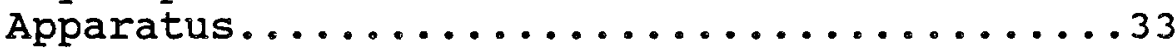

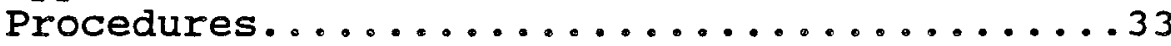

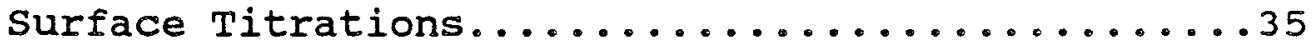

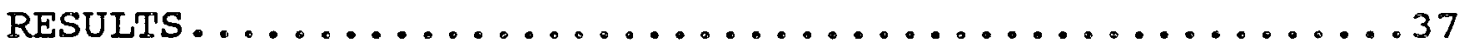

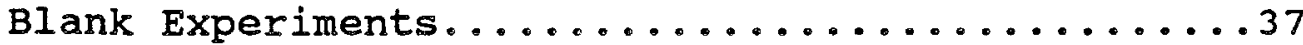

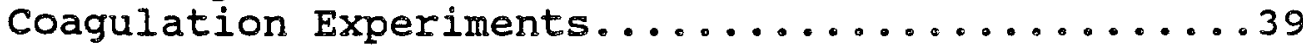

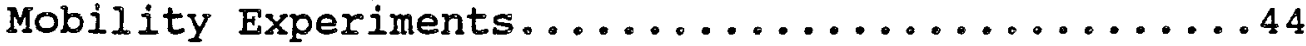

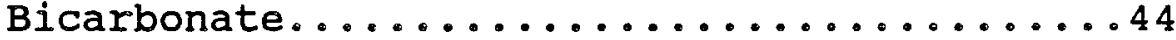

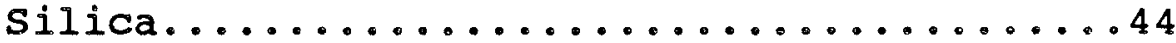

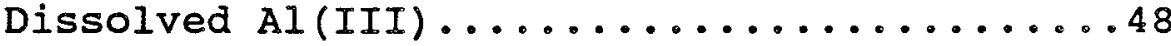

Enhanced Coagulation Experiment............48

Titration Experiments..................48

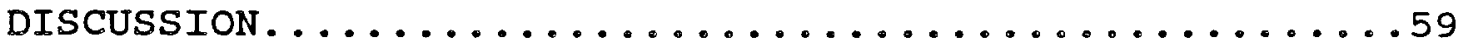

CONCLUSIONS AND RECOMMENDATIONS................ 64 
TABLE OF CONTENTS-Continued

APPENDIX A

COAGULATION EXPERIMENTS..............66

Coagulation Data..................67

Preliminary Fluid Shear Calculation.......73

APPENDIX B

MOBILITY EXPERIMENTS.................. 44

Mobility Data.....................75

pH Stat Computer Program............76

APPENDIX $C$

TITRATION EXPERIMENTS.................. 84

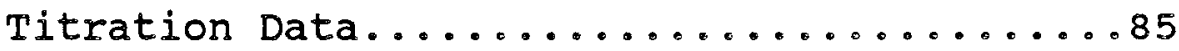

BET Adsorption..................... 88

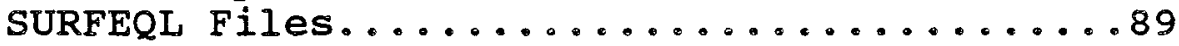

Model Curves......................93

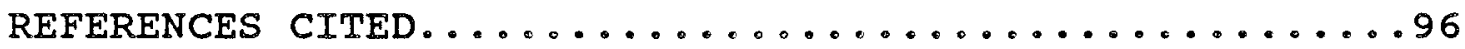




\section{LIST OF ILLUSTRATIONS}

figure

page

1 SEM photo of a typical aluminum (hydr)oxide colloid suspension

2. Mobility of aluminum (hydr) oxide colloids from 27 three different preparations.

3 Apparatus of mobility and titration expts.

4 SEM photo of self-coagulation of colloids in doublets and triplets

5 Results of Coagulation Experiments 1 and 4.

6 SEM photo of colloids coagulated on silica

7 Mobility of aluminum (hydr) oxide colloids with bicarbonate.

8 Mobility of aluminum (hydr) oxide colloids with silica present.

9 Mobility of aluminum (hydr)oxide colloids with dissolved silica present

10 Mobility of aluminum (hydr) oxide colloids with silica particles $\left(8 \times 10^{8} \mathrm{~L}^{-1}\right)$ and aluminum present.

11 Stirred beaker results for experiments 3 and 6.50

12 Titration of water and $10^{-3} \mathrm{M}$ dissolved silica. 52

13 Titration of $\alpha$-alumina.

14 Titration of $\alpha$-alumina $\mathrm{w} / 10^{-5} \mathrm{M} \mathrm{Si}$.

15 Titration of $\alpha$-alumina $w / 10^{-4} \mathrm{M} \mathrm{Si}$. 55

16 Titration of $\alpha$-alumina $w / 10^{-3} \mathrm{M} \mathrm{Si}$. 56

17 Titration of $\alpha$-alumina $w / 10^{-3} \mathrm{M} \mathrm{Si}$. with adsorption of $\mathrm{Si}$ 


\section{LIST OF ILLUSTRATIONS-COntinued}

figure

$\mathrm{C}-1$ Model runs $\mathrm{w} /$ variable surface area for $\mathrm{Al}_{2} \mathrm{O}_{3}$

C-2 Model runs $w /$ variable $\mathrm{pK}^{\prime}$ s for $\mathrm{Al}_{2} \mathrm{O}_{3}$

C-3 Model runs $\mathrm{w} / \mathrm{variable} \mathrm{pK}$ 's for ligand exch. page

93

94

95 


\section{LIST OF TABLES}

Table

page

1 Previous Determinations of $\alpha$

2 Example of Relative Contribution to coagulation by silica Particles

3 Equations for chemical modelling 22

4 Summary of Experimental Conditions for 31 Coagulation Experiments

$5 \quad$ Blank Experiments 38

6 Summary of Conditions and $\alpha$ Values for Expts. 1-6 
ABSTRACT

Values of $\alpha$ (coagulation efficiency) for coagulation of aluminum (hydr)oxide colloids by supramicron silica particles were generally near 0.01 . Although the freshly suspended particles were oppositely charged, dissolved silica from the particulate silica adsorbs to the colloids reversing their charge. Bicarbonate also adsorbs and shifts the $\mathrm{pH}_{i e p}$ of the aluminum (hydr)oxide colloids. The addition of dissolved $A l$ (III) had a similar effect on both types of particles.

Dissolved silica adsorbs to the hydrous aluminum oxide surface and undergoes ligand exchange. This exchange can be simulated by a constant capacitance model for adsorption of aqueous species to the oxide surface and fits laboratory titration data. 


\section{INTRODUCTION}

The purpose of the research conducted for this thesis was to gain insight into chemical conditions responsible for the fast versus slow removal of submicron particles from natural waters as well as from raw water sources being processed at water-treatment plants. Removal involves the heterogeneous coagulation of submicron colloids with larger supramicron particles that settle out in lakes or in sedimentation tanks.

Rates of coagulation in water treatment and natural waters are particulary important where removal of submicron colloids are of interest. Specific toxic organics may be strongly sorbed to these colloids and thus provide a means of passing through water treatment unaffected. Additionally, the surfaces of these colloids may act as sites for the formation of chlorinated organics, especially when the surfaces are coated with natural organic matter (NOM). Smaller-sized particles are relatively more abundant than larger ones in some natural waters(Bales, 1984), and represent a significant fraction of the available surface area for sorption. Consequently, their removal by hetero-coagulation is important in water treatment. 
In this research a physically and chemically welldefined system was used to model the more heterogenous natural system. Measuring the rate of submicron particle coagulation/removal in the system was the ultimate goal. The surface charge of both submicron and supramicron particles in the system strongly influences this rate. This surface charge is determined by the structure and chemical properties that make up the particles as well as inorganic ions in solution and $\mathrm{pH}$.

The majority of research was conducted with submicron aluminum (hydr)oxide colloids prepared in the lab. These particles posses the characteristics suitable for a welldefined system. They are monodispersed with a narrow range of size $(0.5 \mu \mathrm{m})$. They have a positive surface charge at natural water $\mathrm{pH}$, and there is a substantial chemical equilibrium data base for aluminum (hydr)oxide.

The supramicron particle chosen for the system was silica. Silica was chosen because it is commercially available, it has a strong negative surface charge at natural water $\mathrm{pH}$, opposite to that of the colloids, and can be enumerated easily by optical particle counting.

The objective then was to use these two particles in two well-defined physical systems - transport via shear and via settling -- to measure the rate of removal (coagulation) of the aluminum hydr(oxide) colloids with the larger silica particles from $\mathrm{pH} 5$ to $\mathrm{pH}$. This rate was 
predicted to be quite high based on the favorable electrostatic conditions. That is, the coagulation efficiency or fraction of particle-particle collisions that result in sticking should be near one. Secondly, the effect of selected ions on the surface charge of the colloids, and hence the coagulation efficiency was investigated as the result of observations made in the initial experiments. Finally, the surface charge properties of the colloids were investigated with the aid of a computer chemical equilibrium model. The model results were used to interpret results of the experiments and to further understanding of the surface charge properties(i.e coagulation rate) in order to give better predictions of coagulation in natural waters. 


\section{BACKGROUND}

\section{Coagulation Model}

Several current models exist for coagulation. For slow coagulation, each of these models separates this process into two steps. one is purely physical step (particle transport) and the other is a combination of physical and chemical steps(adhesion).

Model calculations suggest that submicron particles should be largely removed from lakes due to coagulation (O'Melia, 1985), provided that the coagulation efficiency (i.e. $\alpha$, fraction of particle-particle contacts that result in sticking) is similar to that measured for larger particles.

The deterministic model used in this research follows that by O'Melia(1980). It makes use of an empirical coagulation efficiency factor $(\alpha)$ which describes the second, physio-chemical, step of the model. This sticking or coagulation efficiency is the reciprocal of the theoretical Fuch's stability ratio $w$.

The sticking factor or coagulation efficiency is defined as follows:

$$
\alpha=\frac{\text { Rate of particle attachment }}{\text { Rate of particle collisions }}
$$


This factor is dependent on the physio-chemical processes present which determine the attachment rate. An $\alpha$ of one indicates a fully destabilized particle(i.e. each collision results in coagulation).

Initial calculations by stumm and Ell(1971) suggest $\alpha$ is in the range of $10^{-6}$ in fresh waters. Stumm(1977) suggests $\alpha$ to be $\approx 0.1-1.0$ in seawater. Most laboratory and field data indicate $\alpha$ ranges from 0.007 (Ali et al., 1984 ) to 0.8 (Gibbs, 1983) for fresh water. Table 1 presents values of $\alpha$ from several sources, most of which are for supramicron sized particles. An estimated value for $\alpha$ for chrysotile-asbestos fibers in four southern California reservoirs is near 0.001 (Bales et al., 1984).

In the coagulation experiments conducted the disappearance of only one class of particles was of interest, the disappearance aluminum hydr(oxide) submicron colloids. The supramicron particle concentrations were assumed to be constant, and the colloids were assumed only to coagulate with the supramicron particles. Both these assumptions were verified. The resulting pseudo-first order differential equation used to calculate $\alpha$ (adapted from O'Melia, 1980) gives the rate of disappearance of the submicron colloids with time $\left(-\mathrm{dn}_{1} / \mathrm{dt}, \mathrm{L}^{-1} \mathrm{~s}^{-1}\right)$ : 
Table 1: Previous Deterwinations of a

\begin{tabular}{|c|c|c|c|c|}
\hline Coagulant & Colloid & Transport & $\alpha$ & Invesitgator \\
\hline $\mathrm{NaCl}$ & $\begin{array}{c}\text { Polystyrene } \\
\text { latex }\end{array}$ & $\begin{array}{l}\text { Shear } \\
\text { Brownian } \\
\text { Shear }\end{array}$ & $\begin{array}{c}0.364 \\
0.375 \\
0.344-0.488\end{array}$ & $\begin{array}{l}\text { Swift and } \\
\text { Friedlander (1964) } \\
\text { Birkner and } \\
\text { Morgan (1968) }\end{array}$ \\
\hline$A I(I I I)$ & silica & $\begin{array}{l}\text { Shear } \\
\text { Brownian }\end{array}$ & $\begin{array}{l}0.011 \\
0.01\end{array}$ & $\begin{array}{l}\text { Hahn and } \\
\text { Stumm (1968) }\end{array}$ \\
\hline $\begin{array}{l}\text { NaCl } \\
\text { Syn. Sea } \\
\text { Water }\end{array}$ & $\begin{array}{l}\text { Clays } \\
\text { Estuary } \\
\text { Sediments }\end{array}$ & Shear & $\begin{array}{l}0.012-0.12 \\
0.02-0.15 \\
0.05-0.22\end{array}$ & $\begin{array}{l}\text { Edzwald, Upchurch, } \\
\text { and o'Melia(1974) }\end{array}$ \\
\hline $\begin{array}{l}\mathrm{Ca}^{2+} \\
\text { Filtered Lake } \\
\text { Water }\end{array}$ & $\mathrm{Al}_{2} \mathrm{O}_{3}$ & $\begin{array}{l}\text { Shear } \\
\text { Shear }\end{array}$ & $\begin{array}{c}0.01-0.063 \\
0.086\end{array}$ & Osman-sigg(1982) \\
\hline $\begin{array}{l}\text { Filtered Lake } \\
\text { water }\end{array}$ & $\begin{array}{l}\text { Natural Lake } \\
\text { Colloids }\end{array}$ & shear & $0.01-0.08$ & $\begin{array}{l}\text { Ali,o'Melia, et.al } \\
(1984)\end{array}$ \\
\hline
\end{tabular}


where $n_{i}$ is the concentration $\left(L^{-1}\right)$ of supramicron size class $i$ particles $(i=2$ to $\infty)$, and $n_{1}$ is the concentration of submicron particles $(i=1) . k_{i j}$ is the coagulation rate constant for the ith size class and jth physical mechanism $\left(\mathrm{Ls}^{-1}\right)$.

The coagulation rate constant $k_{i j}$ depends on the three types of mechanisms which make up the first step of the coagulation model(particle transport). They are Brownian diffusion, differential settling, and fluid shear. Equations 3,4 , and 5 show the calculation for $k_{i 1}, k_{i 2}$, and $k_{i 3}$ for these three mechanisms, respectively. In every case all particles are assumed to be spherical.

$$
\begin{aligned}
& k_{i 1}=\frac{\frac{2 \pi k T}{3 \mu} \frac{\left(d_{1}+d_{i}\right)^{2}}{d_{1} d_{i}}}{k_{i 2}=\frac{\pi g\left(\rho_{p}-\rho\right)\left(d_{1}+d_{i}\right)^{2}\left(d_{i}{ }^{2}-d_{1}{ }^{2}\right)}{72 \mu}} \\
& k_{i 3}=\frac{G\left(d_{1}+d_{i}\right)^{3}}{6}
\end{aligned}
$$

$d_{1}$ is the diameter of the submicron particles, $5 \times 10^{-5} \mathrm{~cm}$; $d_{i}$ is the diameter of supramicron particle size class $i$, 
$\mathrm{cm}$; $G$ is the fluid shear rate, $163 \mathrm{~s}^{-1} ; \mu$ is the viscosity $0.01 \mathrm{gcm}^{-1} \mathrm{~s}^{-1}$ for water; $\rho_{p}$ is the particle density, $2.6 \mathrm{gcm}^{-3} ; \quad \rho$ is the density of water, $1.0 \mathrm{gcm}^{-3}$; $g$ is the gravitational constant, $980 \mathrm{cms}^{-1} ; \quad \mathrm{k}$ is Boltzmann's constant, $1.4 \times 10^{-16} \mathrm{gcm}^{2} \mathrm{~s}^{-2} \mathrm{~K}^{-1} ; \quad T$ is the absolute temperature, $298 \mathrm{~K}$.

The two mechanisms used to induce particle transport in this research were fluid shear and differential settling. Each was used separately in determining $\alpha$. In either case the contribution of Brownian diffusion to the total coagulation rate constant $\Sigma k_{i j}$ is negligible. For example, the $k_{i j}$ 's for the $12-16 \mu \mathrm{m}$ silica particle size class ( $14 \mu \mathrm{m}$ ave. dia., $i=3$ ) are $k_{31}=2.62 \times 10^{-10}$ $\mathrm{cm}^{3} \mathrm{~s}^{-1}, \mathrm{k}_{32}=2.89 \times 10^{-8} \mathrm{~cm}^{3} \mathrm{~s}^{-1}$, and $\mathrm{k}_{33}=8.28 \times 10^{-8}$ $\mathrm{cm}^{3} \mathrm{~s}^{-1}$. This size class accounts for the largest percentage of the total coagulation and confirms that coagulation due to Brownian collisions can be neglected (Table 2). In the fluid shear experiments all the particles are suspended and differential settling can be neglected. Similarly, in the settling column experiments fluid shear was small(G) and can be neglected. Table 2 shows the relative contribution of each size group of a typical silica particle distribution to coagulation, $\left(n_{i} k_{i j} / \Sigma n_{i} k_{i j}\right) \times 100$.

Integrating equation (2) and substituting $k_{i j}$ for each mechanism of interest yields equation (6) for differential 
Table 2: Example of Relative contribution to Coagulation by Silica Particles

\begin{tabular}{c|c|c|c}
\hline \multirow{2}{*}{} & & \multicolumn{3}{|c}{ percent } \\
\cline { 2 - 4 } size $\mu \mathrm{M}$ & $\mathrm{n}_{\mathrm{i}} / \mathrm{\Sigma}_{i}$ & \multicolumn{2}{|c}{$\mathrm{n}_{i} k_{i j}\left(s^{-1}\right)$} \\
\hline $1.5-8$ & 14 & 0.1 & 0.7 \\
$8-12$ & 24 & 5.1 & 8.7 \\
$12-16$ & 39 & 31.1 & 37.1 \\
$16-20$ & 18 & 37.6 & 34.6 \\
$20-24$ & 4 & 19.3 & 14.5 \\
$>24$ & 1 & 6.8 & 6.8 \\
& 100 & 100.0 & 100.0 \\
\hline
\end{tabular}

Note: Size distribution, $n_{i} / \Sigma n_{i}$, is from the rounded average of exps. 1-5. $n_{i} k_{i j}$ is based on this distribution and $10^{8}$ particles $\mathrm{L}^{-1}$ total. 
settling and equation (7) for fluid shear. These equations can be used to determine $\alpha$ experimentaliy.

$$
\begin{aligned}
& \alpha=\frac{-t \Sigma k_{i 2} n_{i}}{\ln \frac{n_{1}}{n_{1} \circ}}, i=2 \text { to } \infty \\
& \alpha=\frac{-t \Sigma k_{i 3} n_{i}}{\ln \frac{n_{1}}{n_{1} \circ}}, i=2 \text { to } \infty
\end{aligned}
$$

To compute $\alpha$ the concentration of submicron particles remaining at any time $t\left(n_{1}, n_{1}{ }^{0}=\right.$ conc. at time zero) needs to be measured. The supramicron particle size distributions needs to be established to determine the coagulation rate constants $\mathrm{k}_{\mathrm{i} 2}$, and $\mathrm{k}_{\mathrm{i3}}$. For shear experiments the rpm of the stirrer must be measured to calculate G used in equation (5). The supramicron particle concentration distribution must be measured to determine values for $n_{i}$.

\section{Surface Chemical Model}

The surface speciation of aluminum (hydr)oxide will determine its net surface charge and consequently its mobility and coagulation efficiency. To compare computer model runs with laboratory titrations, a constant- 
capacitance model was assumed to characterize the surface adsorption of ions from solution.

In the model used, equations (8) and (9) give the expression for the intrinsic equilibria of the amphoteric proton coordination of the aluminum (hydr) oxide surface. The adsorption of silica to the oxide surface was assumed to be a ligand exchange. Equation (10) gives the equilibria for the ligand exchange of silica onto the aluminum oxide surface. Equation (11) includes ligand exchange plus dissociation of the surface complex.

$\mathrm{K}^{S} \mathrm{aI}(\mathrm{int})=\frac{\{\equiv \mathrm{AlOH}\}\left[\mathrm{H}^{+}\right]}{\left\{\equiv \mathrm{AlOH}_{2}{ }^{+}\right\}} e^{-\mathrm{e} \psi / \mathrm{KT}}$

$\mathrm{K}_{\mathrm{S} 2(\mathrm{int})}=\frac{\left\{\equiv \mathrm{AlO}^{-}\right\}\left[\mathrm{H}^{+}\right]}{\{\equiv \mathrm{A} 1 \mathrm{OH}\}} \mathrm{e}^{-\mathrm{e} \psi / \mathrm{KT}}$

$*_{\mathrm{K}^{\mathrm{S}}}{ }_{{ }_{\mathrm{Si}}}=\frac{\{\equiv \mathrm{AlOH}\}\left[\mathrm{H}_{2} \mathrm{SiO}_{4}{ }^{2-}\right]\left[\mathrm{H}^{+}\right]^{2}}{\left\{\equiv \mathrm{AlH}_{3} \mathrm{SiO}_{4}\right\}}$

$* K_{2}^{S_{S i}}=\frac{\{\equiv \mathrm{A} I \mathrm{OH}\}\left[\mathrm{H}_{2} \mathrm{SiO}_{4}^{2-}\right]\left[\mathrm{H}^{+}\right]}{\left\{\equiv \mathrm{AlH}_{2} \mathrm{SiO}_{4}^{-}\right\}} e^{-\mathrm{e} \psi / \mathrm{kT}}$

Concentrations of surface species (in braces\} are in mol $\mathrm{cm}^{-2}$ and solution species [in brackets] are in mol $\mathrm{L}^{-1}$. $\Psi$ is the surface potential(volts), $e$ is the charge on an electron, $k$ is Boltzmann's constant, and $T$ is absolute temperature. 
The surface charge-density $\left(C \mathrm{~cm}^{-2}\right)$ is given by:

$$
\sigma=\left\{\equiv \mathrm{AlO}^{-}\right\}+\left\{\equiv \mathrm{AlOH}^{2+}\right\}+\left\{\equiv \mathrm{AlSiO}_{4} \mathrm{H}^{-}\right\}
$$

where $F$ is the Faraday constant. The relation between charge and potential is given by:

$$
C=\sigma / \psi
$$

where $C$ is capacitance $\left(F \mathrm{~m}^{-2}\right)$ in this model. Finally, mass balance requires that:

$$
\mathrm{S}_{\mathrm{T}}=\left\{\equiv \mathrm{AlO}^{-}\right\}+\left\{\equiv \mathrm{AlOH}_{2}{ }^{+}\right\}+\left\{\equiv \mathrm{AlH}_{2} \mathrm{SiO}_{4}-\right\}+\{\equiv \mathrm{AlOH}\}+\left\{\equiv \mathrm{AlH}_{3} \mathrm{SiO}_{4}\right\}
$$

where $S_{T}$ is the total number of surface sites (mol $\mathrm{cm}^{-1}$ ). The program used to compute concentrations of the species present in the surface chemical model is called SURFEQL(Westall et. al., 1976, and Westall, 1980) • The program is a calculation procedure to determine equilibrium concentrations of ions, complexes, and solids in an aqueous solution. It will also calculate adsorption of ions or complexes at solid surfaces making use of a constant capacitance model. Inputs are component concentrations, equilibrium constants for the reactions considered, and a capacitance value.

Table 3 gives the set of equations used in the chemical modelling along with literature values for the equilibrium constants. 
Table 3: Equations for chemical modelling

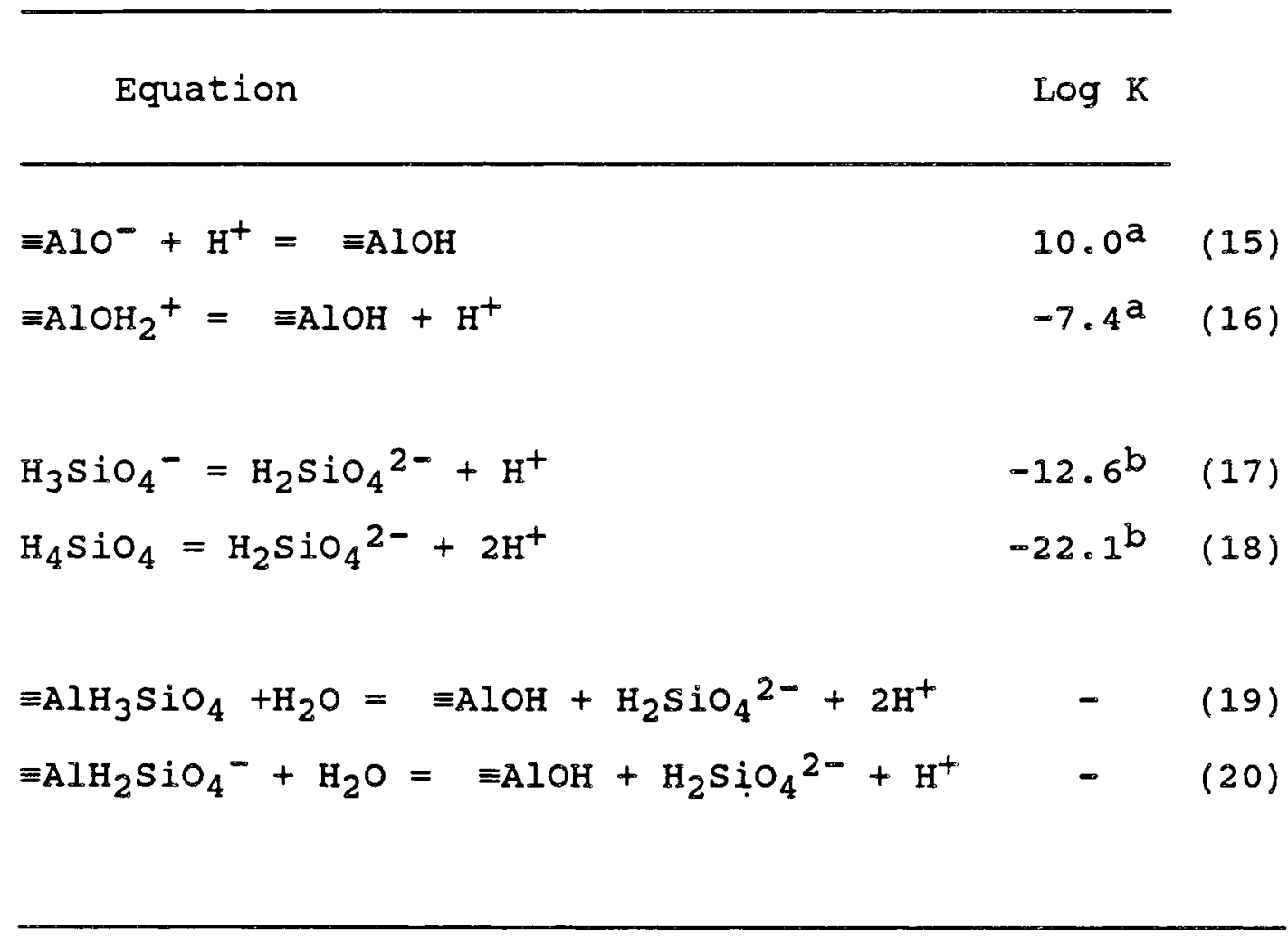

COMPONENTS: $\equiv \mathrm{AlOH}, \mathrm{H}_{2} \mathrm{SiO}_{4}{ }^{2-}, \mathrm{H}^{+}, \mathrm{e}^{-\mathrm{e} \Psi / \mathrm{kt}}$ (electrostatic component)

aReference: Kummert \& Stumm, 1980

beference: Stumm \& Morgan, 1981

Note: Equilibrium constants for equations (19) and (20) are not found in the literature. 
MATERIALS AND METHODS

Supramicron silica particles together with submicron aluminum (hydr)oxide particles were used in this experimental work. The objective in choosing these particles was to investigate the coagulation of a submicron particle with a supramicron particle where the charge of each at natural water $\mathrm{pH}$ conditions is different. This section will define the preparation of these particles, and their chemical and physical properties.

Four distinct sets of experiments were conducted:

1. coagulation experiments in a settling column; 2 . coagulation experiments in a stirred beaker; 3 . mobility experiments on the submicron colloids; and 4. titration of the aluminum hydr(oxide) colloids in the presence of dissolved silica. The coagulation and mobility experiments were done with colloid concentrations relevant to natural waters.

All procedures discussed made use of only reagent grade water (type I) filtered through a $0.22 \mu \mathrm{m}$ filter.

\section{Particles}

Silica. Silica $\left(\mathrm{SiO}_{2}\right)$ was Min-U-Sil 15 obtained from Pennsylvania sand Glass corp. of Berkeley springs, West 
Virginia. The manufacturer reports a silica content of 90.7 percent and a specific gravity of 2.65 . Silica was suspended in a $0.5-\mathrm{L}$ glass stoppered bottle and decanted with water until the remaining particles would settle in about 10 minutes. The typical volume average diameter after decanting was 10-11 $\mu \mathrm{M}$. The reported $\mathrm{pH}_{\text {iep }}$ (isoelectric point) for amorphous silica is 2.0 (stumm and Morgan, 1981).

The cleaning procedure of just washing and decanting the silica particles with water was less rigorous than that of Vuceta(1976) and Young(1981); the latter noted little difference between cleaned versus uncleaned material. Later, concern of contamination led us to more rigorous cleaning as per Young(1981). However, the results of repeated experiments using the extra-clean silica demonstrated that the original procedure was adequate.

Aluminum (Hydr)oxide colloids. Two different aluminum (hydr)oxide colloids were used. For all but the titration experiments, the colloids were prepared in the lab as needed. The preparation was slightly modified from that of Brace and Matijevic(1973). First, all glassware was thoroughly cleaned, acid washed(10 percent $\mathrm{HNO}_{3}$ ), and rinsed repeatedly with water. A solution of $1 \mathrm{mM}$ aluminum sulfate(as Al) was prepared and filtered through a $0.1 \mu \mathrm{M}$ filter prewashed with $250 \mathrm{~mL}$ of water. The filtrate was 
placed in a $0.5 \mathrm{I}$ glass stopped bottle with teflon tape on the stopper to insure a tight seal. The bottle was placed in a $98^{\circ} \mathrm{C} \pm 2^{\circ} \mathrm{C}$ oven for approximately 4 days. The suspension of aluminum (hydr)oxide colloids was then transferred to a $500 \mathrm{~mL}$ separatory funnel and dripped into $400 \mathrm{ml}$ of water maintaining constant $\mathrm{pH} 9$ with the addition of $0.01 \mathrm{M} \mathrm{NaOH.} \mathrm{Finally,} \mathrm{the} \mathrm{suspension} \mathrm{was} \mathrm{centrifuged} \mathrm{at}$ 2000 rpm for 15, 30, and 45 minutes and decanted after each spin. A successful preparation resulted in a particle concentration of approximately $10^{11}$ particles per liter of a monodispersed colloid with a very tight size distribution $(0.5 \mu \mathrm{M} \pm 0.1 \mu \mathrm{M})$ (Figure 1). The success of a preparation was strongly dependent on maintaining a very constant temperature, and avoiding contamination.

The iso-electric point of the colloids can vary between preparations. As noted by Brace and Matijevic(1973), aging time and incomplete removal of sulfate during hydrolysis and centrifugation are two possible reasons. The typical preparation would result in an $\mathrm{pH}_{\text {iep }}$ of $\mathrm{pH} 7.5-8$. These values agree with Chowdhury(1988), but not necessarily with Brace and Matijevic(1973). Figure 2 shows the mobility curves for aluminum (hydr)oxide colloids prepared by the author, Chowdhury, and Brace and Matijevic. The variations with the Chowdhury's curve could be attributed to slight differences in preparation and electrophoretic mobility 


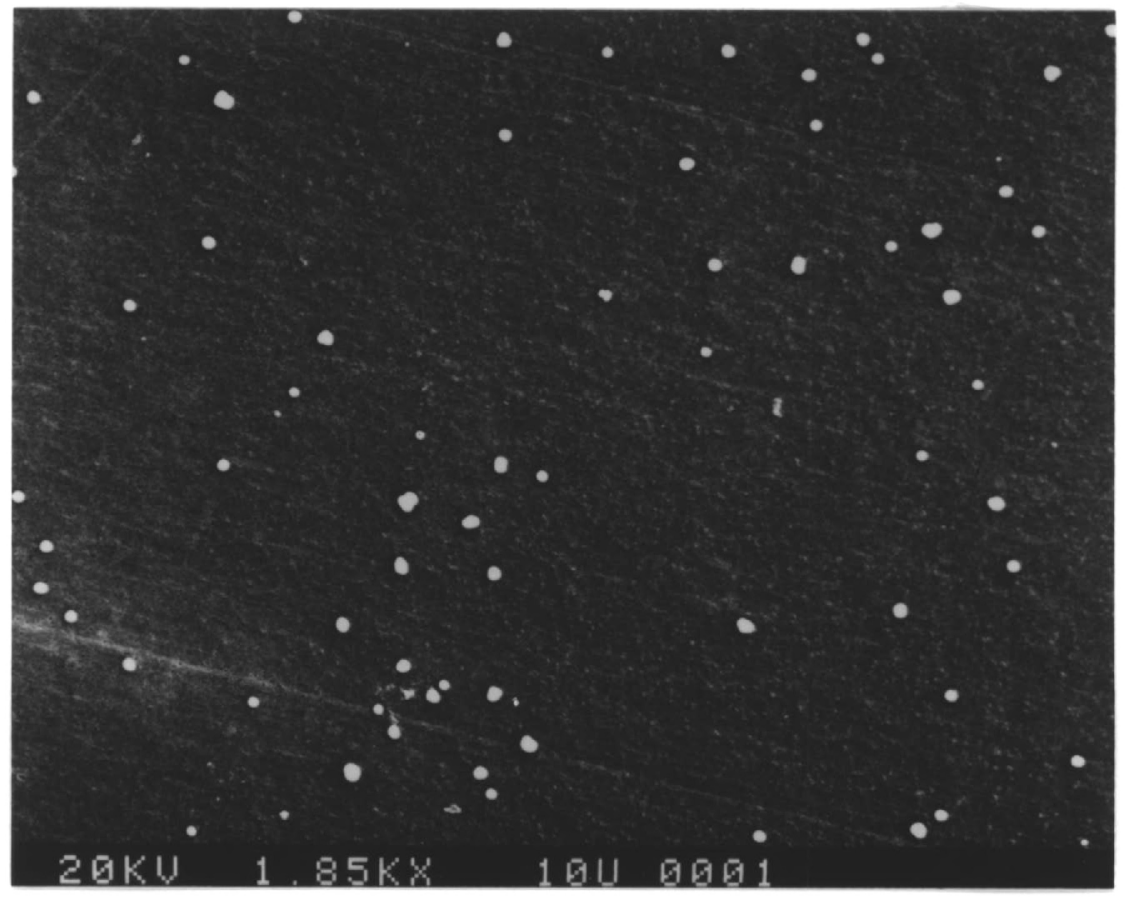

Figure 1: SEM photo of a typical aluminum (hydr) oxide colloid suspension. 


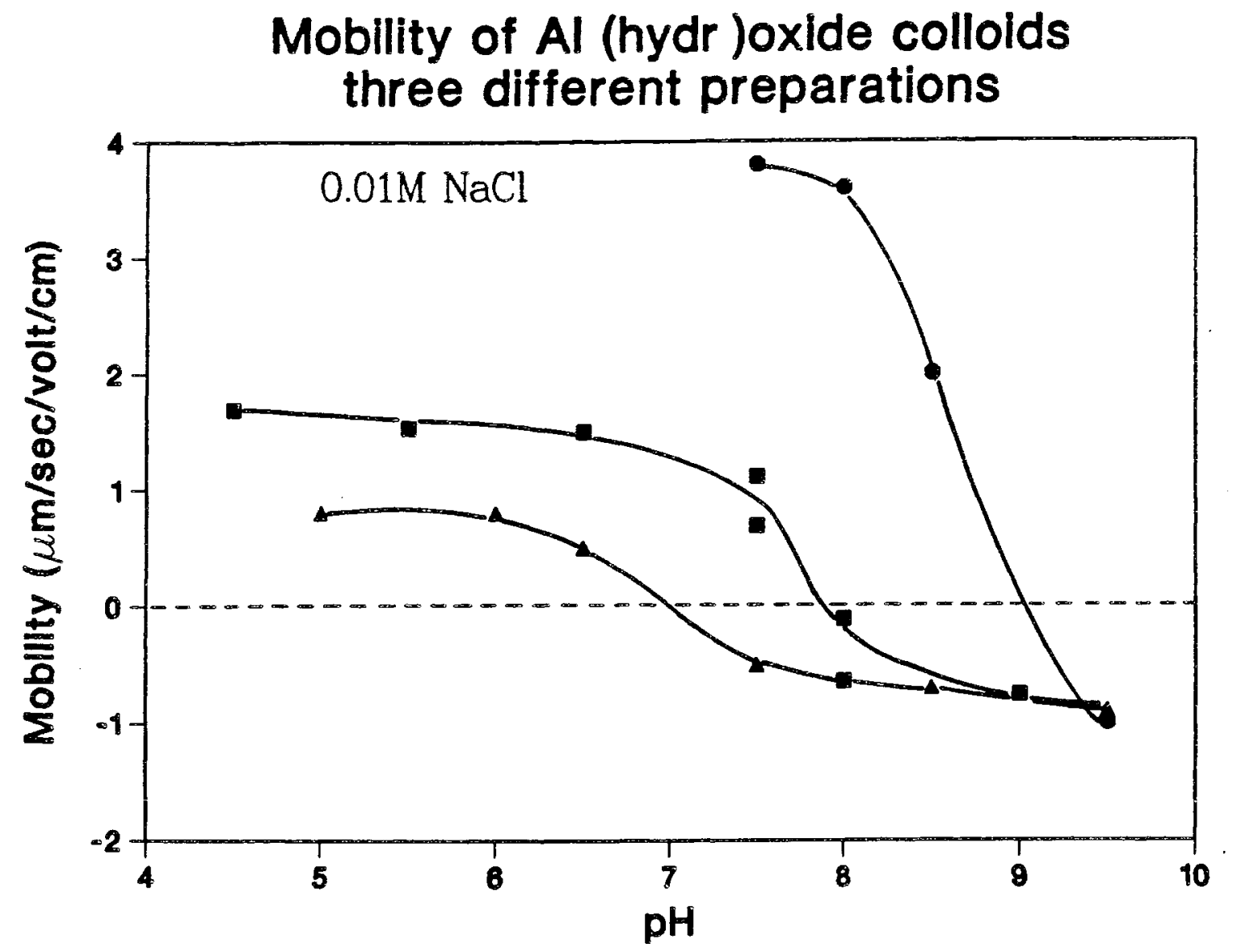

Figure 2: Mobility of aluminum (hydr) oxide colloids from three different preparations.

- this work,

- Chowdhury (1988),

Matijevic (1973) 
measurement procedures.

Further information on the physical and chemical properties of the aluminum (hydr)oxide colloids can be found in Brace and Matijevic(1973).

Due to the small amounts of the above colloid that were able to be produced, a second manufactured aluminum (hydr)oxide colloid was used in the surface titration

experiments. The product is named " $\alpha$-alumina" and is produced by Buehler Ltd. $(0.3 \mu \mathrm{m}, \# 40-6305-016)$. The $\alpha$-alumina was first heated overnight in an oven at $250^{\circ} \mathrm{C}$, then placed in $1 \mathrm{M} \mathrm{NaOH}$ overnight. The suspension was then washed with $1 \mathrm{M} \mathrm{HCl}$ for 15 minutes, and decanted several times with water, saving the supernatant. Decanting took place 30 minutes after shaking, to remove the larger (supramicron) particles. The clean, decanted suspension was filtered and the resultant solid left to dry overnight in a $100^{\circ} \mathrm{C}$ oven. The dry powder was then stored in a desiccator until used.

\section{Coagulation Experiments}

Apparatus. Coagulation experiments were designed to determine the rate at which aluminum (hydr)oxide colloids coagulate with larger silica particles in a dilute suspension. Two different types of coagulation reactors were used(one for settling, one for fluid shear). A $70 \mathrm{~cm}$ x $8 \mathrm{~cm}$ glass settling column mounted on teflon ends was 
used in the differential settling experiments. Holes were drilled in the teflon to enable filling and withdrawing samples. Fluid shear experiments were conducted in a 4-I pyrex beaker stirred overhead. The beaker was sealed on top with plexiglass.

Analytical Techniques. Enumeration of silica particles was done by a Hiac optical particle counter. Typically, samples of a silica suspension were diluted into the working range of the machine and the average of three runs was used. The counter was set to measure concentration ( $\mathrm{L}^{-}$ 1) in 6 ranges of $1.5-8,8-12,12-12,20-24$, and $>24 \mu \mathrm{M}$. Enumeration of the colloids was done by counting individual colloids on a photo taken by a scanning Electron Microscope(SEM) or when the number was less than 20 , on the SEM video screen. A sample of known volume was diluted and filtered onto a $0.22 \mu \mathrm{M}, 47 \mathrm{~mm}$ polycarbonate filter (Nuclepore Corp.). The area of filtration was that of the inside of the Millipore filter holder. A piece of the filter was then mounted for SEM viewing. Typically 3-4 photos(5-10 if from the screen) of different portions of the filter were counted and averaged. The concentration of the colloids was back calculated from this data.

Procedures. The suspension used in reactors consisted of 4 $\times 10^{8} \mathrm{~L}^{-1}$ to $9 \times 10^{8} \mathrm{~L}^{-1}$ of aluminum (hydr)oxide particles, 
and $8 \times 10^{7} \mathrm{~L}^{-1}$ to $1 \times 10^{8} \mathrm{~L}^{-1}$ of the silica particles in a $0.01 \mathrm{M}$ ionic strength electrolyte of $0.009 \mathrm{M} \mathrm{NaCl}$ and 0.001 $\mathrm{M} \mathrm{NaHCO}_{3}$. The suspension was prepared just prior to the experiment and the $\mathrm{pH}$ was adjusted to 5.5. At this $\mathrm{pH}$ the two types of particles are, separately, opposite in charge. Table 4 summarizes the experimental conditions for both types of experiments.

Samples were enumerated for both silica particles and aluminum(hydr)oxide colloids. samples for colloid enumeration were allowed to settle for 10 minutes in order to remove most silica particles before filtering for SEM mounts. In addition, the mobility of the colloids was measured with a Rank Brothers particle microelectrophoresis apparatus using a flat cell (Mark II, Cambridge, England). At least 5 colloids were timed with each polarity setting, and an average mobility and standard deviation were calculated. When colloids were near their iso-electric point many more were counted as the variation of mobility was relatively the greatest.

For differential settling the column was inverted every 30 minutes to keep the silica particles suspended. Samples of 20-60 mL were taken 5 minutes after inversion at a depth of $8 \mathrm{~cm}$ at $0,4.5,8.5$, and 12.5 hours. This sequence was determined to give the most consistent silica particle distribution. 
Table 4: Summary of Experimental Conditions for Coagulation Experiments

SETTLING COLUMN

- $70 \mathrm{~cm}$ X $8 \mathrm{~cm}$ dia.

- Inverted at $30 \mathrm{~min}$. intervals

STIRRED BEAKER

- $3000 \mathrm{~mL}$ suspension

$-G=160 \mathrm{~s}^{-1}$

SUSPENSION (typical)

- $8 \times 10^{8} \mathrm{~L}^{-1}$ of $\mathrm{Al}$ (hydr) oxide

- $9 \times 10^{7} \mathrm{~L}^{-1}$ of Min-u-Sil 15

- $0.009 \mathrm{M} \mathrm{NaCl}$

$-0.001 \mathrm{M} \mathrm{NaHCO}_{3}$

\section{ANALYSIS}

- Al (hydr)oxide by SEM

- Silica by Hiac counter

- Mobility with Rank Bros. particle micro-electrophoresis apparatus 
For the fluid-shear experiments, the suspension in the beaker reactor was stirred at velocity gradient of 163 $\sec ^{-1}$ which was the minimum gradient to keep the silica particles suspended. This corresponded to $400 \mathrm{rpm}$ for the configuration and was calculated as per cornwell and Bishop(1983). The high velocity gradient increases the collision frequency and decreases the removal time without affecting the coagulation efficiency which is independent of the physical mechanism which causes particle collisions. 20-60 $\mathrm{mL}$ samples were taken at $0,4,8,12$, and 24 hours. Samples were taken at both the bottom and top of the beaker for silica enumeration and the results averaged.

Blank experiments were conducted in both reactors with just the aluminum (hydr)oxide colloids to confirm that coagulation with silica particles was the only mechanism for their removal. Similarly, blank experiments were run with just silica particles to assure that their number and distribution remained constant. This was necessary to assure correct use of the pseudo-first-order coagulation rate equation (2).

\section{Mobility Experiments}

A series of mobility experiments using bicarbonate, dissolved and particulate silica, and aluminum were conducted to determine the electrostatic properties of the aluminum (hydr)oxide colloids with these species present. 
Apparatus. All the experiments were conducted in a constant $\mathrm{pH}$ reactor mixed by a magnetic stirrer. The reactor consisted of a $200 \mathrm{~mL}$ jacketed vessel with a tefion top. A Fischer $825 \mathrm{mp} \mathrm{pH}$ meter with corning glass and reference electrodes was connected to an Apple II+ computer through a serial interface. This computer controlled two stepper motors attached to autoburettes, which added either acid or base to the reactor(Baker $0.01 \mathrm{M} \mathrm{NaOH}$ and $\mathrm{HCl}$ Dilute-it reagents) as necessary to maintain the desired $\mathrm{pH}$ (Figure 3). Nitrogen stripped of $\mathrm{CO}_{2}$ by $1 \mathrm{M} \mathrm{NaOH}$ and humidified was bubbled through the reactor.

Procedures. A suspension of the colloids $(200 \mathrm{~mL})$ was prepared to the same concentration as in the coagulation experiments and with the same electrolyte. The species of interest was then added.

Three types of experiments were conducted. In the first set of experiments, bicarbonate was added in concentrations of $0.001 \mathrm{M}, 0.005 \mathrm{M}$ and $0.01 \mathrm{M}$ and the $\mathrm{pH}$ was varied between 3 and 9 . At each step the suspension was allowed to equilibrate for 45 minutes, after which a sample was withdrawn and the mobility was measured. The measurements were made in a Rank Brothers electrophoretic particle mobility unit using a flat cell and visible light. At least 10 particles were timed in each polarity setting and the average mobility and standard deviation were 


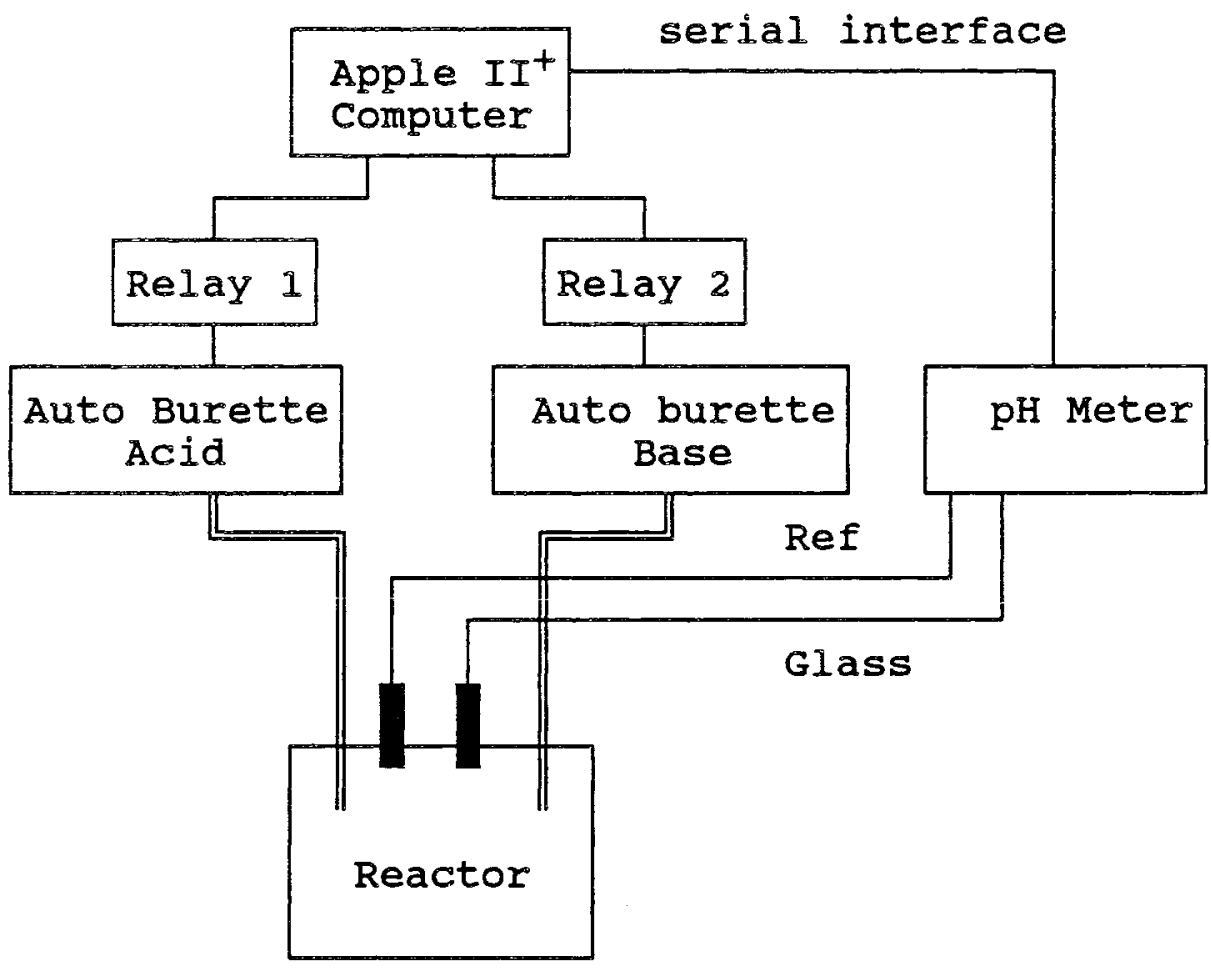

Figure 3: Apparatus for mobility and titration expts. 
calculated. The $\mathrm{pH}$ was first raised from 3 to 9 and then back with a small hysteresis noted between mobilities measured at identical $\mathrm{pH}$ values.

In the second set of experiments both dissolved silica and Min-u-sil were added in separate experiments and the $\mathrm{pH}$ was held constant at 5.5. The mobility was measured with time up to 220 minutes.

Finally, both dissolved silica and dissolved aluminum were added in separate experiments in increasing concentrations, the suspension was allowed to equilibrate for 100 minutes and the mobility was measured. The silica concentrations were varied from 0 to $1 \mathrm{mM}$ and aluminum from 0 to $250 \mu \mathrm{g} / 1$. In the latter case(addition of Al) $\mathrm{Min}-\mathrm{u}-$ sil was also present in the same concentration as in the coagulation experiments $\left(8 \times 10^{8} \mathrm{~L}^{-1}\right)$.

\section{Surface Titrations}

surface titrations were conducted on the commercial " $\alpha$-alumina" in the presence of varying concentrations of dissolved silica. The same reactor was used as in the mobility experiments. A $200-\mathrm{mL}$ solution of $0.01 \mathrm{M} \mathrm{NaCl}$ and the dissolved silica concentration of interest were placed in the reactor. To this was added $2 \mathrm{~g}$ of the $\alpha$-alumina. The reactor was sealed and the suspension purged overnight. with nitrogen to remove $\mathrm{CO}_{2}$. The titration was also done under nitrogen. The initial $\mathrm{pH}$ was noted and acid added to 
bring the pH to 3.5. Base was then added to try and maintain $0.5 \mathrm{pH}$ differences between data points, with the final point at $\mathrm{pH}$ 10.5. The suspension was allowed to equilibrate 30-45 minutes between each data point before the $\mathrm{pH}$ was read. Obtaining $0.5 \mathrm{pH}$ differences involved overshooting the intended $\mathrm{pH}$ because the suspension $\mathrm{pH}$ would lower as the system came to equilibrium.

$\alpha$-alumina was titrated in the absence of dissolved silica and in the presence of $10^{-5} \mathrm{M}, 10^{-4} \mathrm{M}$, and $10^{-3} \mathrm{M}$ dissolved silica. In addition, a solution of $10^{-3} \mathrm{M}$ dissolved silica alone, and a reagent water sample were titrated. 


\section{RESULTS}

\section{Blank Experiments}

Blank experiments with the aluminum (hydr)oxide colloids or silica alone were conducted to ensure that no "self-coagulation" occurred. Table 4 summarizes results of the four blank experiments. Silica concentrations for the stirred beaker vary less than 2 percent from the average valve, and less than 20 percent from the average for the settling column. In both cases the variation with time was random and not decreasing. Aluminum (hydr)oxide concentrations did not vary from the average by more than 3 percent for either reactor, and also varied randomly with time. This supports the assumption that the $n_{i}$ values in equations (6) and (7) are constant over the time scale of the experiments, and enables interpreting results using the pseudo-first order model.

For aluminum (hydr)oxide the "self-coagulation" is smal1. This is reflected in equations (2), (6), and (7) in that the summation does not include $n_{1}$. Thus, it was expected that positively charged or near-neutral aluminum (hydr)oxide colloids would coagulate only with negatively charged silica particles in the subsequent experiments. Although self-coagulation did not occur in the blank 
Table 5: Blank Experiments

\begin{tabular}{|c|c|c|}
\hline Al (hydr) oxide & \multicolumn{2}{|c|}{ particles $L^{-1}$} \\
\hline TIME (hrs) & STIRRED $\left(\times 10^{8}\right)$ & SETTLING $\left(X 10^{8}\right)$ \\
\hline $\begin{array}{r}0 \\
4 \\
8 \\
12\end{array}$ & $\begin{array}{l}8.3 \pm .71 \\
7.9 \pm .60 \\
8.0 \pm .63 \\
8.3 \pm .56\end{array}$ & $\begin{array}{l}8.3 \pm .88 \\
7.9 \pm .43 \\
8.1 \pm .63 \\
7.8 \pm .55\end{array}$ \\
\hline Silica & \multicolumn{2}{|c|}{ particles $\mathrm{L}^{-1}$} \\
\hline $\begin{array}{c}\text { TIME (hrs) } \\
0 \\
4 \\
8 \\
12\end{array}$ & $\begin{array}{c}\operatorname{STIRRED}\left(\times 10^{7}\right) \\
8.17 \\
8.24 \\
7.9 \\
8.09\end{array}$ & $\begin{array}{l}\text { SETTLING }\left(\times 10^{7}\right) \\
\begin{array}{c}1.73 \\
1.20 \\
1.40 \\
1.09\end{array}\end{array}$ \\
\hline
\end{tabular}

Note: Standard Deviation is $s(n-1)$. 
experiments with only one type of particle present, some self-coagulation of the colloids was observed in later experiments with silica particles present (Figure 4).

\section{Coagulation Experiments}

Results of experiments conducted in both reactors indicated $\alpha$ values near 0.01 (Table 6). Within a single experiment, $\alpha$ was relatively constant as shown in Figure 5 by a relatively constant slope for experiments 1 and 4 . colloid removal was mainly due to coagulation with silica particles (Figure 6). Appendix A contains the measured silica size distributions, and observed $n_{1} / n_{1} \circ$ values for each experiment. Reported $\alpha$ values were averaged over the entire length of the experiment.

For the settling column experiments $\alpha$ remained approximately the same for both the pH 5.5 experiment (exp. 1) and the $\mathrm{pH} 7.5$ experiment (exp. 2). $\alpha$ was expected to be greater for experiments conducted a pH 5.5 versus pH 7.5 due to the expected larger positive mobility of colloids at pH 5.5 versus 7.5 . The mobilities of particles in each experiment at 4 hrs. were not much different, which accounts for the similar $\alpha$ value(Table 6). 


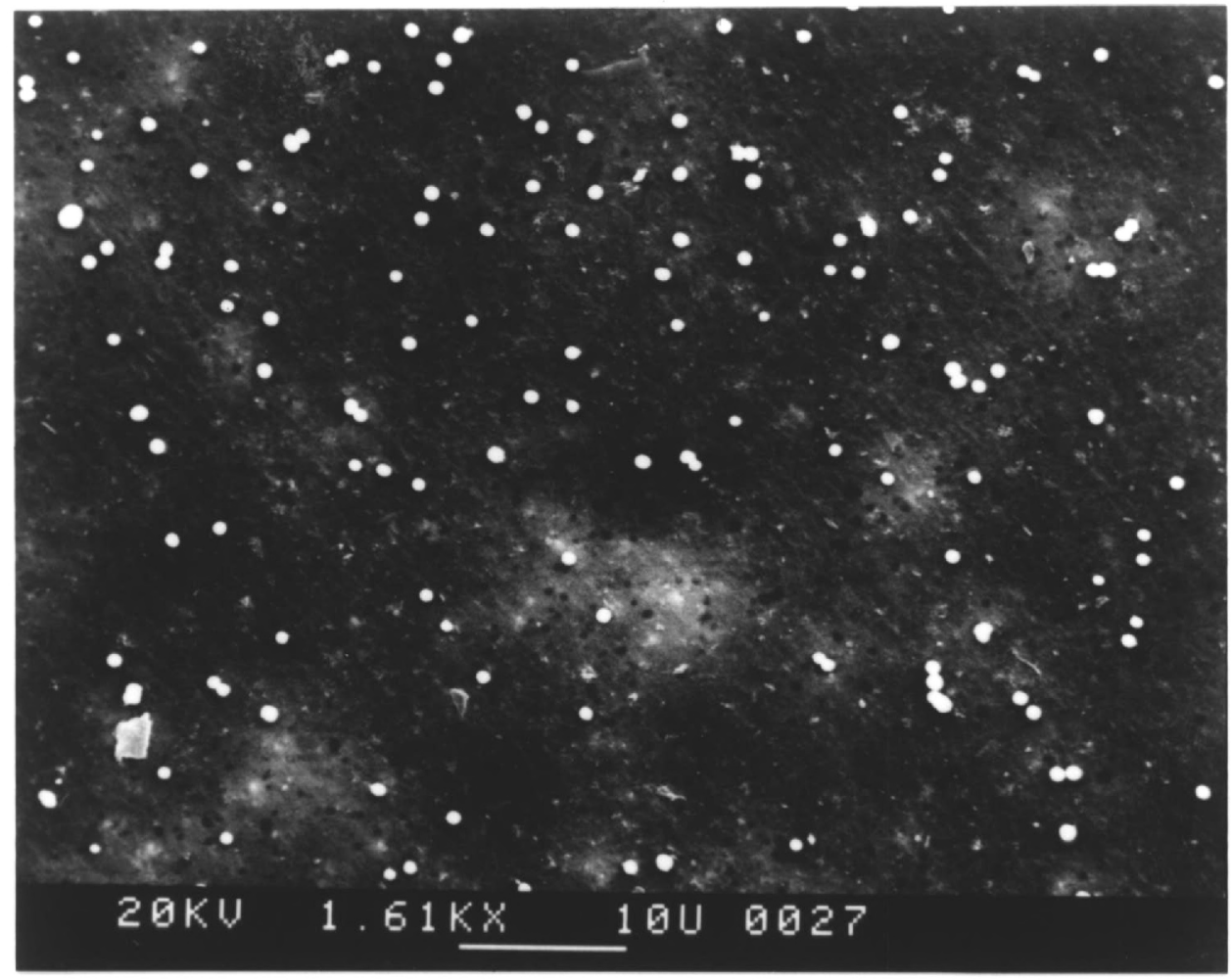

Figure 4: SEM photo of self-coagulation of colloids in doublets and triplets. 
Table 6: Summary of Conditions and $\alpha$ values for Experiments 1 - 5 .

\begin{tabular}{|c|c|c|c|c|c|c|c|c|c|}
\hline \multirow[b]{2}{*}{ Exp. } & \multirow{2}{*}{$\begin{array}{l}\text { Expt. } \\
\text { Type }\end{array}$} & \multirow[b]{2}{*}{$\mathrm{pH}$} & \multirow[b]{2}{*}{$I \quad(M)$} & \multirow{2}{*}{$\begin{array}{r}n_{0} \\
\text { alox }\end{array}$} & \multirow{2}{*}{$\begin{array}{l}\text { for } \\
\left(L^{-1}\right)\end{array}$} & \multirow{2}{*}{$\begin{array}{l}n_{j} \text { for } \\
\text { silica }\left(I^{-1}\right)\end{array}$} & \multicolumn{2}{|c|}{$\begin{array}{l}\text { Mobility } \\
\frac{\mu \mathrm{m} s}{\mathrm{~V} \text { cm }}-1\end{array}$} & \multirow[b]{2}{*}{$\alpha$} \\
\hline & & & & & & & $0 \mathrm{hr}$ & $4 \mathrm{hr}$ & \\
\hline $\begin{array}{c}1 \\
2^{a} \\
3 \\
4 \\
5 \\
6 a^{b} \\
6 b^{b} \\
6 c^{b}\end{array}$ & $\begin{array}{l}\text { settling } \\
\text { settling } \\
\text { fl. shear } \\
\text { fl. shear } \\
\text { fl. shear } \\
\text { fl. shear } \\
\text { fl. shear } \\
\text { fl. shear }\end{array}$ & $\begin{array}{l}5.5 \\
7.5 \\
5.5 \\
5.5 \\
5.5 \\
5.5 \\
6.5 \\
7.0\end{array}$ & $\begin{array}{l}0.01 \\
0.01 \\
0.01 \\
0.01 \\
0.01 \\
0.01 \\
0.01 \\
0.01\end{array}$ & $\begin{array}{l}7.71 \\
3.85 \\
7.46 \\
8.46 \\
8.20 \\
9.47 \\
5.56 \\
2.29\end{array}$ & $\begin{array}{l}\times 10^{8} \\
\times 10^{8} \\
\times 10^{8} \\
\times 10^{8} \\
\times 10^{8} \\
\times 10^{8} \\
\times 10^{8} \\
\times 10^{8}\end{array}$ & $\begin{array}{l}1.08 \times 10^{8} \\
1.10 \times 10^{8} \\
9.51 \times 10^{7} \\
1.11 \times 10^{8} \\
7.90 \times 10^{7} \\
1.23 \times 10^{8} \\
1.11 \times 10^{8} \\
9.49 \times 10^{7}\end{array}$ & $\begin{array}{l}+0.95 \\
-0--- \\
-0.46 \\
+0.79 \\
+0.02 \\
+0.81 \\
+0.50 \\
-0.68\end{array}$ & $\begin{array}{l}+1.01 \\
+1.22 \\
-0.76 \\
+0.34 \\
-0.46 \\
+0.49 \\
+0.37 \\
-0.46\end{array}$ & $\begin{array}{l}0.011 \\
0.013 \\
0.011 \\
0.011 \\
0.015 \\
0.002 \\
0.008 \\
0.020\end{array}$ \\
\hline
\end{tabular}

a Mobility for $8 \mathrm{hrs.} \mathrm{instead} \mathrm{of} 4 \mathrm{hrs,}$ no report for $0 \mathrm{hrs}$.

$b_{A 1}(I I I)=200 \mu \mathrm{g} / \mathrm{L}$ 
Results of Coagulation Expts. $1 \& 4$

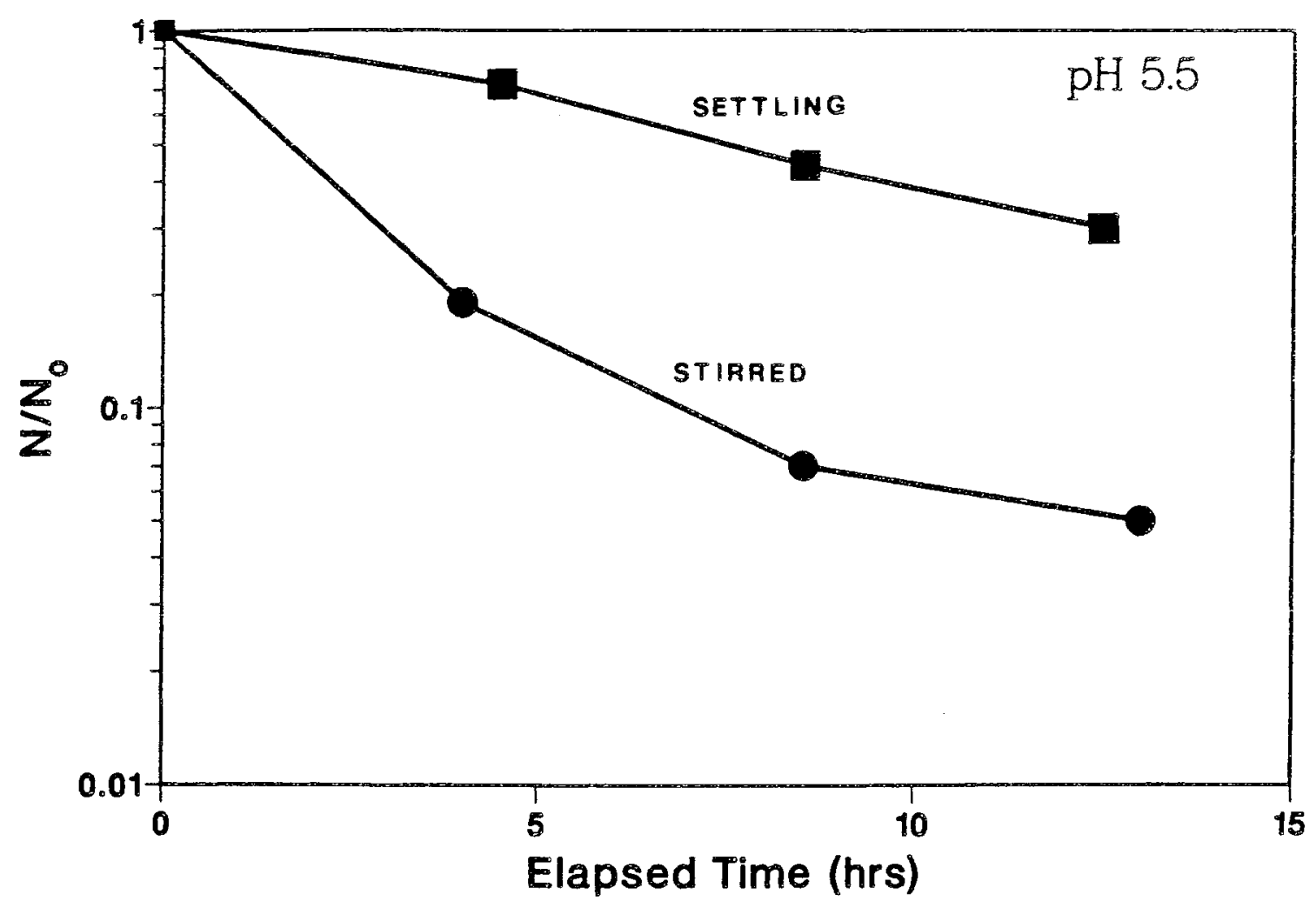

Figure 5: Results of coagulation experiments 1 and 4. Expt. 1, Expt. 4 


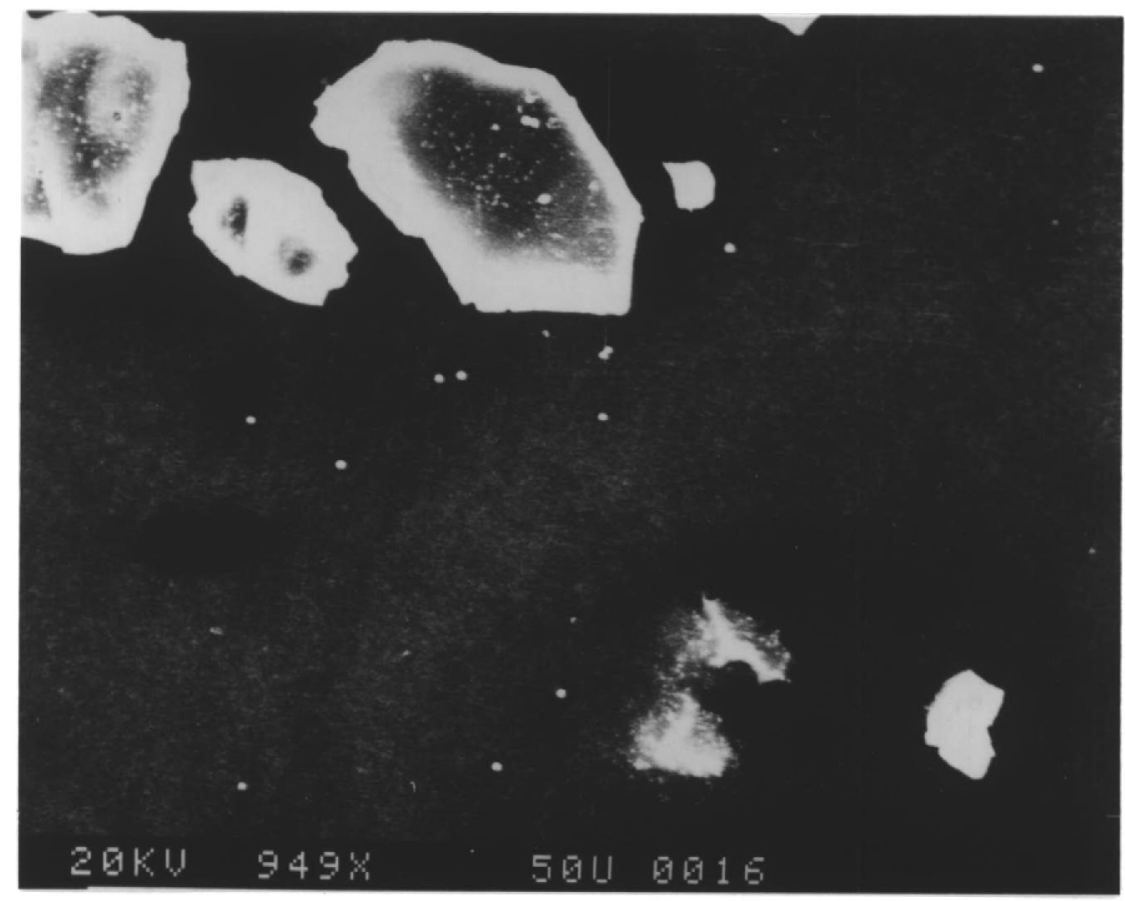

Figure 6: SEM photo of colloids coagulated on silica. 


\section{Mobility Experiments}

Bicarbonate. Figure 7 shows the mobility curves for aluminum (hydr)oxide colloids in the presence of bicarbonate. The iso-electric pH's for the colloids were $7.8,6.7$, and 5.9 in the absence of bicarbonate and in the presence of $0.0 \mathrm{M}, 0.001 \mathrm{M}$, and $0.01 \mathrm{M}$ bicarbonate respectively. The $\mathrm{pH}_{\mathrm{iep}}$ for the colloids shifted $1.2 \mathrm{pH}$ units lower upon a $0.001 \mathrm{M}$ bicarbonate addition (the concentration used in the coagulation experiments). Thus bicarbonate can account for a decrease in the mobility observed in the coagulation experiments, but not for the charge reversal observed in the shear experiments.

Silica. Figure 8 shows the change in mobility with time of the aluminum (hydr)oxide colloids in the presence of silica particles and $1 \mathrm{mM}$ dissolved silica. Silica particles reversed the mobility(i.e. charge) of the colloids in 50 minutes which came to an equilibrium mobility in 75 minutes.

1mM dissolved silica caused the colloids to reverse charge in 75 minutes The colloids reached an equilibrium mobility in 100min.

Figure 9 shows the effect of increasing dissolved silica concentrations of the mobility of aluminum (hydr)oxide colloids. Dissolved silica can create charge reversal at a concentration of $10^{-4} \mathrm{M}$. Above $5.0 \times 10^{-4} \mathrm{M}$ 


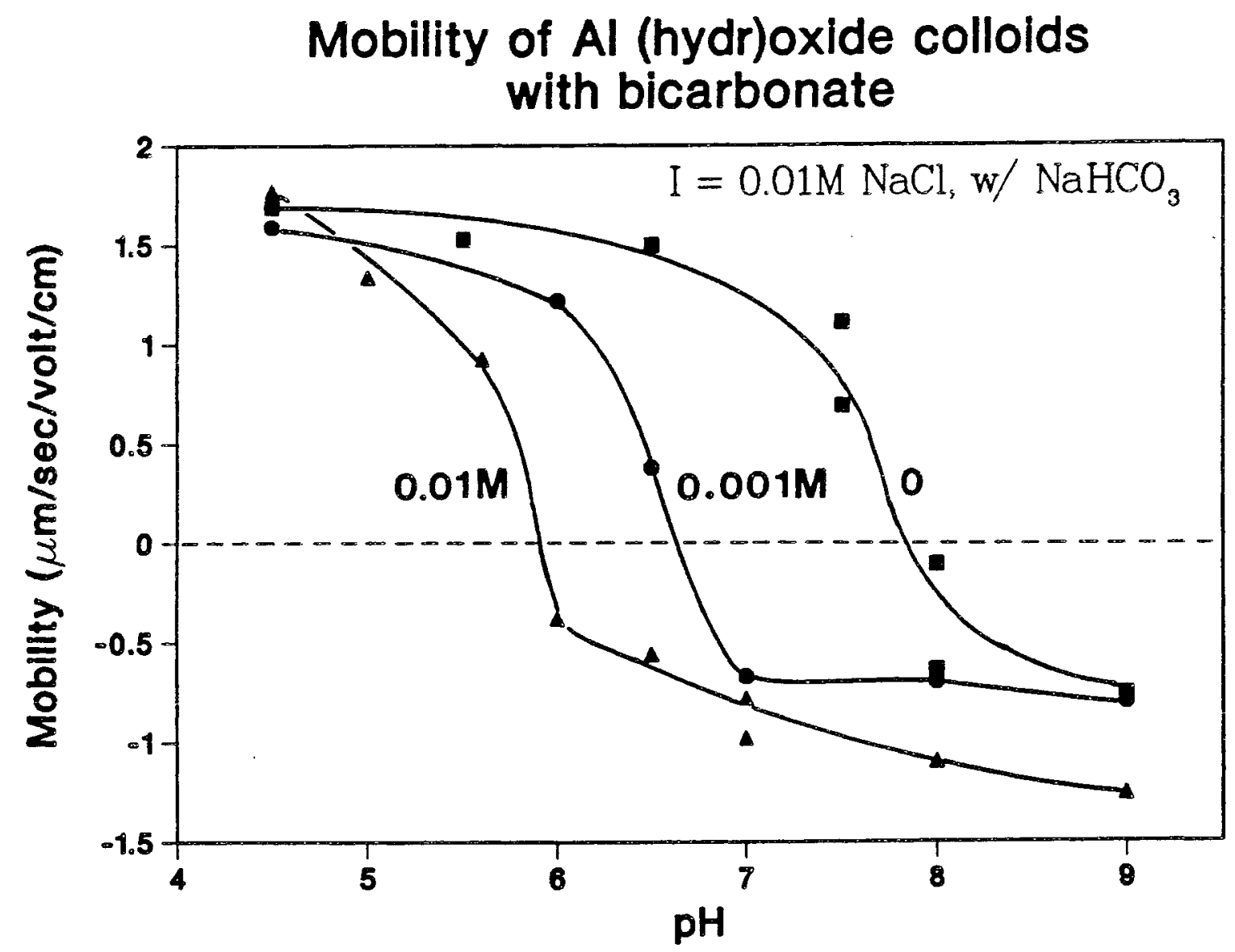

Figure 7: Mobility of aluminum (hydr) oxide colloids with bicarbonate. no $\mathrm{HCO}_{3}-\bullet 0.001 \mathrm{M} \mathrm{HCO}_{3}{ }^{-}$,

- $0.01 \mathrm{M} \mathrm{HCO}_{3}^{-}$. 


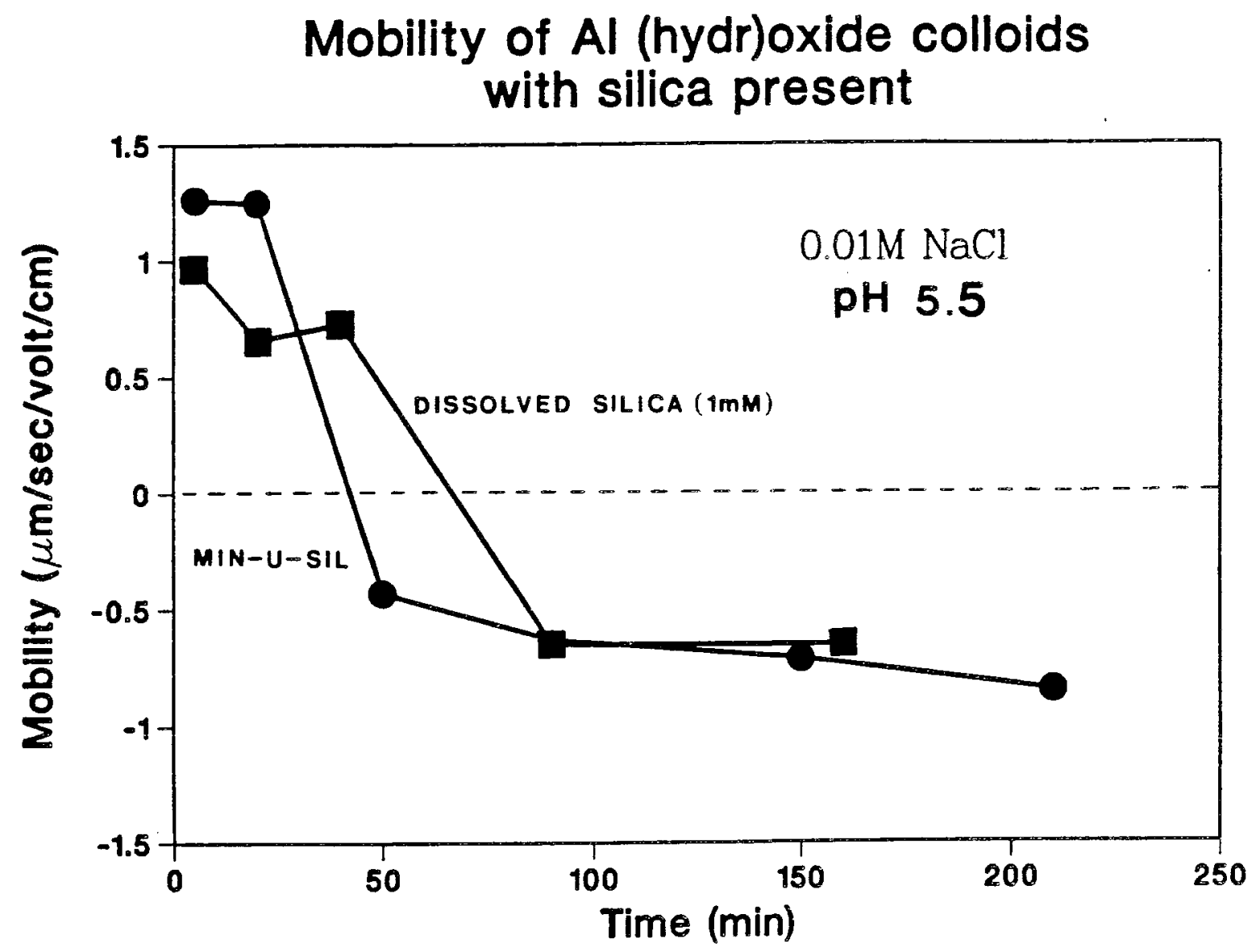

Figure 8: Mobility of aluminum (hydr)oxide colloids with silica present. silica particles(min-u-sil), aissolved silica(1mM). 


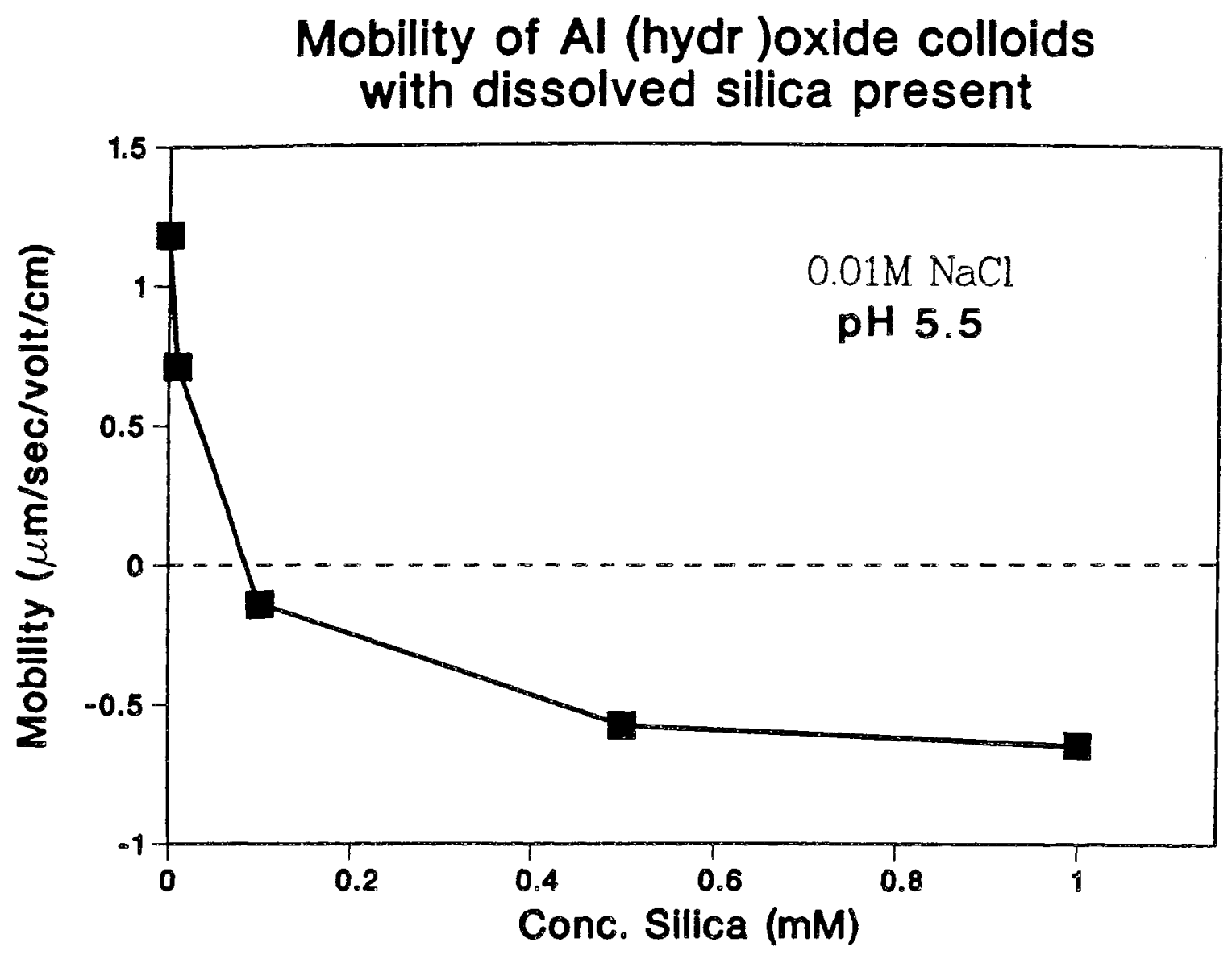

Figure 9: Mobility of aluminum (hydr)oxide colloids with dissolved silica present. 
no additional lowering of the mobility is seen. $10^{-4} \mathrm{M}$ is below the equilibrium saturation concentration attainable for the dissolution of amorphous silica at $25^{\circ} \mathrm{C}$.

Dissolved Al(II). Figure 10 shows the ability of dissolved $\mathrm{Al}$ (added as $\mathrm{AlCl}_{3}$ ) to restore positive mobility to the aluminum (hydr)oxide colloids in the presence of particulate silica (Min-u-sil, same concentration as in coagulation experiments, $10^{8} \mathrm{~L}^{-1}$ ). Charge reversal of the aluminum (hydr)oxide colloids occurred at a concentration of $225 \mu \mathrm{g} / \mathrm{I} \mathrm{Al}$ (III) (as Al). $200 \mu \mathrm{g} / \mathrm{L}$ of $\mathrm{Al}$ (III) also reversed the charge of the silica particles from negative to positive (denoted as vertical line in Figure 10). This effect was also observed by Letterman (1982) at the same Al to grams of Min-u-sil ratio.

\section{Enhanced Coagulation Experiment}

Figure 11 shows the results of exp. 6 in which Al(III) was added to the beaker reactor $(200 \mu \mathrm{g} / \mathrm{L}$, see also Table 6). Coagulation was inefficient at $\mathrm{pH} 5.5(\alpha=0.002)$. An increase in $\mathrm{pH}$ to 6.5 (after 24 hours) and 7.0 (after 30 hours) improved coagulation efficiency, with observed $\alpha$ values of 0.008 (exp. 6b) and 0.02 (exp 6c), respectively. Mobility data (Appendix A, Table A-7) show that both the colloids and silica particles were positive initially in the presence of $\mathrm{Al}$ (III). As the $\mathrm{pH}$ was raised the colloids 


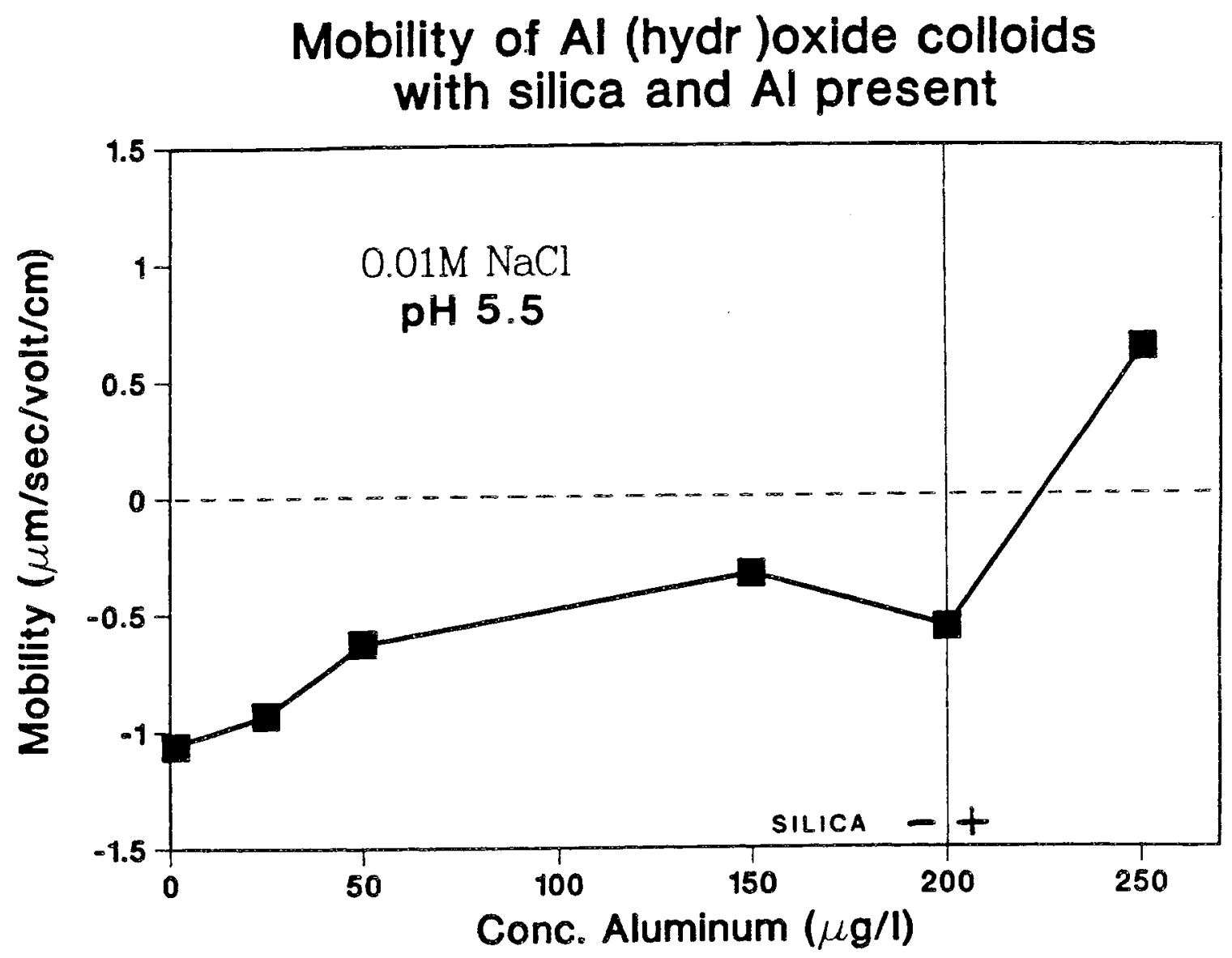

Figure 10: Mobility of aluminum (hydr) oxide colloids with silica particles $\left(8 \times 10^{8} \mathrm{~L}^{-1}\right)$ and aluminum present, vertical Iine at $200 \mu \mathrm{gL}^{-1}$ denotes charge reversal of silica particles from negative to positive. 


\section{Stirred beaker results expts. 3 \& 6}

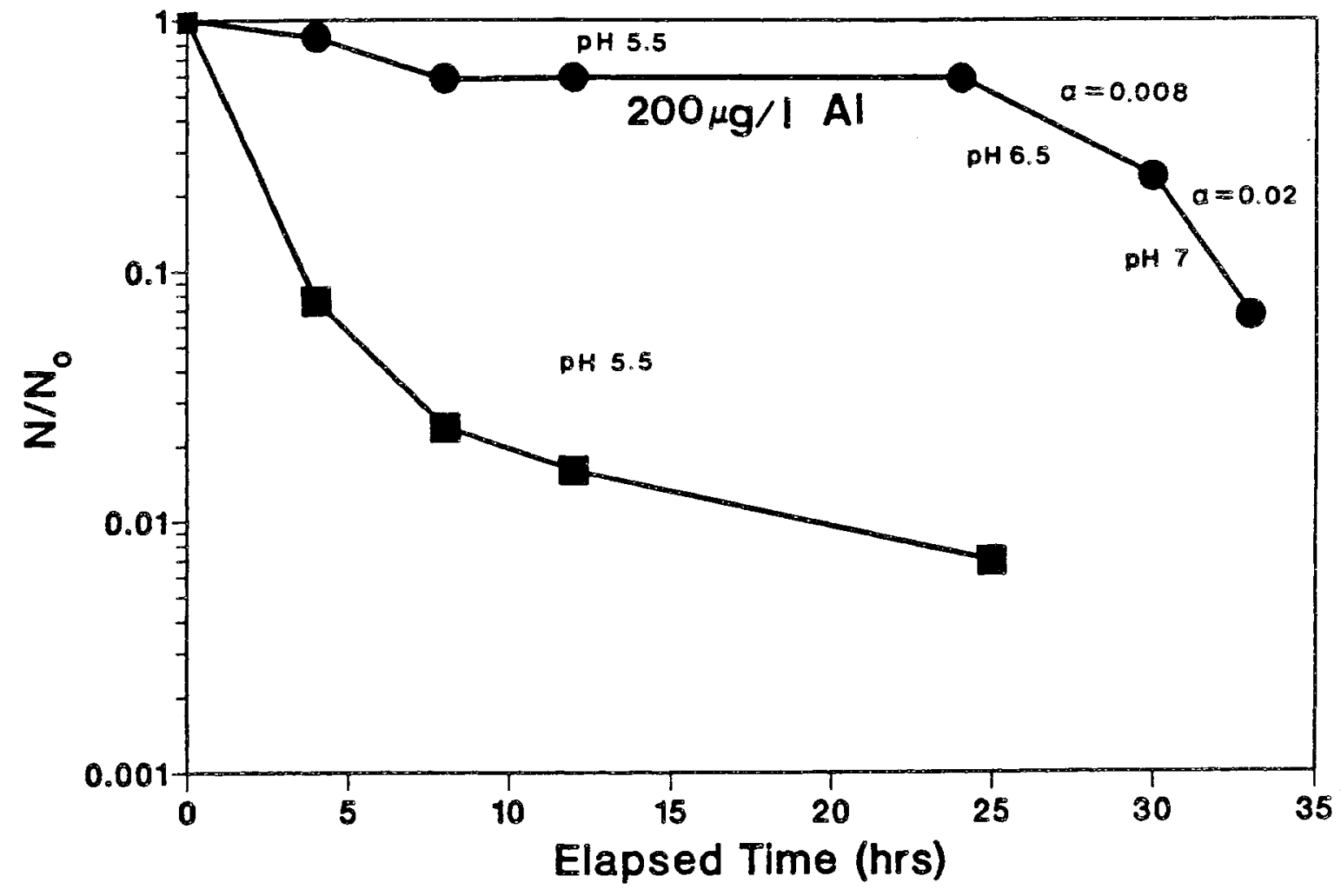

Figure 11: Stirred beaker results for experiments 3 and 6 . - expt. 3, expt. 6 . 
became negative while the silica remained positive which accounts for the increased coagulation efficiency.

\section{Titration Experiments}

Figure 12 shows the titration of reagent water alone and with $10^{-3} \mathrm{M}$ dissolved silica. The analogous computer model titrations (solid lines) support the lab titrations, and confirm the dissociation constants used for silica and water used in the computer titrations (Table 3 ).

Figure 13 shows the titration of $\alpha$-alumina (10 $\mathrm{gL}^{-1}$ ) and best-fit computer-model curve used to established the surface parameters, and dissociation constants.

From the visual best fit to the curve the capacitance was 1.75 with 1.3 sites $\mathrm{nm}^{-2}, 15 \mathrm{~m}^{2} \mathrm{~g}^{-1}$ surface area and a total surface site concentration of $3.25 \times 10^{-4}$ mol $\mathrm{L}^{-1}$. The surface area of the $\alpha$-alumina obtained from BET gas adsorption was $15.3 \mathrm{~m}^{2} \mathrm{~g}^{-1} \pm 0.3 \mathrm{~m}^{2} \mathrm{~g}^{-1}$ (Appendix c). This value agrees with the value determined by parameterization of surface area from model calculations. These surface parameters were held constant in subsequent model runs with dissolved silica present.

$\mathrm{K}_{\mathrm{S}}^{\mathrm{S}} \mathrm{l}$ and $\mathrm{K}_{\mathrm{a} 2}^{\mathrm{S}}$ are -6.7 and 9.3 respectively as determined by the best-fit model runs. This is compared with values of -7.0 and 10 presented in Table 3 .

Figures $14,15,16$ show the titration of $\alpha$-alumina (10 $\mathrm{g} \mathrm{L}^{-1}$ ) in the presence of $10^{-5} \mathrm{M}, 10^{-4} \mathrm{M}$, and $10^{-3} \mathrm{M}$ 


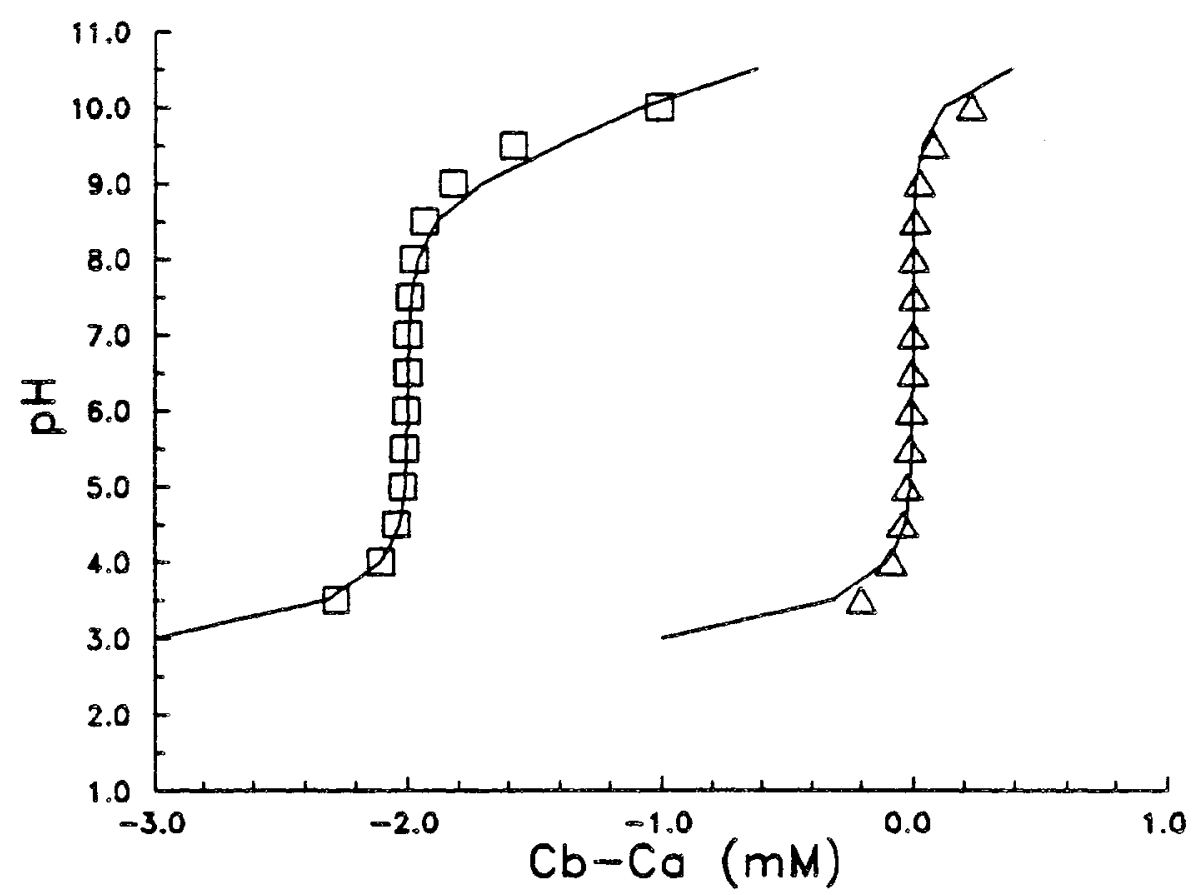

Figure 12: Titration of water and $10^{-3} \mathrm{M}$ dissolved silica. $010^{-3} M$ silica, $\Delta$ reagent water, model titrations in solid lines. $\mathrm{pK}_{\mathrm{W}}-14$. 


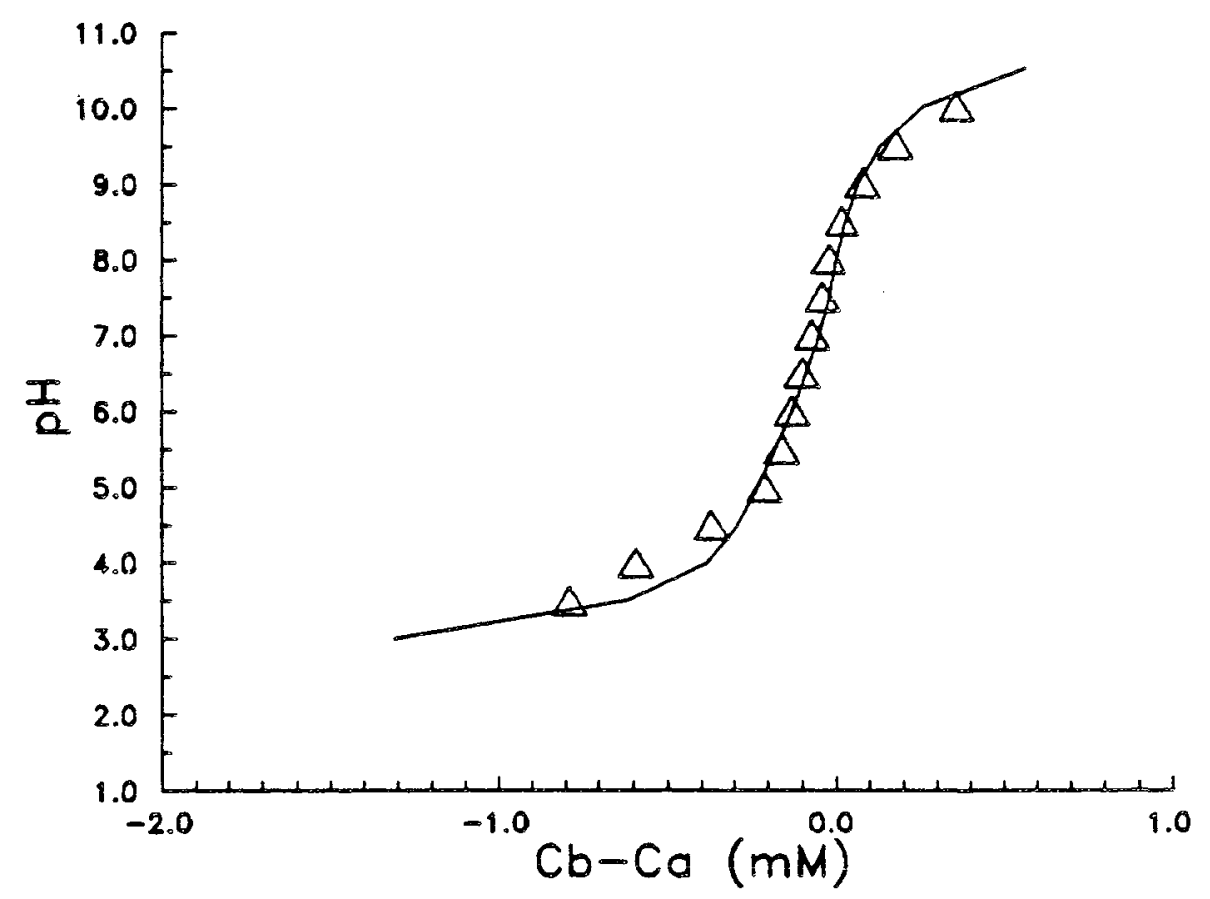

Figure 13: Titration of $\alpha$-alumina.

model parameters: $10 \mathrm{gL}^{-1}, 15 \mathrm{~m}^{2} \mathrm{~g}^{-1}$ capacitance $1.75 \mathrm{Fm}^{-2}, 1.3$ sites $\mathrm{nm}^{-2}$, $\mathrm{pK}^{\mathrm{S}} \mathrm{al} 9.3, \mathrm{pK}_{\mathrm{S}}^{\mathrm{S}}-6.7$, model in solid line. 


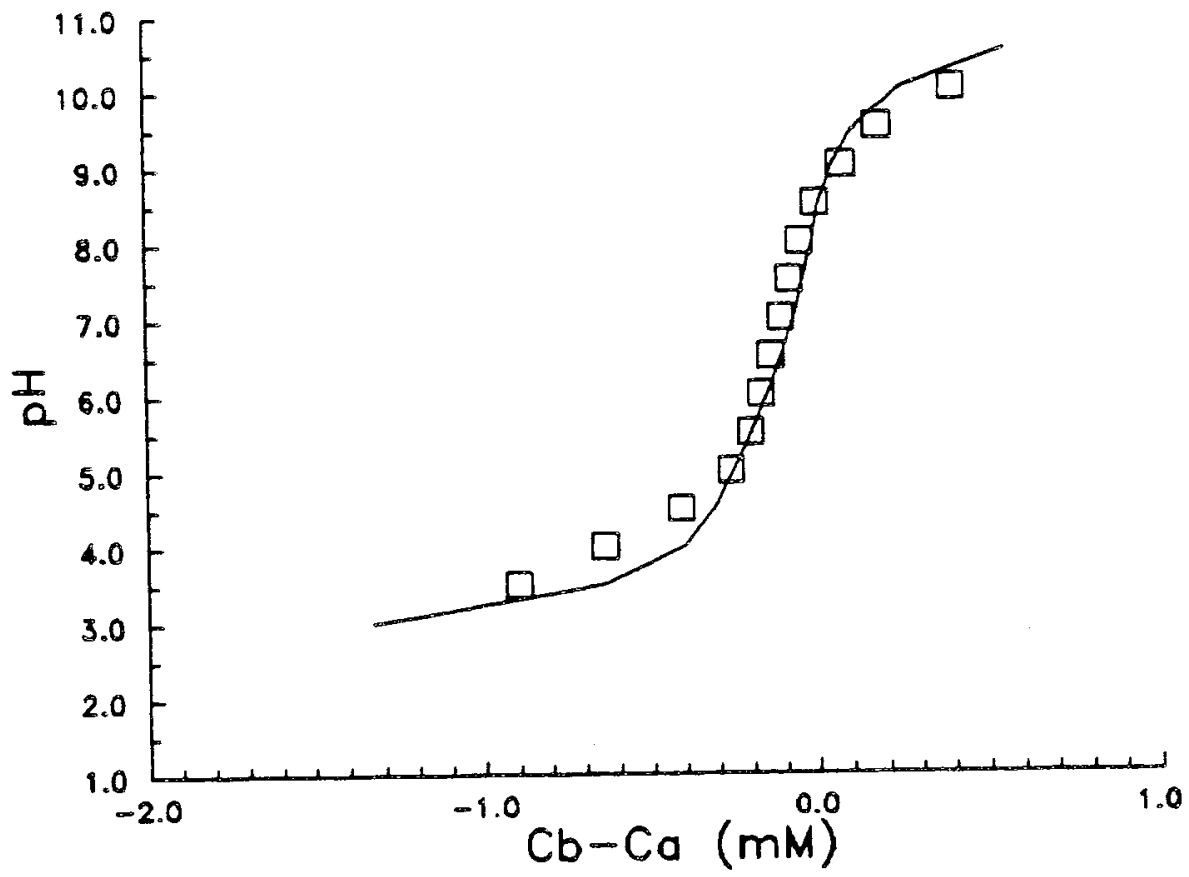

Figure 14: Titration of $\alpha$-alumina $w / 10^{-5} \mathrm{M} \mathrm{Si}$. model parameters: $10 \mathrm{gL}^{-1}, 15 \mathrm{~m}^{2} \mathrm{~g}^{-1}$, capacitance $1.75 \mathrm{Fm}^{-2}, 1.3$ sites $\mathrm{nm}^{-2}$, $\mathrm{pK}^{\mathrm{s}} \mathrm{al} 9.3, \mathrm{pK}_{\mathrm{S}}^{\mathrm{S}}-6.7$, model in solid line, no adsorption of silica in model. 


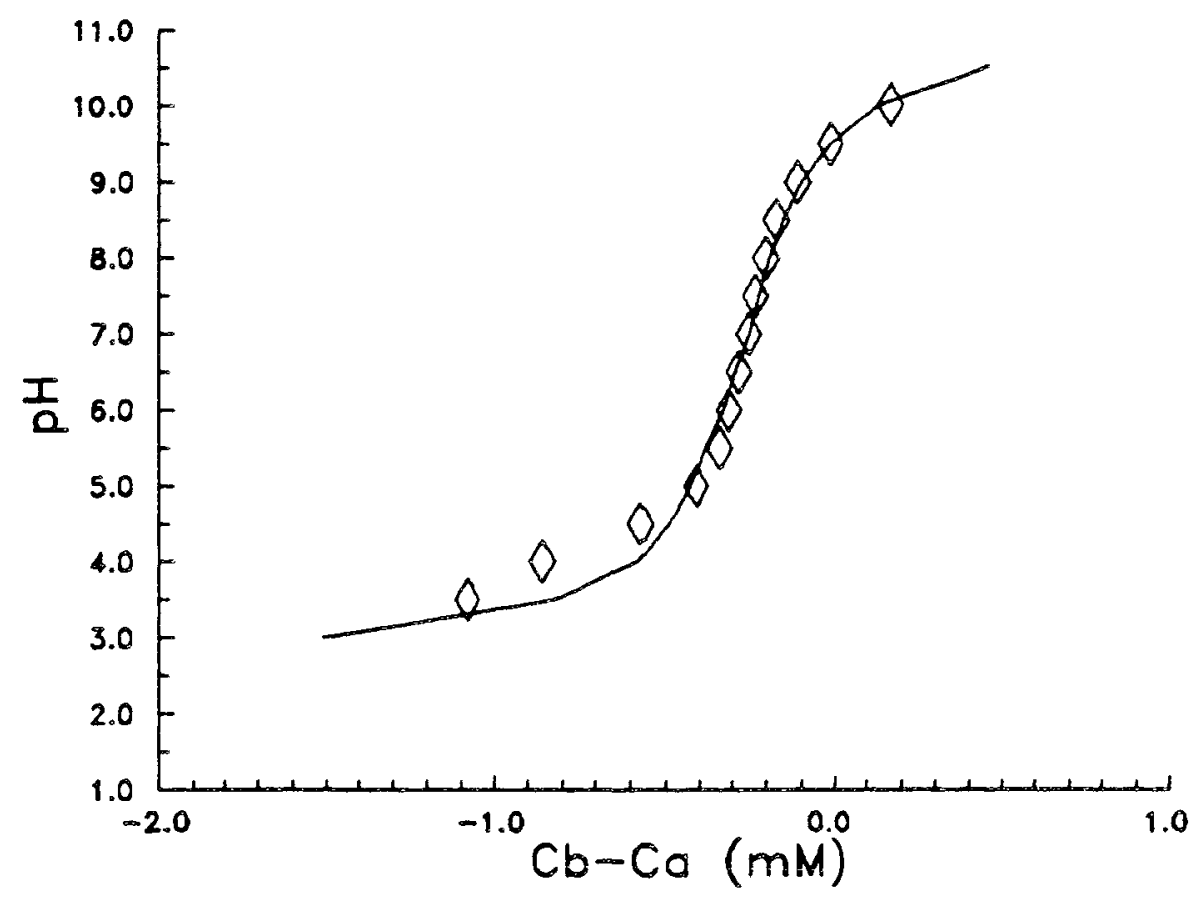

Figure 15: Titration of $\alpha$-alumina $w / 10^{-4} \mathrm{M} \mathrm{Si}$. model parameters: $10 \mathrm{gL}-1,15 \mathrm{~m}^{2} \mathrm{~g}^{-1}$. capacitance $1.75 \mathrm{Fm}^{-2}, 1.3$ sites $\mathrm{nm}^{-2}$, $\mathrm{pk}^{\mathrm{S}}$ al $9.3, \mathrm{pk}_{\mathrm{S}}-6.7$, model in solid line, no adsorption of silica in model. 


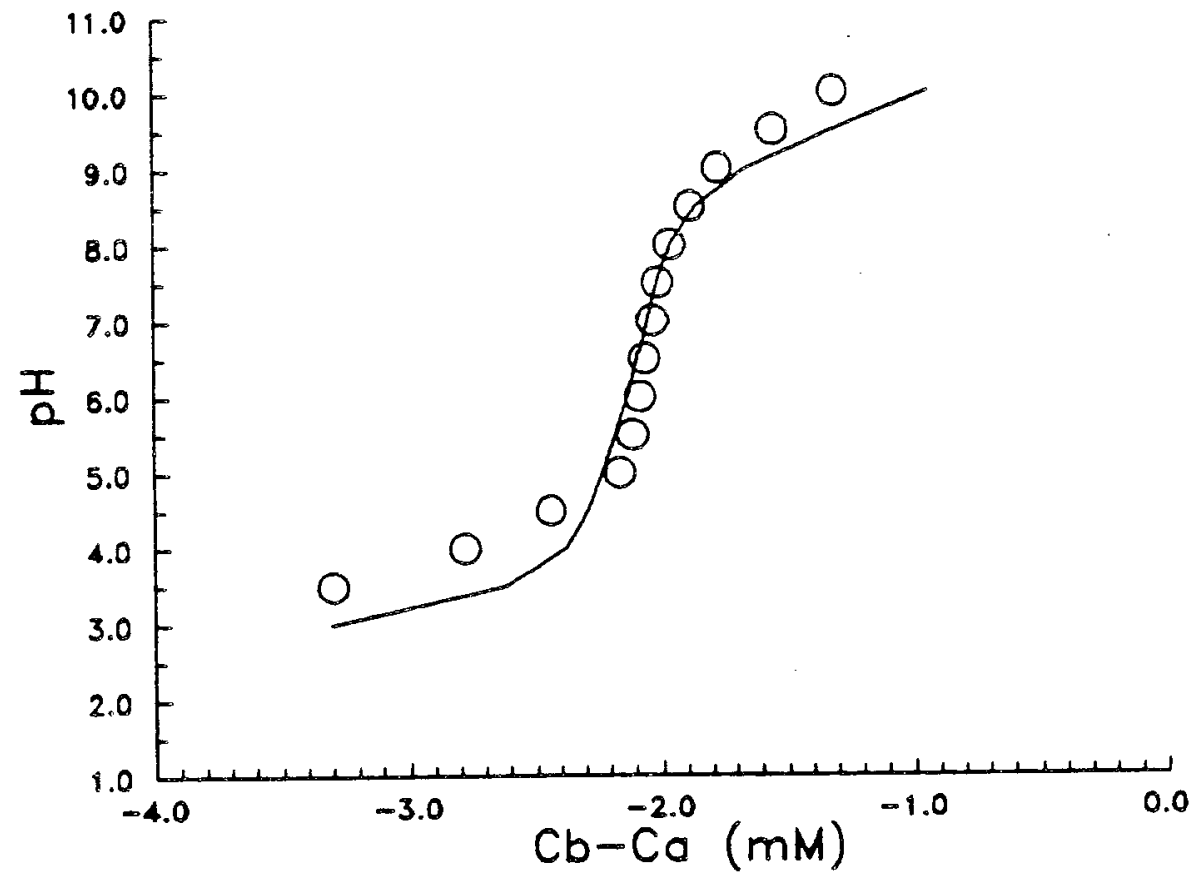

Figure 16: Titration of $\alpha$-alumina $w / 10^{-3} \mathrm{M} \mathrm{Si}$. model parameters: $10 \mathrm{gL}-1,15 \mathrm{~m}^{2} \mathrm{~g}^{-1}$, capacitance $1.75 \mathrm{Fm}^{-2}, 1.3$ sites $\mathrm{nm}^{-2}$ $\mathrm{pK}^{\mathrm{S}} \mathrm{al} 9.3, \mathrm{pK}_{\mathrm{S}}^{\mathrm{S}}-6.7$, model in solid line, no adsorption of silica in model. 
dissolved silica. For the titrations of $\alpha$-alumina with $10^{-5} \mathrm{M}$ dissolved silica and $\alpha$-alumina with $10^{-4} \mathrm{M}$ silica, the model curves, without silica adsorption to the oxide surface, fit the data satisfactorily and suggest that silica was not adsorbing to the surface.

For the titrations of $\alpha$-alumina with $10^{-3} \mathrm{M}$ dissolved silica the model run without adsorption does not fit (Figure 16). In Figure 17 the model run with adsorption of silica to the surface fits more satisfactorily and suggests that adsorption of silica to the surface with ligand exchange is occurring. $K^{S_{1}}{ }_{S i}$ and $K^{S_{2}}{ }_{S i}$ as determined by this best-fit model curve in Figure 17 are -25.1 and -16.1 , respectively.

Appendix $C$ contains figures that show the parameterization of values from computer model runs that eventually led to the best-fit curves to the titration data. Appendix $c$ also includes the SURFEQL input files used. 


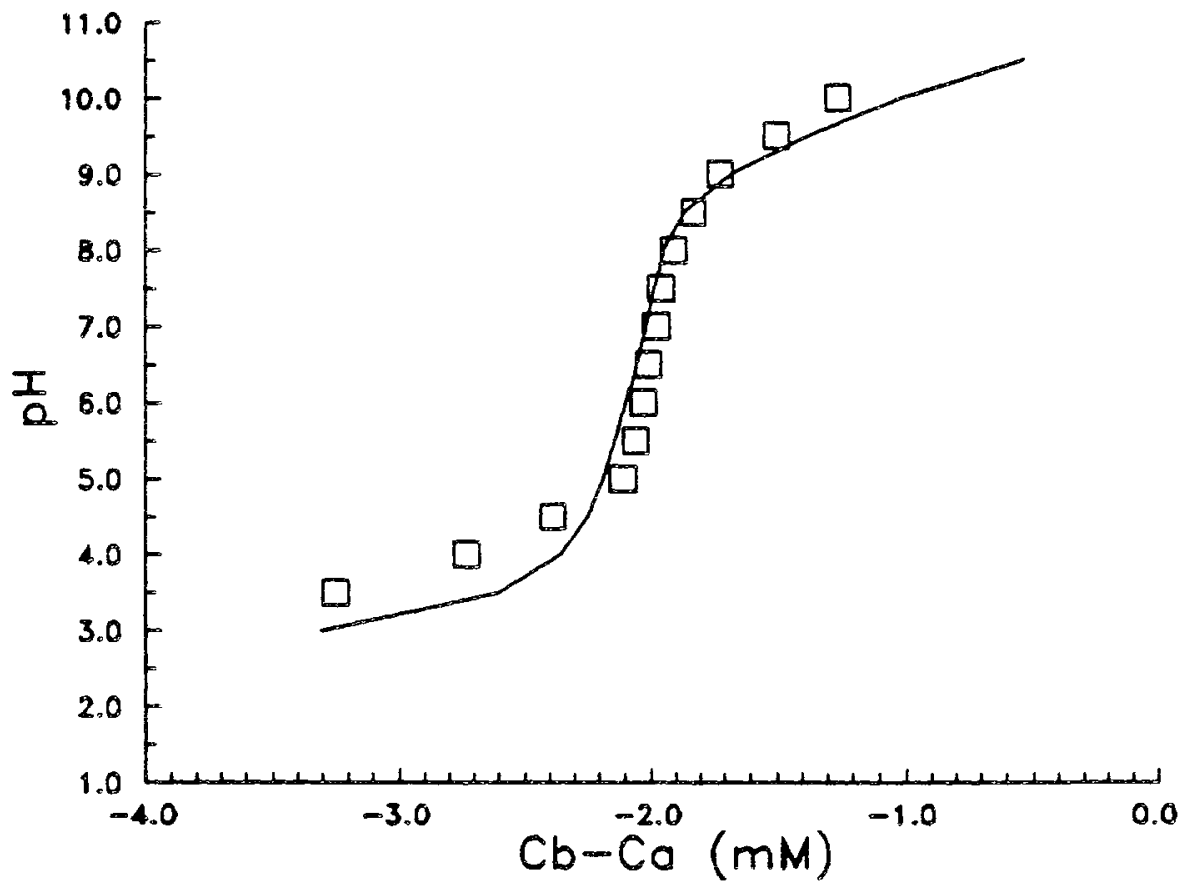

Figure 17: Titration of $\alpha$-alumina $\mathrm{w} / 10^{-3} \mathrm{M} \mathrm{Si}$. model parameters: $10 \mathrm{gL}^{-1}, 15 \mathrm{~m}^{2} \mathrm{~g}^{-1}$, capacitance $1.75 \mathrm{Fm}^{-2}, 1.3$ sites $\mathrm{nm}^{-2}$, $\mathrm{pK}^{5}$ al 9.3, $\mathrm{pK}^{5}$ al -6.7 , model in solid'line, with adsorbtion of $\mathrm{si}, \mathrm{pK}$ 's $3,-6$. 


\section{DISCUSSION}

The observed $\alpha$ values $(.0 .01)$ were in the lower range of those reported the literature cited previous.

For constant $\alpha$ and $n_{i}, n_{1} / n_{1}{ }^{\circ}$ should exhibit a linear decrease with time (Figure 5). SEM photo (Figure 4). indicated that some self-coagulation of the aluminum (hydr)oxide colloids occurred. Triplets and larger groupings of the particles were observed after four hours for the stirred beaker experiments. Thus, the average value of $\alpha$ reported for the fluid-shear experiments reflects both coagulation of the colloids by silica particles as well as by other aluminum (hydr)oxide colloids. The actual $\alpha$ for fluid shear is somewhat lower than reported in Table 6 , because collisions/coagulation between submicron particles were not considered in the calculations (eq. 2).

The values of $k_{i j}$ for $i=1$ (self-coagulation, $0.5 \mu \mathrm{m}$ colloids) are: $\mathrm{k}_{11}=3.5 \times 10^{-11} \mathrm{~cm}^{3} \mathrm{~s}^{-1}, \mathrm{k}_{12}=0.0 \mathrm{~cm}^{3} \mathrm{~s}^{-1}$, and $k_{13}=2.74 \times 10^{-11} \mathrm{~cm}^{3} \mathrm{~s}^{-1}$. In experiment 1, settling, $\mathrm{k}_{11} \mathrm{n}_{1}$ would be $2.7 \times 10^{-5} \mathrm{~s}^{-1}$ and would account for 1.1 percent of the total coagulation $\left(n_{1}=7.71 \times 10^{8} \mathrm{~L}^{-1}\right)$. In experiment 4 , fluid shear, $\mathrm{k}_{11} \mathrm{n}_{1}$ would be $2.98 \times 10^{-5} \mathrm{~s}^{-1}$ and $k_{13} n_{1}$ would be $2.33 \times 10^{-5} \mathrm{~s}^{-1}\left(\mathrm{n}_{1}=8.46 \times 10^{8} \mathrm{~L}^{-1},\right)$. 
Together these values account for only 0.85 percent of the total coagulation. Based on the above calculations the contribution of self-coagulation from Brownian motion, fluid shear, or differential settling to the overall coagulation rate should be small.

Mobilities of the submicron colloids measured during the fluid shear experiments show a charge reversal to negative within the first four hours apparently due to the adsorption of dissolved silica and/or carbonate species. Results showed a decrease in $\alpha$ values with time (Appendix $A$, and Figure 5) possibly due to slow silica dissolution and/or slow silica adsorption.

Results of the mobility experiments are consistent with observations of others concerning the effect by dissolved organic and inorganic species on charge reversal /neutralization and on coagulation efficiency of particles (e.g. Wiese and Healy, 1975, Ali et al., 1984, Gibbs, 1983, Letterman, 1982, Furlong et al.,1980, Bowers and Huang, 1984). In particular, the important role of silica adsorption, even in undersaturated solutions, is suggested.

In some natural waters, silica may be of equal or greater importance than dissolved natural organic matter in causing charge reversal and in stabilizing particles.

The observed charge reversal by dissolved aluminum is also consistent with results of others regarding the effect of multivalent cations. The common $\mathrm{pH}$ for charge reversal 
of both silica and aluminum (hydr)oxide colloids suggests that they had like surfaces after a few hours into the experiment. A similar observation was made by Wiese and Healy(1975) for $\mathrm{Al}_{2} \mathrm{O}_{3}$ suspensions.

The coagulation of the submicron aluminum (hydx)oxide colloids by particulate silica in the presence of dissolved Al(III) became more destabilized with increasing $\mathrm{pH}(\alpha=$ $0.002,0.008,0.02 ;$ for $\mathrm{pH}=5.5,6.5,7.0$ respectively). This destabilization behavior is probably due to the lower solubility of $\mathrm{Al}(\mathrm{OH})_{3}(\mathrm{~s})$ and thus more surface accumulation of aluminum species at the two higher $\mathrm{pH}$ values. Enmeshment of aluminum (hydr)oxide colloids into an $\mathrm{Al}(\mathrm{OH})_{3}(\mathrm{~s})$ precipitate is more significant at higher $\mathrm{pH}$ values (Chowdhury et al., 1987).

To analyze the surface titrations of the $\alpha$-alumina it was necessary to run computer simulations of these titrations. The purpose was to determine if dissolved silica was adsorbing onto the surface of the $\alpha$-alumina.

First, the dissociation of reagent water and $10^{-3} \mathrm{M}$ aqueous silica were modelled to confirm their equilibrium constants. The surface amphoteric proton coordination for the $\alpha$-alumina was modelled next. Five parameters, surface area, number of surface sites, capacitance, and intrinsic equilibrium constants, were varied until a best fit to the data was achieved (Figure 13). The surface area was also determined by BET gas adsorption for comparison. See 
Appendix $C$ for details of the BET calculation.

Dissolved silica in concentrations of $10^{-3} \mathrm{M}, 10^{-4} \mathrm{M}$, and $10^{-5} \mathrm{M}$ were added to the model, keeping constant the five alumina surface parameters. Finally, the ligand exchange of silica on the alumina surface was included with $10^{-3} M$ dissolved silica initially present in the system. The equilibrium constants were varied for the ligand exchange until a best fit with the alumina with $10^{-3} \mathrm{M}$ silica titration curve was achieved.

For the titration of $\alpha$-alumina in the presence of $10^{-5} \mathrm{M}$, and $10^{-4} \mathrm{M}$ silica, curves from computer model runs with no adsorption fit the data well enough to give inconclusive results as to whether adsorption/ligand exchange was occurring. For the titration of $\alpha$-alumina in the presence of $10^{-3} \mathrm{M}$ silica, the curve from the computer model run with no adsorption does not fit the data. The curve from the model run with adsorption/ligand exchange fits the data and suggests that adsorption of silica to the aluminum oxide surface with ligand exchange is occurring.

The values for the equilibrium constants for this ligand exchange from the best-fit model titration curve as compared to the ligand exchange of silica to an iron oxide surface are only one order of magnitude different for the first pK's (eqs. 21 and 23). This difference could be accounted for by the difference in chemical properties. Yet, the second pK's are almost 3 orders of magnitude 
different (eqs. 22 and 24 ). In the parameterization of the model it was noted that the second $p K$ had less of an effect on the model curves and could therefore vary more and still give satisfactory fits. This could account for a portion of the difference in the second $\mathrm{pK}$ 's.

The two set of chemical equations are:

$\log K$

$\equiv \mathrm{AlOH}+\mathrm{H}_{4} \mathrm{SiO}_{4}=\mathrm{AlH}_{3} \mathrm{SiO}_{4}+\mathrm{H}_{2} \mathrm{O}$

3.0

$\equiv \mathrm{AlOH}+\mathrm{H}_{3} \mathrm{SiO}_{4}^{-}=\equiv \mathrm{AlH}_{2} \mathrm{SiO}_{4}-+\mathrm{H}_{2} \mathrm{O}$

3.5

$\equiv \mathrm{FeOH}+\mathrm{H}_{4} \mathrm{SiO}_{4}=\mathrm{FeH}_{3} \mathrm{SiO}_{4}+\mathrm{H}_{2} \mathrm{O}$

$4 \cdot 1^{\mathrm{a}}$

$\equiv \mathrm{FeOH}+\mathrm{H}_{3} \mathrm{SiO}_{4}^{-}=\mathrm{FeH}_{2} \mathrm{SiO}_{4}^{-}+\mathrm{H}_{2} \mathrm{O}$

$6.2^{a}$

aReference: Stumm, Kummert, and Sigg, (1980) 
CONCLUSIONS AND RECOMMENDATIONS

Values of $\alpha$ for coagulation of aluminum (hydr)oxide colloids by supramicron silica particles were generally near 0.01 . These values are somewhat lower than those that were expected, considering that the particles were originally of opposite charge at $\mathrm{pH}$ 5.5. This is because dissolved silica from the particulate silica adsorbs to the colloids reversing their charge. A similar phenomena is thought to be important in natural waters. Bicarbonate also adsorbs and shifts the $\mathrm{pH}_{i e p}$ of the aluminum (hydr) oxide colloids. The addition of dissolved Al(III) had a similar effect on both types of particles.

Dissolved silica adsorbs to the aluminum oxide surface and undergoes ligand exchange. This exchange can be simulated by a constant capacitance model for adsorption of aqueous species to the oxide surface and fits laboratory titration data to give equilibrium constants.

The fit of the model curve with adsorption was not perfect (Figure 17) and suggests that more titrations experiments are necessary to determine dependable values for the equilibrium constants of ligand exchange. In these experiments surface parameters should be well characterized to give the best results. 
In future coagulation experiments if it is desired to observe $\alpha$ values near one, model particles should be chosen carefully so that desorption/adsorption of undesired ions does not change the particle's mobility and affect the coagulation efficiency. More interestingly, coagulation experiments which try to determine the importance of inorganic ions versus organic ions (e.g. NOM) in decreasing coagulation efficiency of submicron particles would add a valuable piece of information about coagulation of particles in natural water and wastewater systems. 


\section{APPENDIX A}

COAGULATION EXPERIMENTS 
Table A-1: Settling Column Experiment \#1

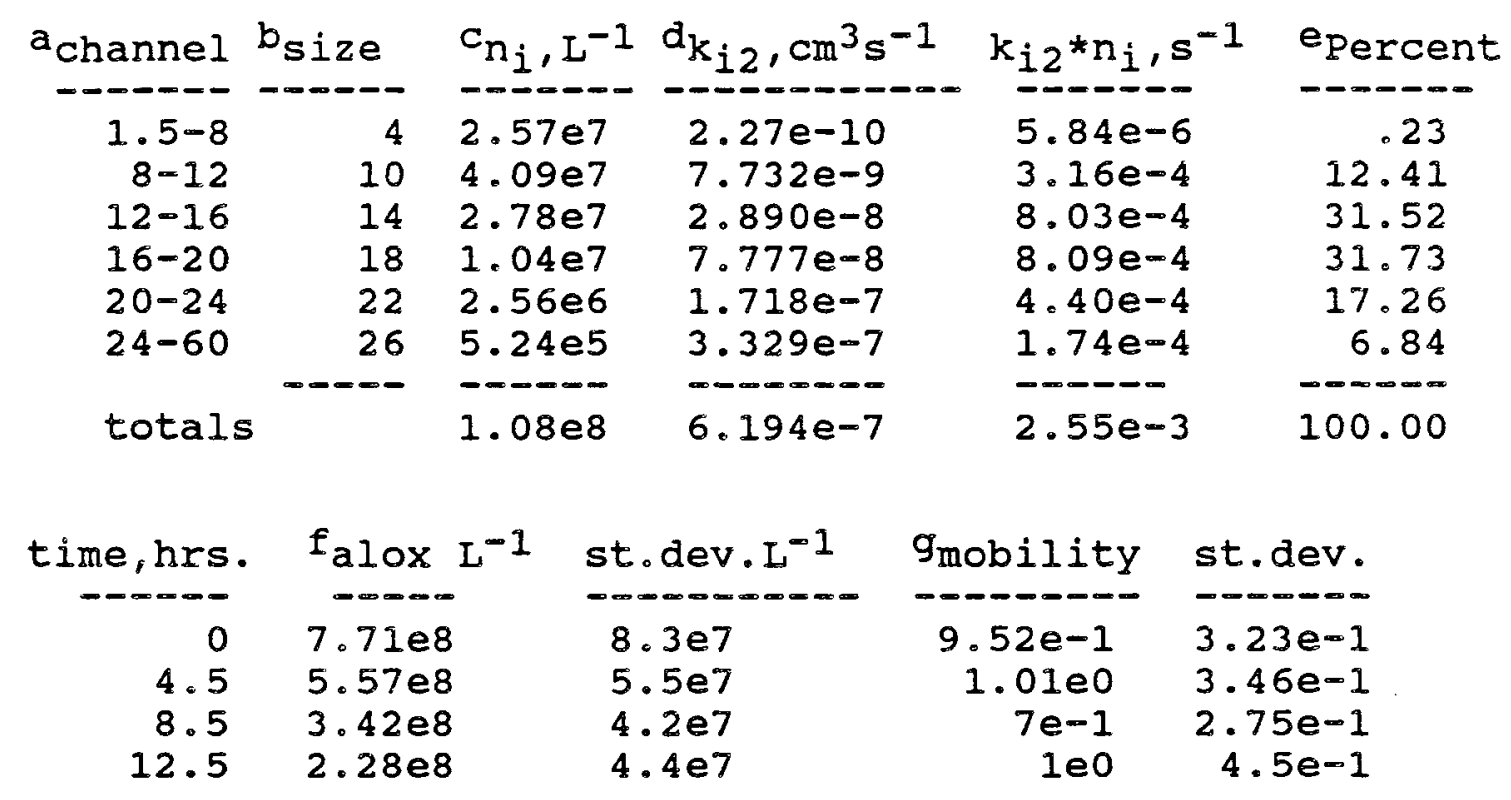

$\underset{-i n i t i a l ~ p H}{-1 n a l ~ p H}$

\begin{tabular}{rrrc}
$t, h r$ & $h_{n_{1} / n_{1} 0} i_{\Sigma\left(k_{i 2} * n_{i}\right)}$ & $j_{\alpha}$ \\
\hline 4.5 & -.72 & $2.549 e-3$ & $7.875 e-3$ \\
8.5 & .44 & $2.549 e-3$ & $1.042 e-2$ \\
12.5 & .30 & $2.549 e-3$ & $1.062 e-2$ \\
$4.5-8.5$ & .61 & $2.549 e-3$ & $1.329 e-2$ \\
$4.5-12.5$ & .41 & $2.549 e-3$ & $1.217 e-2$ \\
$8.5-12.5$ & .67 & $2.549 e-3$ & $1.105 e-2$ \\
ave & & & $--0---\infty$ \\
ave & & & $1.090 e-2$
\end{tabular}

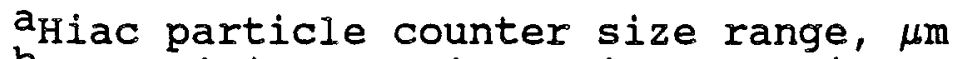

bAve. silica particle size for size range, $\mu \mathrm{m}$ Conc. of silica partilces from counter for size range $\mathrm{d}_{\text {Calculated as per equation (4) }}$

$e\left(k_{i 2} n_{i} / \Sigma k_{i 2 n} i\right) \times 100$

fFrom SEM photos

$g_{\mu \mathrm{ms}}-1 / \mathrm{Vcm}^{-1}$

haluminum (hydr)oxide colloids

itotal from above

jcalculated from equation 
Table A-2: Settling Column Experiment \#2

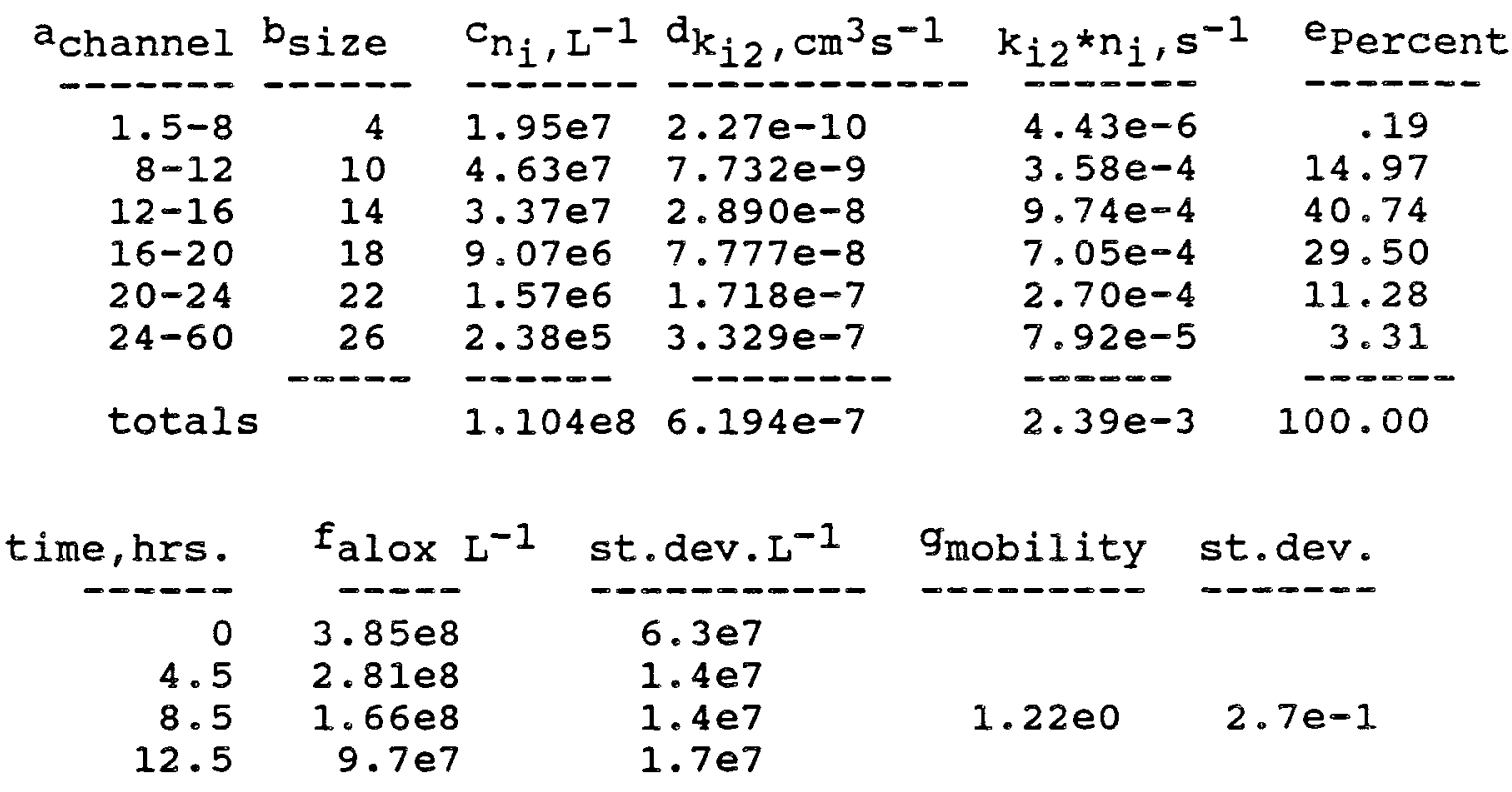

initial $\mathrm{pH}$ final $\mathrm{pH}$

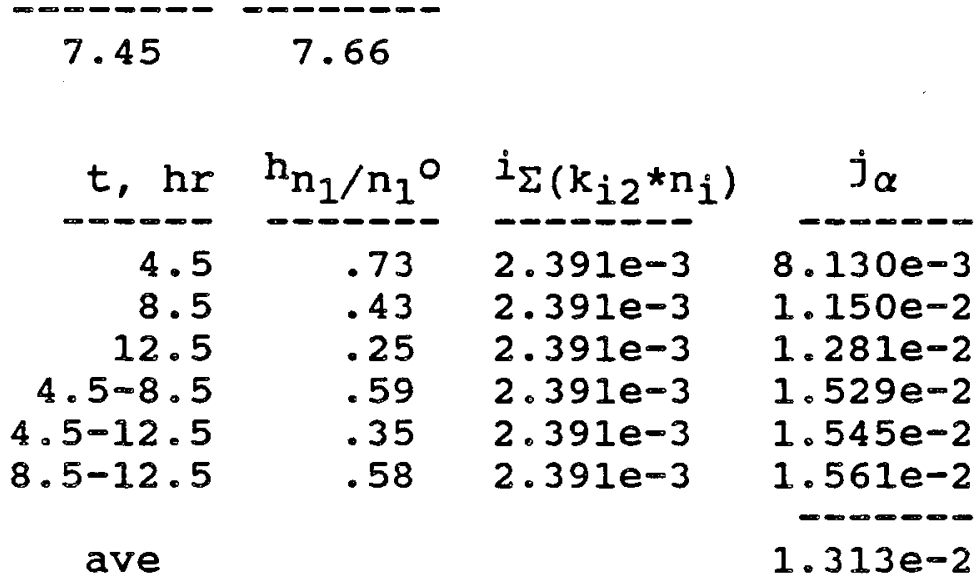

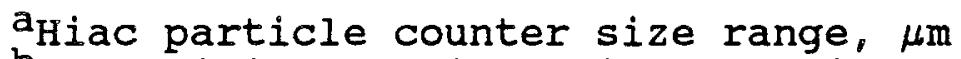

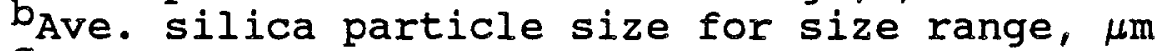
Conc. of silica partilces from counter for size range dCalculated as per equation (4)

$e\left(k_{i 2} n_{i} / \Sigma k_{i 2} n i\right) \times 100$

frrom SEM photos

$\mathrm{g}_{\mu \mathrm{ms}}-1 / \mathrm{Vcm}^{-1}$

haluminum (hydr)oxide colloids

itotal from above

jcalculated from equation 
Table A-3: Fluid Shear Experiment \#3

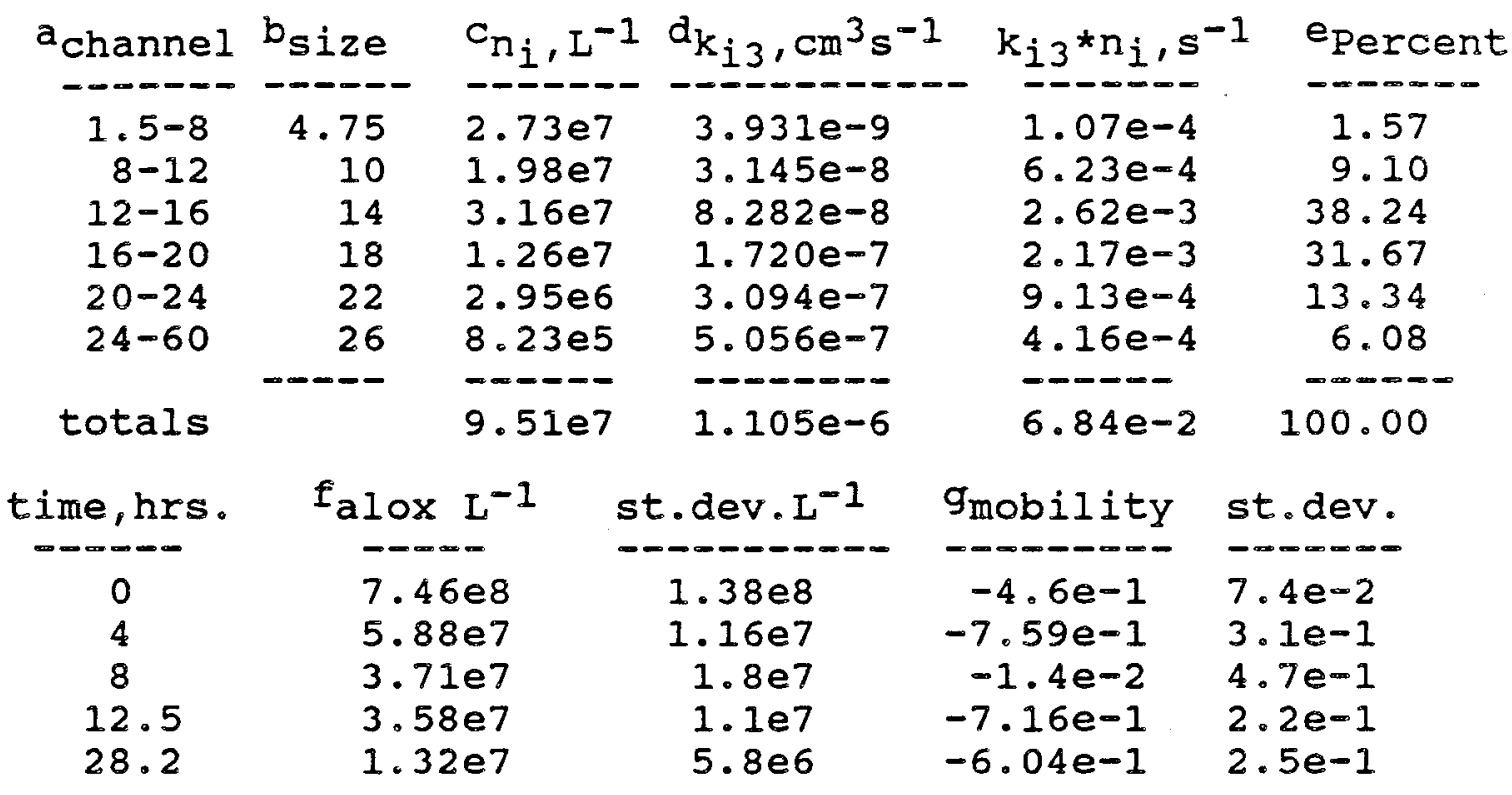

initial $\mathrm{pH}$ final $\mathrm{pH}$

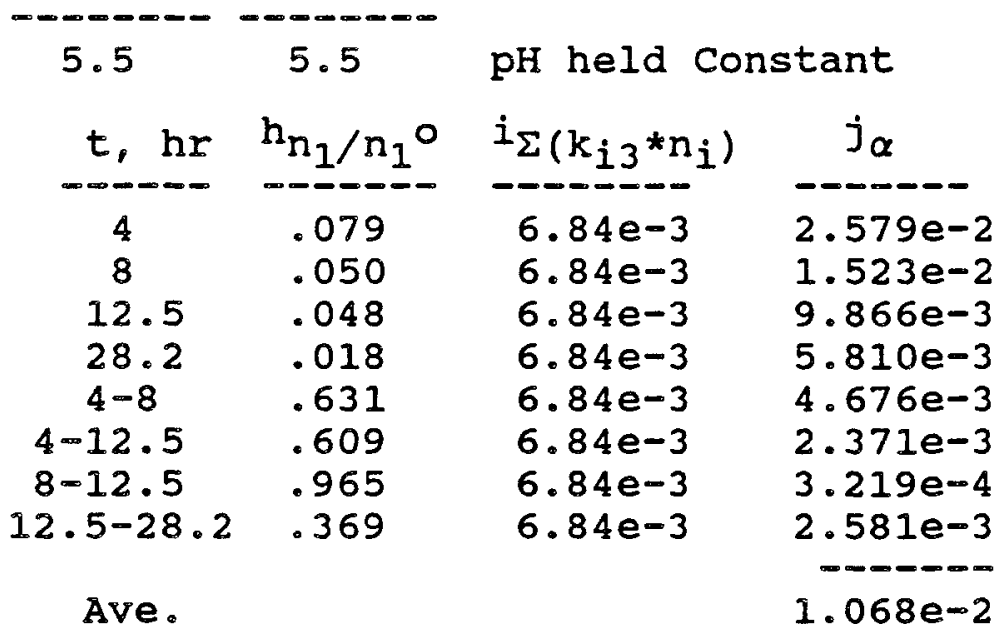

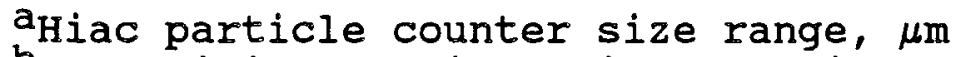

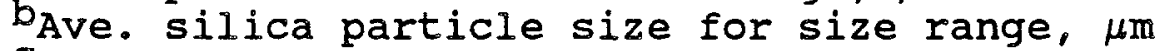

Conc. of silica partilces from counter for size range

dCalculated as per equation (5) with $G=163 \mathrm{~s}^{-1}$

e $\left(k_{i 3} n_{i} / \Sigma k_{i 3 n} i\right) \times 100$

f From SEM photos

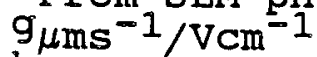

haluminum (hydr)oxide colloids

itotal from above

jcalculated from equation 
Table A-4: Fluid Shear Experiment \#4

\begin{tabular}{|c|c|c|c|c|c|}
\hline${ }^{a}$ channel & $\begin{array}{l}b_{\text {size }} \\
-----\end{array}$ & $c_{n_{i}, L^{-}}$ & $\mathrm{d}_{\mathrm{k}_{\mathrm{i} 3}, \mathrm{~cm}^{3} \mathrm{~s}}$ & $\mathrm{k}_{\mathrm{i} 3}{ }^{*} \mathrm{n}_{\mathrm{i}}, \mathrm{s}$ & epercent \\
\hline $\begin{array}{r}1.5-8 \\
8-12 \\
12-16 \\
16-20 \\
20-24 \\
24-60\end{array}$ & $\begin{array}{r}4.75 \\
10 \\
14 \\
18 \\
22 \\
26\end{array}$ & $\begin{array}{l}3.48 \mathrm{e} 7 \\
3.51 \mathrm{e} 7 \\
2.95 \mathrm{e} 7 \\
9.26 \mathrm{e} 6 \\
2.19 \mathrm{e} 6 \\
5.99 \mathrm{e} 5\end{array}$ & $\begin{array}{l}3.931 e-9 \\
3.145 e-8 \\
8.282 e-8 \\
1.720 e-7 \\
3.094 e-7 \\
5.056 e-7\end{array}$ & $\begin{array}{l}1.37 e-4 \\
1.10 e-3 \\
2.44 e-3 \\
1.59 e-3 \\
6.78 e-4 \\
3.03 e-4\end{array}$ & $\begin{array}{r}2.19 \\
17.64 \\
39.05 \\
25.46 \\
10.83 \\
4.84\end{array}$ \\
\hline totals & ----- & $1.11 \mathrm{e}$ & $1.105 e^{-6}$ & $6.26 e^{-3}$ & 100.00 \\
\hline time, hrs. & $f_{a l o x}$ & $\mathrm{~L}^{-1}$ & st. dev $\cdot \mathrm{L}^{-1}$ & 9 mobility & st. dev. \\
\hline $\begin{array}{r}0 \\
4 \\
0\end{array}$ & $\begin{array}{l}8.46 e \\
1.57 e\end{array}$ & & $\begin{array}{l}8.4 e 7 \\
4.8 e 7\end{array}$ & $\begin{array}{l}7.9 e-1 \\
3.4 e^{-1}\end{array}$ & $\begin{array}{r}1.5 e-1 \\
8 e-2\end{array}$ \\
\hline $\begin{array}{r}8.5 \\
13\end{array}$ & $\begin{array}{r}5.7 e \\
4 e\end{array}$ & & $\begin{array}{r}1.8 \mathrm{e} 7 \\
4 \mathrm{e} 7\end{array}$ & $-5.6 e-1$ & $3.4 e^{-1}$ \\
\hline
\end{tabular}

initial $\mathrm{pH}$ final $\mathrm{pH}$

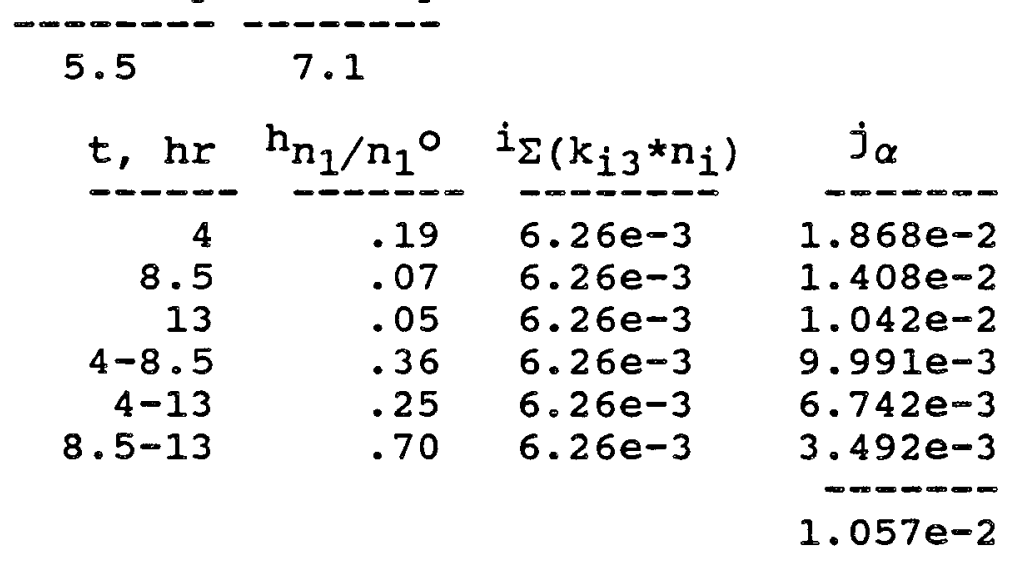

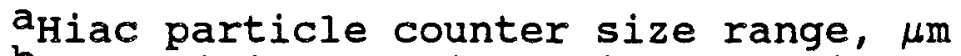

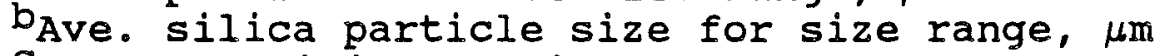

Conc. of silica partilces from counter for size range

dCalculated as per equation (5) with $G=163 \mathrm{~s}^{-1}$

$e\left(k_{i 3} n_{i} / \Sigma k_{i 3 n} i\right) \times 100$

from SEM photos

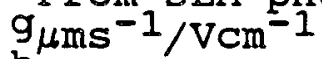

haluminum (hydr) oxide colloids

itotal from above

jcalculated from equation 
Table A-5: Fluid Shear Experiment \#5

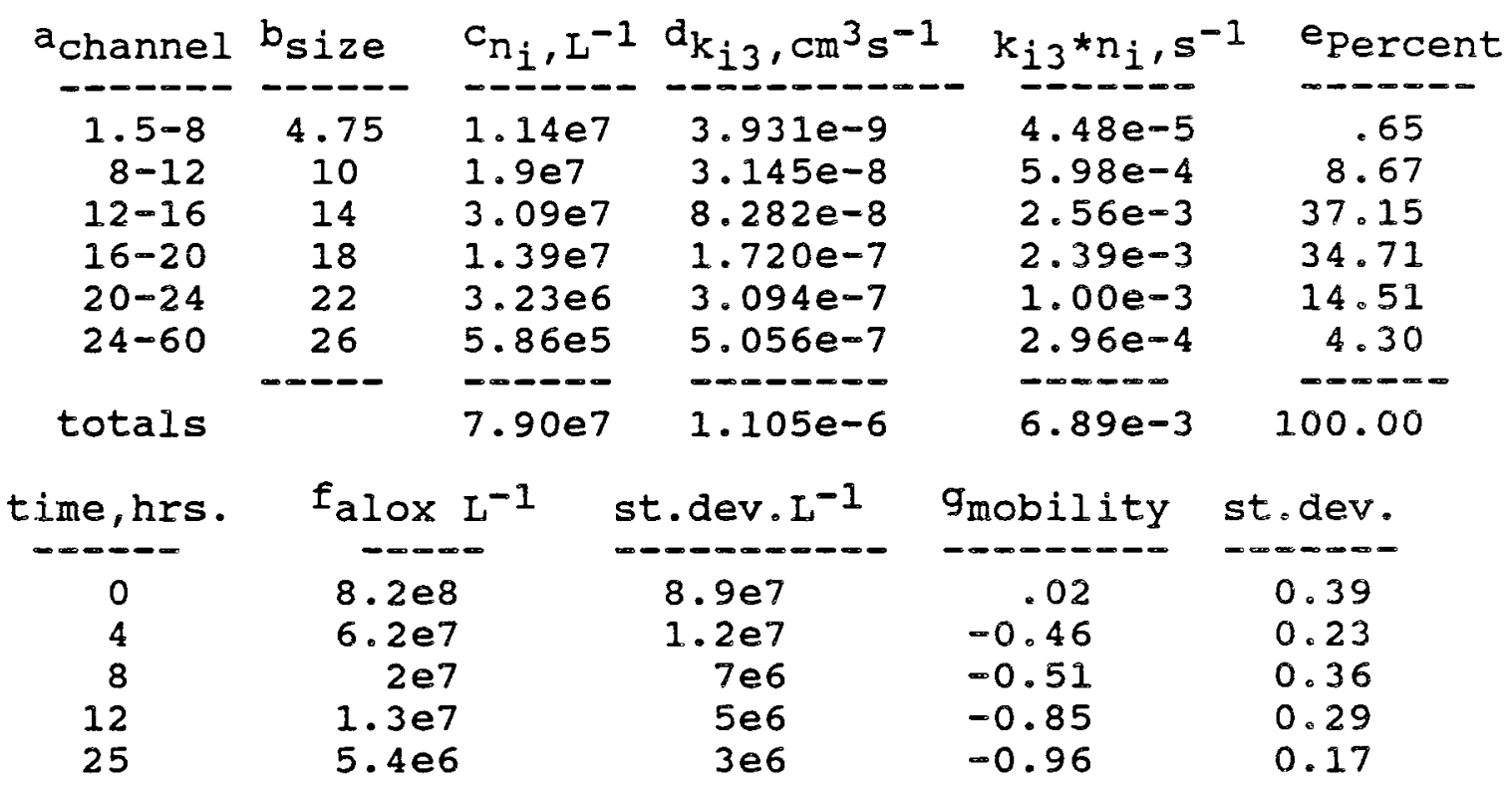

initial $\mathrm{pH}$ final $\mathrm{pH}$

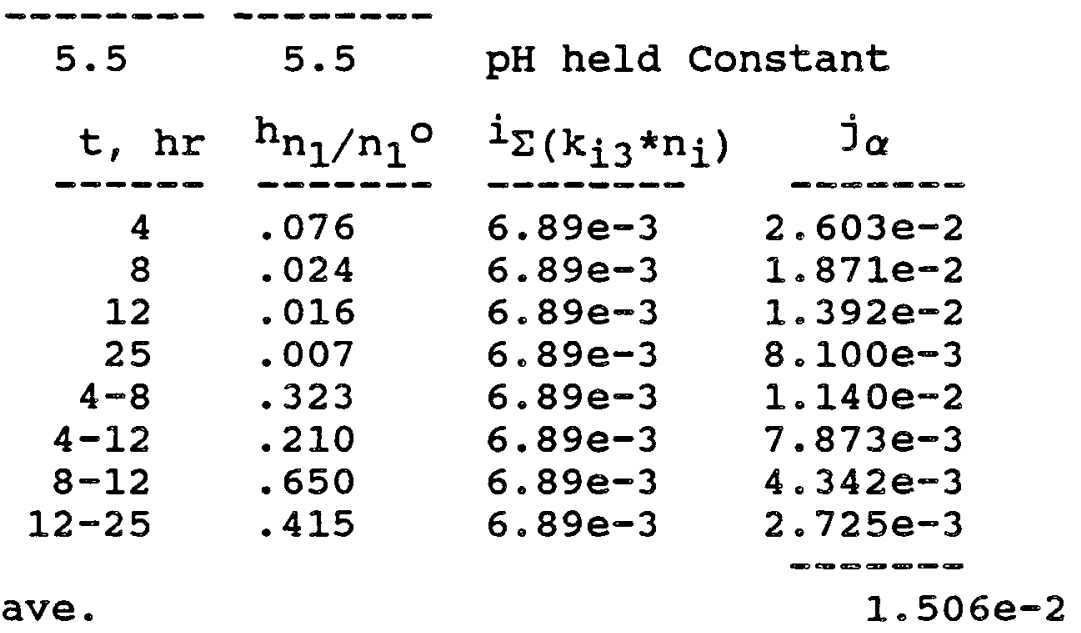

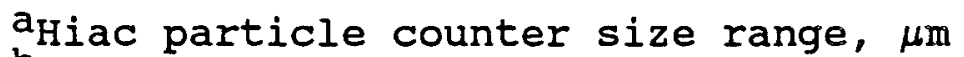

${ }^{b}$ Ave. silica particle size for size range, $\mu \mathrm{m}$ Conc. of silica partilces from counter for size range

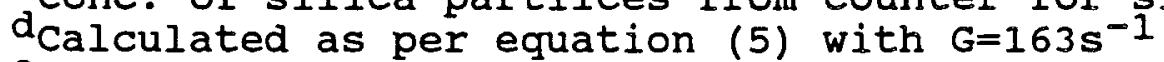
$e\left(k_{i 3} n_{i} / \Sigma k_{i 3 n}\right) \times 100$ fFrom SEM photos $g_{\mu \mathrm{ms}}-1 / \mathrm{Vcm}^{-1}$

haluminum (hydr) oxide colloids itotal from above jcalculated from equation 
Table A-6: Fluid Shear Experiment \#6

\begin{tabular}{|c|c|c|c|c|c|}
\hline a channel & $\mathrm{b}_{\text {size }}$ & $c_{n_{i}, L^{-1}}$ & $d_{k_{i 3}}, \mathrm{~cm}^{3} \mathrm{~s}^{-1}$ & $k_{i 3} * n_{i}, s^{-1}$ & epercent \\
\hline $\begin{array}{r}1.5-8 \\
8-12 \\
12-16 \\
16-20 \\
20-24 \\
24-60\end{array}$ & $\begin{array}{r}4.75 \\
10 \\
14 \\
18 \\
22 \\
26\end{array}$ & $\begin{array}{l}5.5 e 7 \\
2.43 e 7 \\
2.35 e 7 \\
8.79 e 6 \\
2.13 e 6 \\
7.03 e 5\end{array}$ & $\begin{array}{l}3.931 e-9 \\
3.145 e-8 \\
8.282 e-8 \\
1.720 e-7 \\
3.094 e-7 \\
5.056 e-7\end{array}$ & $\begin{array}{l}2.16 e-4 \\
7.64 e-4 \\
1.95 e-3 \\
1.51 e-3 \\
6.59 e-4 \\
3.55 e-4\end{array}$ & $\begin{array}{r}3.96 \\
14.01 \\
35.69 \\
27.73 \\
12.09 \\
6.52\end{array}$ \\
\hline totals & & $1.14 \mathrm{e} 8$ & $1.105 e-6$ & $5.45 e-3$ & 100.00 \\
\hline
\end{tabular}

\begin{tabular}{|c|c|c|c|c|}
\hline time, hrs. & $f_{a 10 \times} L^{-1}$ & st.dev. $L^{-1}$ & $g_{\text {mobility }}$ & st. dev. \\
\hline $\begin{array}{l}0 \\
2\end{array}$ & $9.47 \mathrm{e} 8$ & $8.3 e 7$ & $\begin{array}{r}.81 \\
.89\end{array}$ & $\begin{array}{l}.13 \\
.09\end{array}$ \\
\hline 4 & $7.72 \mathrm{e} 8$ & $1.3 e 8$ & .49 & .10 \\
\hline 8 & $5.45 e 8$ & $4.4 \mathrm{e} 7$ & .67 & .13 \\
\hline 12 & $5.52 \mathrm{e} 8$ & $3.2 \mathrm{e} 7$ & .77 & .14 \\
\hline 24 & $5.56 e 8$ & $3.7 e 7$ & .50 & .17 \\
\hline 28 & & & .37 & .03 \\
\hline 30 & $2.29 e 8$ & $4.1 e 7$ & -.68 & .12 \\
\hline 33 & $6.39 e 7$ & $1.03 \mathrm{e} 7$ & $=.46$ & .13 \\
\hline
\end{tabular}

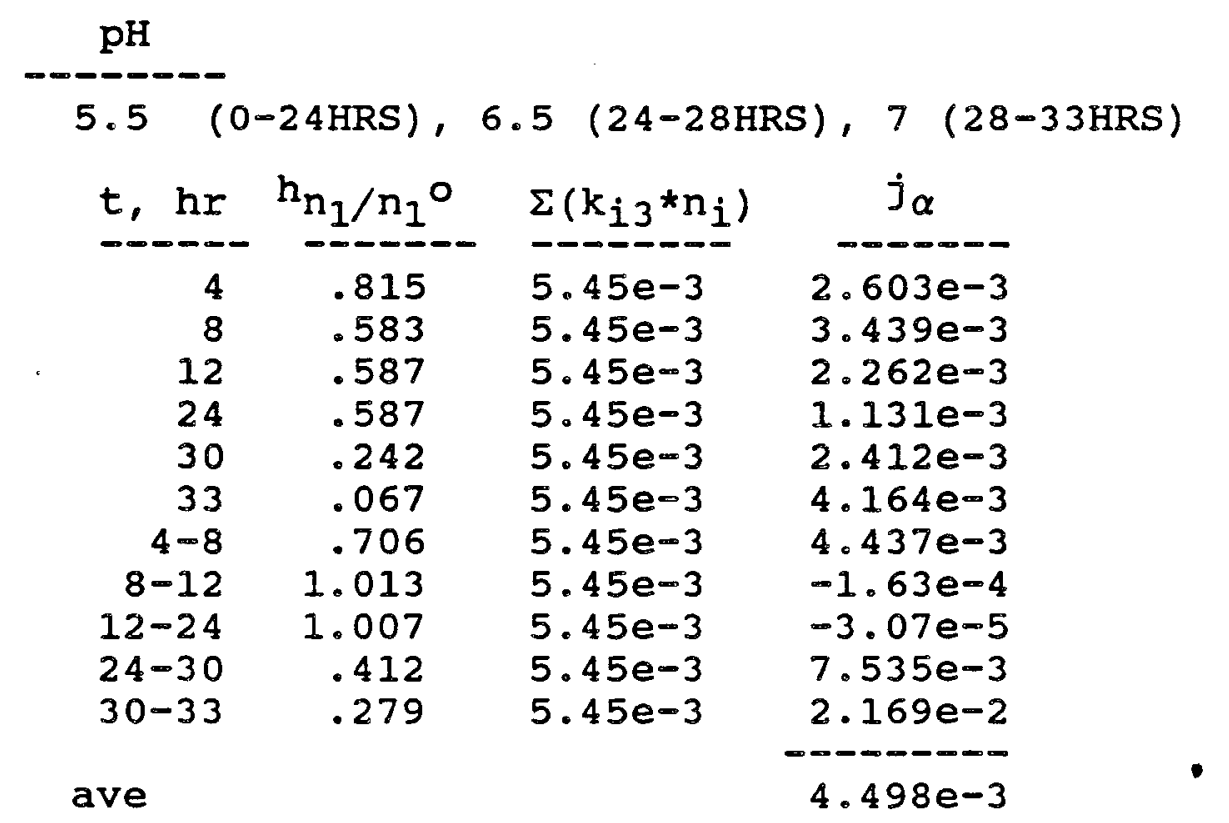

$\mathrm{a}_{\mathrm{Hiac}}$ particle counter size range, $\mu \mathrm{m}$

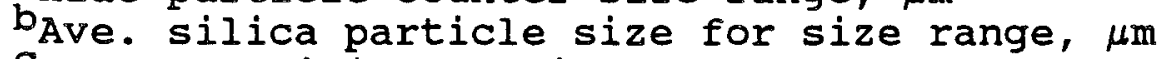

conc. of silica partilces from counter for size range

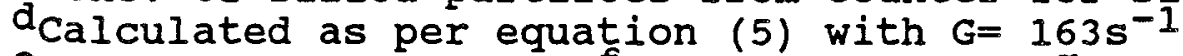

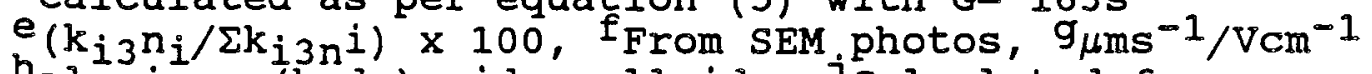

haluminum (hydr) oxide colloids, jcalculated from equa. 
Table A-7: Preliminary Calculation of Coagulation Time for Fluid shear

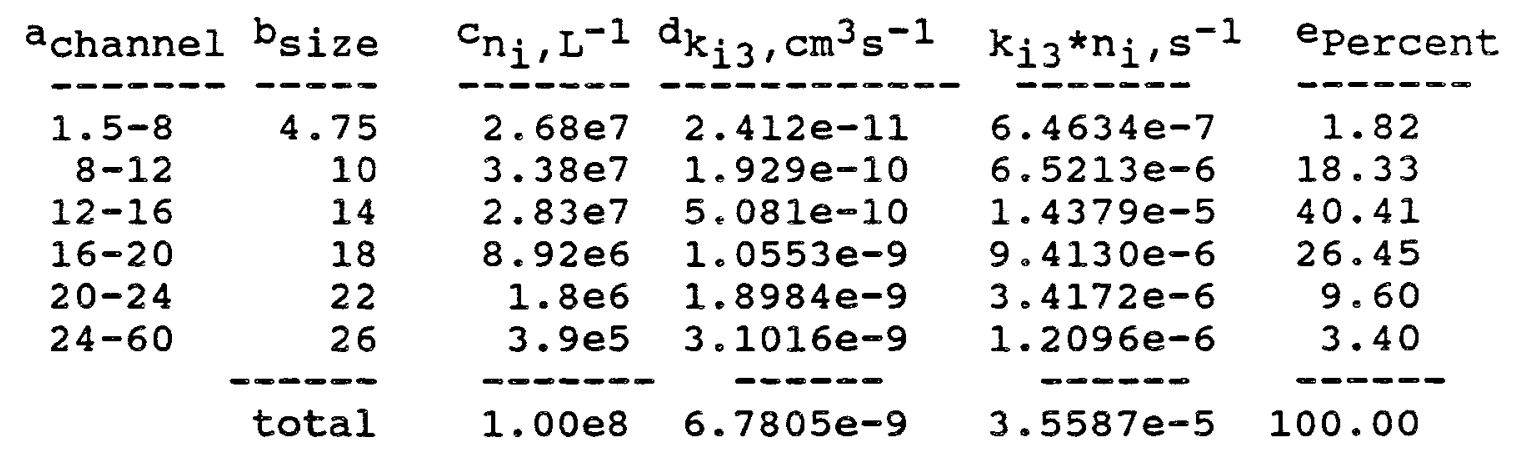

\begin{tabular}{|c|c|c|c|c|c|}
\hline$t, h r$ & $G, s^{-1}$ & $\begin{array}{c}\alpha \\
-\infty-\infty\end{array}$ & $\operatorname{sn}_{i}$ & $f_{k_{i 3}} * n_{i}, s^{-1}$ & $\mathrm{n}_{1} / \mathrm{n}_{1}{ }^{0}$ \\
\hline $\begin{array}{l}3,591 \\
359\end{array}$ & 10 & .01 & $1.0001 e 8$ & $3.5587 e-5$ & $1 e-2$ \\
\hline $\begin{array}{l}359 \\
180\end{array}$ & $\begin{array}{l}10 \\
20\end{array}$ & $\begin{array}{l}.01 \\
.01\end{array}$ & $\begin{array}{l}1.0001 e 8 \\
1.0001 e 8\end{array}$ & $\begin{array}{l}3.5587 e-4 \\
7.1174 e-4\end{array}$ & $\begin{array}{l}1 e-2 \\
1 e-2\end{array}$ \\
\hline 120 & 30 & .01 & $1.0001 \mathrm{e} 8$ & $1.0676 e-3$ & $1 e-2$ \\
\hline 90 & 40 & .01 & $1.0001 \mathrm{e} 8$ & $1.4235 e-3$ & $1 e-2$ \\
\hline 72 & 50 & .01 & $1.0001 e 8$ & $1.7793 e-3$ & $1 e-2$ \\
\hline 45 & 80 & .01 & $1.0001 e 8$ & $2.8469 e-3$ & $1 e-2$ \\
\hline 36 & 100 & .01 & $1.0001 e 8$ & $3.5587 e-3$ & $1 e-2$ \\
\hline 1,795 & 1 & .01 & $1.0001 \mathrm{e} 8$ & $3.5587 e-5$ & $1 e-1$ \\
\hline 180 & 10 & .01 & $1.0001 e 8$ & $3.5587 e-4$ & $1 e^{-1}$ \\
\hline 90 & 20 & .01 & $1.0001 \mathrm{e} 8$ & $7.1174 e-4$ & $1 e-1$ \\
\hline 60 & 30 & .01 & $1.0001 \mathrm{e} 8$ & $1.0676 e-3$ & $1 e-1$ \\
\hline 45 & 40 & .01 & $1.0001 e 8$ & $1.4235 e-3$ & $1 e-1$ \\
\hline 36 & 50 & .01 & $1.0001 e 8$ & $1.7793 e-3$ & $1 e-1$ \\
\hline 22 & 80 & .01 & $1.0001 \mathrm{e} 8$ & $2.8469 e-3$ & $1 e-1$ \\
\hline 18 & 100 & .01 & $1.0001 e 8$ & $3.5587 e-3$ & $1 e-1$ \\
\hline 11 & 160 & .01 & $1.0001 e 8$ & $5.6939 e-3$ & $1 e-1$ \\
\hline
\end{tabular}

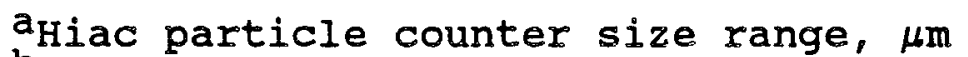

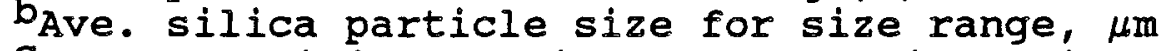

Conc. of silica partilces from typical distribution

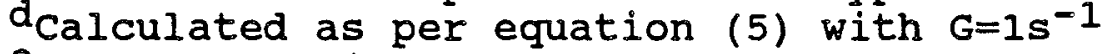

$\left.e\left(k_{i 3} n_{i} / \Sigma k_{i 3 n}\right)\right) \times 100$

calculated with above silica distribution

$\mathrm{G} 1=\mathrm{G} 2$ * $\mathrm{SQRT}(\mathrm{V} 1 / \mathrm{V} 2) \quad \mathrm{V} 1=4 \mathrm{~L}$ (From apparatus), $\mathrm{V} 2=2 \mathrm{~L}$ G2, V2 Taken from Fig. 12, Cornwell and Bishop(1983) 
APPENDIX B MOBIIITY EXPERIMENTS 
Table B-1: Mobility of Aluminum oxide Colloids in the Presence of Dissolved Silica

RECIPE: $0.001 \mathrm{M}$ BICARB, 0.009M NaCI, 60ppm(1mM) silica TIME (MIN) MOBILITY ST. DEV.

$\begin{array}{rrr}5 & .97 & .23 \\ 20 & .66 & .15 \\ 40 & .73 & .19 \\ 90 & -.65 & .17 \\ 160 & . .65 & .17\end{array}$

90 .96 .19 WITHOUT SILICA AS A BLANK

MOEILITY OF ALOX IN THE FRESENCE OF WASHED MIN-UI-SIL CONDITIONS:

$\mathrm{FH} 5.5$

NaCI $0.009 M$

NaHCO3 $0.001 \mathrm{M}$

BES P/L ALOX

EET P/L MS

MS HEATED AT 400 C FOR 24 HFS., WASHED WITH $4 N$ HNO3 ANO $4 N \mathrm{NaOH}$ EACH FQR FOLLOUED BY MILI-Q WASHES AND OECANTINGS UNNTIL ALL FINES REMOVED AND $\mathrm{PH} \sim 7.0$.

TIME (MIN)

MOEILITY

(UM $/ S E C) /(U O L T / C M)$
WT IH MS
WITHOUT MS
.93
-.59
-.36
1.09
.67

5
60
159 
Table B-2: Mobility of Aluminum oxide colloids and Particle Silica with Dissolved Aluminum

CONDITIONS :

$\mathrm{pH} 5.5$

$\mathrm{NaCl} 0.009 \mathrm{M}$

$\mathrm{NaHCO} 3 \quad 0.001 \mathrm{M}$

$8 E 8$ P/L ALOX

$8 \mathrm{E} 7 \mathrm{P} / \mathrm{L}$ MS

$\begin{array}{rrr}\text { ug/I AS AI3+ } & \text { MOBILITY ALOX } & \text { MOBILITY SILICA } \\ 0 & -.83,-0.73 & - \\ .25 & -1.07 & - \\ 2.5 & -1.05 & - \\ 25 & -.93 & - \\ 50 & -.63 & - \\ 100 & -0.72,-0.77 & - \\ 150 & -.33 & + \\ 200 & -.56 & + \\ 250 & 0.64,0.49 & \end{array}$


Table B-3: Mobility of Aluminum oxide Colloids vs $\mathrm{pH}$

$0.01 \mathrm{M} \mathrm{NaCl}$

0.01M Nacl

PH MOBILITY ST. DEV.DIRECTION MOBILITY ST. DEV.DIRECTION

$\begin{array}{rrrrrrr}4.5 & 1.69 & .15 & \text { B } & & & \\ 5.5 & 1.53 & .14 & \text { B } & 1.42 & .17 & \text { B } \\ 6.5 & 1.5 & .15 & \text { B } & & & \\ 7 & .64 & .18 & \text { B } & & & \\ 7.5 & .69 & .17 & \text { A } & 1.11 & .08 & \text { B } \\ 7.75 & .15 & .31 & \text { B } & & & \\ 8 & -.64 & .18 & \text { B } & -.11 & .21 & \text { B } \\ 8.3 & -.62 & .13 & \text { B } & & & \\ 9 & -.76 & .11 & \text { A } & & & \end{array}$

$0.001 \mathrm{M} \mathrm{NaHCO} 3$

PH MOBILITY ST.DEV.DIRECTION MOBILITY ST.DEV.DIRECTION

$\begin{array}{rrrrrrr}4.5 & 1.59 & .11 & \text { B } & & & \\ 6 & 1.22 & .13 & \text { B } & & & \\ 6.5 & . .38 & .08 & \text { B } & & & \\ 7 & -.63 & .13 & \text { A } & & & \\ 7 & -.67 & .15 & \text { B } & -.97 & .17 & \text { A } \\ 8 & -.5 & .15 & \text { A } & -.84 & .18 & \text { A } \\ 9 & -.67 & .16 & \text { A } & -.75 & .11 & \text { A }\end{array}$

$0.01 \mathrm{M} \mathrm{NaHCO} 3$

pH MOBILITY ST.DEV.DIRECTION MOBILITY ST. DEV.DIRECTION

$\begin{array}{rrrrrrr}4.5 & 1.77 & .3 & \text { B } & & & \\ 5 & 1.34 & .27 & \text { B } & 2.14 & .34 & \text { A } \\ 5.6 & .93 & .18 & \text { B } & & & \text { A } \\ 6 & -.35 & .14 & \text { A } & -.38 & .08 & \text { A } \\ 6.5 & -.56 & .11 & \text { A } & & & \\ 7 & -.98 & .36 & \text { A } & -.78 & .13 & \text { A } \\ 8 & -1.1 & .13 & \text { A } & & & \\ 9 & -1.26 & .29 & \text { A } & & & \end{array}$


REM PROGRAM USED FOR CONTROLIING THE PHSTAT TO REM MAINTAIN A CONSTANT PH

REM INITIALIZING

0001 HOME $: F 1=0: F 3=0: D A Y=0$

$0002 \mathrm{M}=10: \mathrm{Z} 9=-16384$

$0003 \mathrm{DDRB}=-15870: \mathrm{AC}=0$

$0004 \mathrm{~PB}=-15872: \mathrm{AB}=0$

$0005 \mathrm{TL}=0.01$

$0006 \mathrm{D} \$=\mathrm{CHR} \$(4)$

$0007 \mathrm{~W} \$=\operatorname{CHR} \$(23)$

REM INPUT VARIABLES

O010 INPUT "EXPERIMENT ID $=$ "; ID $\$$

0011 INPUT "ENTER PH SET POINT $=$ "; SPH

0012 INPUT "ENTER PRINT INTERVAL (MIN) $=$ "; PI

0013 INPUT "ENTER ALIQUOT SIZE FOR ACID $=$ "; M1

0014 INPUT "ENTER STRENGTH OF ACID $(\mathrm{M})=$ "; $\mathrm{C} 1$

0015 INPUT "ENTER ALIQUOT SIZE FOR BASE $={ }^{\circ}$; M2

0016 INPUT "ENTER STRENGTH OF BASE $(\mathrm{M})=$ "; C2

0017 INPUT "ENTER PH TOLERANCE $=$ " ; TL

$0020 \mathrm{ACD}=\mathrm{M} 1 * 0.00025 * \mathrm{C} 1 / 1000$.

$0021 \mathrm{BAS}=\mathrm{M} 2 * 0.00025 * \mathrm{C} 2 / 1000$.

REM PRINT INPUT VARIABLES

0030 PRINT D\$ ; "PR\#1"

0031 PRINT "EXPERIMENT ID $=$ "; ID $\$$

0032 PRINT "MOLE OF ACID PER ADDITION $=$ "; ACD

0033 PRINT "MOLE OF BASE PER ADDITION $=$ "; BAS

0034 PRINT "PH TOLERANCE $=$ "; TL

0035 PRINT "SET POINT PH $=$ "; SPH

0036 PRINT : PRINT : PRINT : PRINT 
0037 PRINT "TIME(SEC) \# ACID \# BASE PH"

0038 PRINT “

0039 PRINT D\& ; "PR\#0"

0040 GOSUB 2000

0041 GOSUB 3000

$0042 \mathrm{TO}=\mathrm{MIN}+\mathrm{SEC} / 60+\mathrm{HR} * 60$

0043 GOSUB 7000

0044 HOME

0045 GOSUB 6000

0046 POKE $-16368,0$

REM MAIN PROGRAM.

REM RUNS EVERYTIME IT RECEIVES A SIGNAL FROM THE PHSTAT

$0100 \mathrm{~K}=$ PEEK (Z9)

0105 IF $\mathrm{K}>127$ THEN GOSUB 8000

0110 IF F1 $=0$ GOTO 40

0115 GOSUB 2000

$0120 \mathrm{DF}=\mathrm{ABS}(\mathrm{SPH}-\mathrm{PH})$

0125 IF $(P H-S P H)>=$ TL THEN GOSUB 4000

0130 IF (SPH - PH) > = TL THEN GOSUB 5000

0135 GOSUB 3000

$0140 \mathrm{TIME}=\mathrm{MIN}+\mathrm{SEC} / 60+\mathrm{HR}^{*} 60$

0145 IF (TIME - TO) < PI GOTO 165

0150 GOSUB 7000

$0155 \mathrm{TO}=\mathrm{TIME}$

0160 GOSUB 6000

0165 GOTO 100

REM SUBROUTINE TO READ THE PH PROBE

2000 PRINT D ; "IN\#3"

2005 VTAB 24 : HTAB 1

2010 INPUT PHS

2015 HOME

2020 PRINT D\$ ; "IN\#0" 
$2025 \mathrm{PH}=\operatorname{VAL}(\operatorname{LEFT} \$(\mathrm{PH} \$, 7))$

$2030 \mathrm{PH}=\operatorname{INT}\left(\mathrm{PH}^{*} 1000+0.5\right) / 1000$

2035 RETURN

REM SUBROUTINE TO READ THE CLOCK

3000 PRINT DS; "IN\#3"

3005 PRINT D\$; "PR\#3"

3010 PRINT W\$; "C"

3015 INPUT T\$

3020 PRINT D\$; "IN\#O"

3025 PRINT D\$; "PR\#O"

$3030 \mathrm{HR}=\mathrm{VAL}(\mathrm{MID} \$(\mathrm{~T} \$, 12,2))$

$3035 \mathrm{MIN}=$ VAL $(\operatorname{MID} \$(\mathrm{~T} \$, 15,2))$

3040 SEC $=$ VAL $($ MID\$ $(T \$, 18,2))$

3045 IF $F 1<>0$ GOTO 3060

$3050 \mathrm{IHR}=\mathrm{HR}:$ IMIN $=$ MIN $:$ ISEC $=\mathrm{SEC}$

$3055 \mathrm{~F} 1=1$

3060 IF SEC > = ISEC GOTO 3075 .

$3065 \mathrm{MIN}=\mathrm{MIN}-1: \mathrm{SEC}=\mathrm{SEC}+60-$ ISEC

3070 GOTO 3080

3075 SEC = SEC - ISEC

3080 IF MIN > = IMIN GOTO 3095

$3090 \mathrm{HR}=\mathrm{HR}-1: \mathrm{MIN}=\mathrm{MIN}+60-\mathrm{IMIN}$

3095 GOTO 3105

$3100 \mathrm{MIN}=$ MIN - IMIN

3105 GOSUB 9000

$3110 \mathrm{O} \$=\operatorname{RIGHT} \$(\mathrm{~T} \$, 8): \mathrm{D} 7 \$=\operatorname{LEFT} \$(\mathrm{~T} \$, 11)$

3115 RETURN

REM SUBROUTINE FOR ACID ADDITION

4000 POKE DDRB, 255

$4005 \mathrm{FOR} I=1 \mathrm{TO} \mathrm{M} 1$

4010 POKE PB, I

$4015 \mathrm{JJ}=0$ 
4020 POKE $P B, 0$

4025 NEXT I

$4030 \mathrm{AC}=\mathrm{AC}+1$

4035 RETURN

REM SUBROUTINE FOR BASE ADDITION

5000 POKE DDRB, 255

5005 FOR I $=1$ TO M2

5010 POKE PB, 8

$5015 \mathrm{JJ}=0$

5020 POKE PB,O

5025 NEXT I

$5030 \mathrm{AB}=\mathrm{AB}+1$

5035 RETURN

REM DISPLAY ON SCREEN

6000 HOME

6005 PRINT D7\$

6010 VTAB 10

6015 PRINT "PH ELAPSED TIME TIME \# ADDITION"

6020 PRINT

$6025 \mathrm{TS}=\mathrm{TIME} * 60.0$

6030 PRINT PH ; TAB(10) ; HR ; “" ; MIN ; ":" ; SEC ; TAB(21); O\$

6035 VTAB 12 : HTAB 33 : PRINT AC; ${ }^{*} /{ }^{n} ; A B$

6040 RETURN

REM PRINT ON PAPER

7000 PRINT D\$; “PR\#1"

7005 IF F1 $<>0$ GOTO 7025

7010 PRINT : PRINT : PRINT : PRINT : PRINT D7\$ : PRINT : PRINT

7015 PRINT "PH ELAPSED TIME TIME \# ADDITION"

$7020 \mathrm{~F} 1=1:$ PRINT

7025 PRINT TIME ; TAB(15) ; AC ; TAB(25); AB; TAB(35); PH

7030 PRINT D\$; "PR\#0"

7035 RETURN 
REM SUBROUTINE FOR CHANGING CURRENT SETTING 8000 POKE -16368,0 : HOME 8005 PRINT "PARAMETER CHANGE MENU" : PRINT 8010 PRINT "1) RESET PH-SET POINT" 8015 PRINT "2) RESET PRINT INTERVAL" 8020 PRINT "3) RESET ELAPSED TIME" 8025 PRINT "4) RESET ALIQUOT SIZES" 8030 PRINT "5) RETURN TO PROGRAM" 8035 PRINT “6) EXIT" 8040 PRINT “7) RESET PH TOLERANCE" 8045 PRINT : INPUT "ENTER YOUR CHOICE $=$; ; 9 8050 HOME 8055 IF K9 $=5$ THEN RETURN 8060 ON K9 GOSUB 8075, 8085, 8095, 8120, 8130, 8135, 8140 8065 GOTO 8000 8070 RETURN 8075 INPUT "ENTER SET-POINT PH" 8080 RETURN 8085 INPUT "ENTER PRINT INTERVAL" 8090 RETURN 8095 INPUT “ENTER NUMBER OF ELAPSED DAYS $=$ "; DAY 8100 INPUT “ENTER INITIAL HOUR $={ }^{*}$; HR 8105 INPUT "ENTER INITIAL MINUTE $=$ "; MIN 8110 INPUT "ENTER INITIAL SECOND $=$ "; SEC 8115 RETURN 8120 INPUT "ENTER ALIQUOT SIZE FOR ACID $=$ "; M1 8125 INPUT "ENTER ALIQUOT SIZE FOR BASE $=$ "; M2 8130 RETURN

8135 END

8140 INPUT "ENTER PH TOLERANCE $={ }^{n} ; \mathrm{TL}$ 8145 RETURN REM CALCULATION OF ELAPSED TIME 


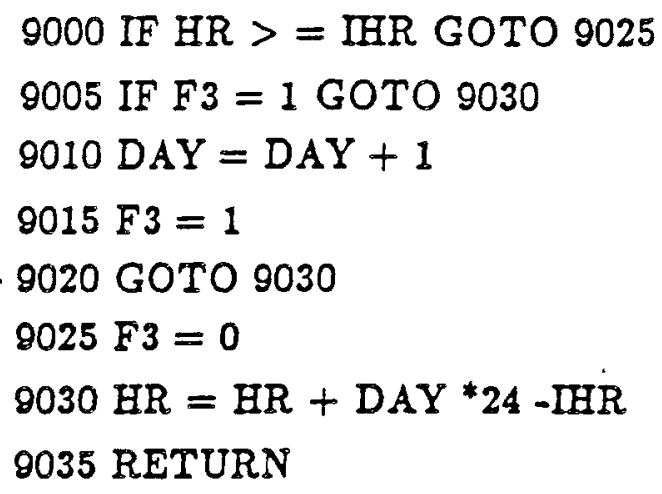


APPENDIX C

TITRATION EXPERIMENTS 
Table C-1: RAW AND REDUCED DATA FOR ALPHA ALUMINA

TITRATIONS WITH DISSOLVED SILICA

TITRATION OF WATER

(0.4ML OF 0.IM HCI ADDED TO GET TO pH 3.5)

BASE

ADDED

$(\mathrm{mL} 0.1 \mathrm{M} \mathrm{NaOH})$
3.5
4
4.5
5
5.5
6
6.5
7
7.5
8
8.5
9.5
10

$\mathrm{NaOH}$ )
0

0.234

0.32

0.354

0.376

0.384

0.396

0.402

0.408

0.41

0.42

0.452

0.564

0.86
$\mathrm{Cb}-\mathrm{Ca}$

$\mathrm{mol} / \mathrm{L}$

$-0.0002$

$-0.00008$

$-0.00004$

$-0.00002$

$-0.00001$

$-0.00000$

$-0.00000$

0.000001

0.000004

0.000005

0.00001

0.000026

0.000082

0.00023

TITRATION OF 1OE-3M SILICA

(4.56ML OF 0.1M HCl ADDED TO GET TO $\mathrm{pH} 3.5$ )

BASE

ADDED

(mI $0.1 \mathrm{M} \mathrm{NaOH}$ )

\section{5}

4

4.5

5

5.5

6

6.5

7

7.5

8

8.5

9

9.5

10
0.35

0.47

0.516

0.53

0.546

0.556

0.56

0.574

0.604

0.69

0.91

1.39

2.54
$\mathrm{Cb}-\mathrm{Ca}$

mol/L

$-0.00228$

$-0.00210$

$-0.00204$

$-0.00202$

$-0.00201$

$-0.00200$

$-0.00200$

$-0.002$

$-0.00199$

$-0.00197$

$-0.00193$

$-0.00182$

$-0.00158$

$-0.00101$ 
Table C-1 continued

TITRATION OF ALUMINA, 10G/L (1.58ML OF 0.IM HCI ADDED TO GET TO $\mathrm{pH} \mathrm{3.5)}$

BASE

ADDED

(mL $0.1 \mathrm{M} \mathrm{NaOH)}$

3.5
4
4.5
5
5.5
6
6.5
7
7.5
8
8.5
9
9.5
10

3.5

4

5

5

6

.5

7

.5

8

5
9

9.5

10
NaOH)
0

0.4

0.84

1.15

1.25

1.32

1.38

1.436

1.486

1.54

1.618

1.742

1.936

2.3
$\mathrm{Cb}-\mathrm{Ca}$

mol/L

$-0.00079$

$-0.00059$

$-0.00037$

$-0.00021$

$-0.00016$

$-0.00013$

$-0.0001$

$-0.00007$

$-0.00004$

$-0.00002$

0.000019

0.000081

0.000178

0.00036

TITRATION OF ALUMINA + 10E-5M SILICA, 10G/L (1.8ML OF 0.1M HCl ADDED TO GET TO $\mathrm{pH} 3.5$ )

BASE

ADDED

(mL $0.1 \mathrm{M} \mathrm{NaOH}$ )

3.5

4

4.5

5

5.5

6

6.5

7

7.5

8

8. 5

9.5

10

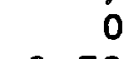

0.52

0.97

1.28

1.386

1.456

1.52

1.576

1.63

1.69

1.786

1.95

2.16

2.6
$\mathrm{Cb}-\mathrm{Ca}$

$\mathrm{mol} / \mathrm{L}$

$-0.0009$

$-0.00064$

$-0.00041$

$-0.00026$

$-0.00020$

$-0.00017$

$-0.00014$

$-0.00011$

$-0.00008$

$-0.00005$

$-0.00000$

0.000075

0.00018

0.0004 
Table C-1 Continued

TITRATION OF ALUMINA + 1OE-4M SILICA, 10G/L (2.16mL OF 0.1M HCI ADDED TO GET TO pH 3.5)

BASE

ADDED

(mL $0.1 \mathrm{M} \mathrm{NaOH}$ )

3.5

4

4.5

5

5.5

6

6.5

7

7.5

8

8.5

9

9.5

10
$\mathrm{NaOH)}$

0.43

1.01

1.34

1.466

1.536

1.596

1.646

1.69

1.75

1.816

1.94

2.14

2.5
$\mathrm{Cb}-\mathrm{Ca}$

$\mathrm{mol} / \mathrm{L}$

$-0.00108$

$-0.00086$

$-0.00057$

$-0.00041$

$-0.00034$

$-0.00031$

$-0.00028$

$-0.00025$

$-0.00023$

$-0.00020$

$-0.00017$

$-0.00011$

$-0.00001$

0.00017

TITRATION OF ALUMINA + 1OE-3M SILICA, 1OG/L (6.6ML OF 0.1M HCl ADDED TO GET TO pH 3.5)

BASE

ADDED

$(\mathrm{mL} 0.1 \mathrm{M}$ NaOH)

3.5

4
4

5
5

5.5

6

6.5

7

7.5

8

8.5

9

9.5

10
0

1.04

1.71

2.28

2.38

2.44

2.48

2.54

2.58

2.84

3.06

3.5

3.98
2.68
$\mathrm{Cb}-\mathrm{Ca}$

$\mathrm{mol} / \mathrm{L}$

$-0.0033$

$-0.00278$

$-0.00244$

$-0.00216$

$-0.00211$

$-0.00208$

$-0.00206$

$-0.00203$

$-0.00201$

$-0.00196$

$-0.00188$

$-0.00177$

$-0.00155$

$-0.00131$ 
Table C-2: Surface Area of Alpha-Alumina from BET Adsorption

Equation used: $\quad S . A .=(3.2152 * A * V C) /(A C * X g)$

$\begin{array}{cccccc}\text { Run \# Xg(grams) } & \text { A } & \text { AC } & \text { VC(cm3) S.A.(m2/g) } \\ 1 & 0.2752 & 1927 & 1280 & 0.80 & 15.009 \\ 2 & 0.2752 & 2027 & 1415 & 1.00 & 15.788 \\ 3 & 0.2752 & 1946 & 1440 & 1.00 & 15.157 \\ 4 & 0.2752 & 1972 & 2112 & 1.40 & 15.360 \\ 5 & 0.2752 & 1946 & 2089 & 1.40 & 15.157 \\ 6 & 0.2752 & 1974 & 2099 & 1.40 & 15.375\end{array}$

Average Surface Area $15.308+-0.273$ 
Table c-3: SURFEQL Input Files

\section{Titration of water}

$\begin{array}{rlrr}50 & -7.0 & 1.00 \mathrm{E}-7 \\ 5 & -2.0 & 1.00 \mathrm{E}-2 \\ 103 & -2.0 & 1.00 \mathrm{E}-2 \\ & & & \\ 00002 & & & \\ 13595 & -14.00 & 50 & -1 \\ 00003 & & & \\ 00500 & 7.00 & 50 & 1\end{array}$

Titration of Dissoved Silica

$\begin{array}{rccccc}50 & -7.0 & 1.00 \mathrm{E}-7 & & \\ 5 & -2.0 & 1.00 \mathrm{E}-2 & & \\ 103 & -2.0 & 1.00 \mathrm{E}-2 & & \\ 164 & -4.0 & 1.0 \mathrm{E}-3 & & \\ & & & & & \\ 00002 & & & & & \\ 13595 & -14.00 & 50 & -1 & & \\ 25100 & 12.6 & 50 & 1 & 164 & 1 \\ 25110 & 22.1 & 50 & 2 & 164 & 1 \\ 00003 & & & & & \\ 00500 & 7.00 & 50 & 1 & & \end{array}$


Table c-3 continued

Titration of $\alpha-$ Alumina

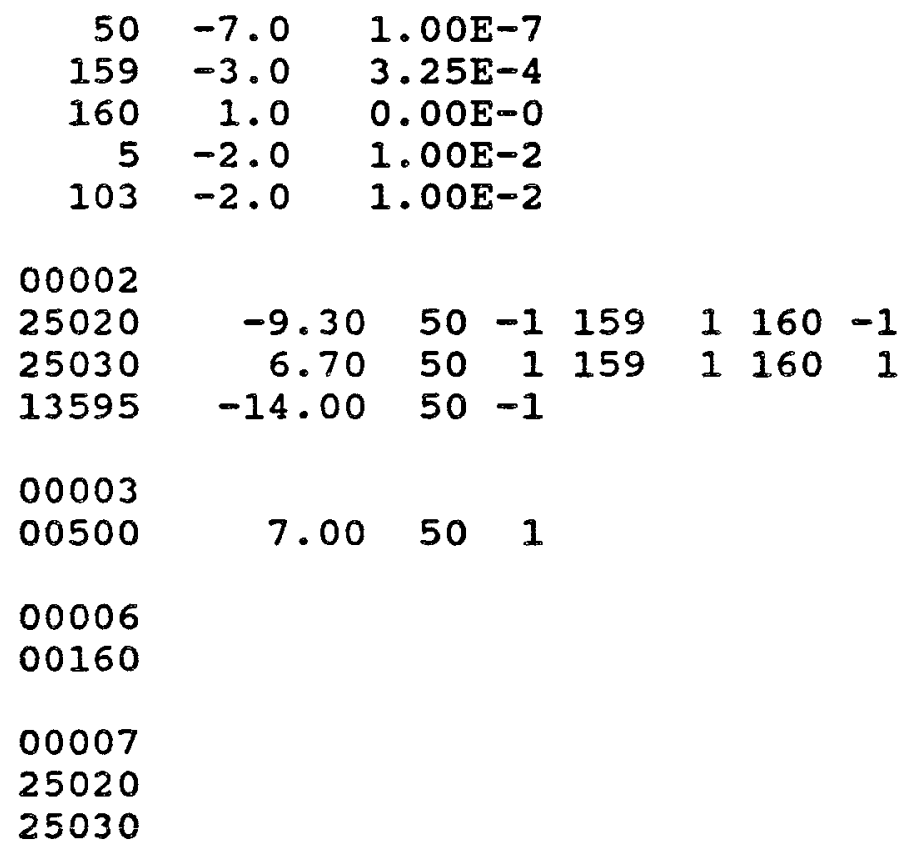


Talbe $c-3$ continued

Titration of $\alpha-A$ lumina and silica, no adsorption

$\begin{array}{rrr}50 & -7.0 & 1.00 E-7 \\ 159 & -3.0 & 3.25 E-4 \\ 160 & 1.0 & 0.00 E-0 \\ 5 & -2.0 & 1.0 O E-2 \\ 103 & -2.0 & 1.0 O E-2 \\ 164 & -4.0 & 1.0 E-3\end{array}$

00002

$\begin{array}{llllllll}25020 & -9.30 & 50 & -1 & 159 & 1 & 160 & -1\end{array}$

$\begin{array}{llllllll}25030 & 6.70 & 50 & 1 & 159 & 1 & 160 & 1\end{array}$

$13595-14.00 \quad 50-1$

$\begin{array}{llllll}25100 & 12.6 & 50 & 1 & 164 & 1\end{array}$

$\begin{array}{llllll}25110 & 22.1 & 50 & 2 & 164 & 1\end{array}$

00003

$00500 \quad 7.00 \quad 50 \quad 1$

00006

00160

00007

25020

25030 
Table C-3 continued

Titration of $\alpha$-alumina with silica, adsorption and ligand exchange

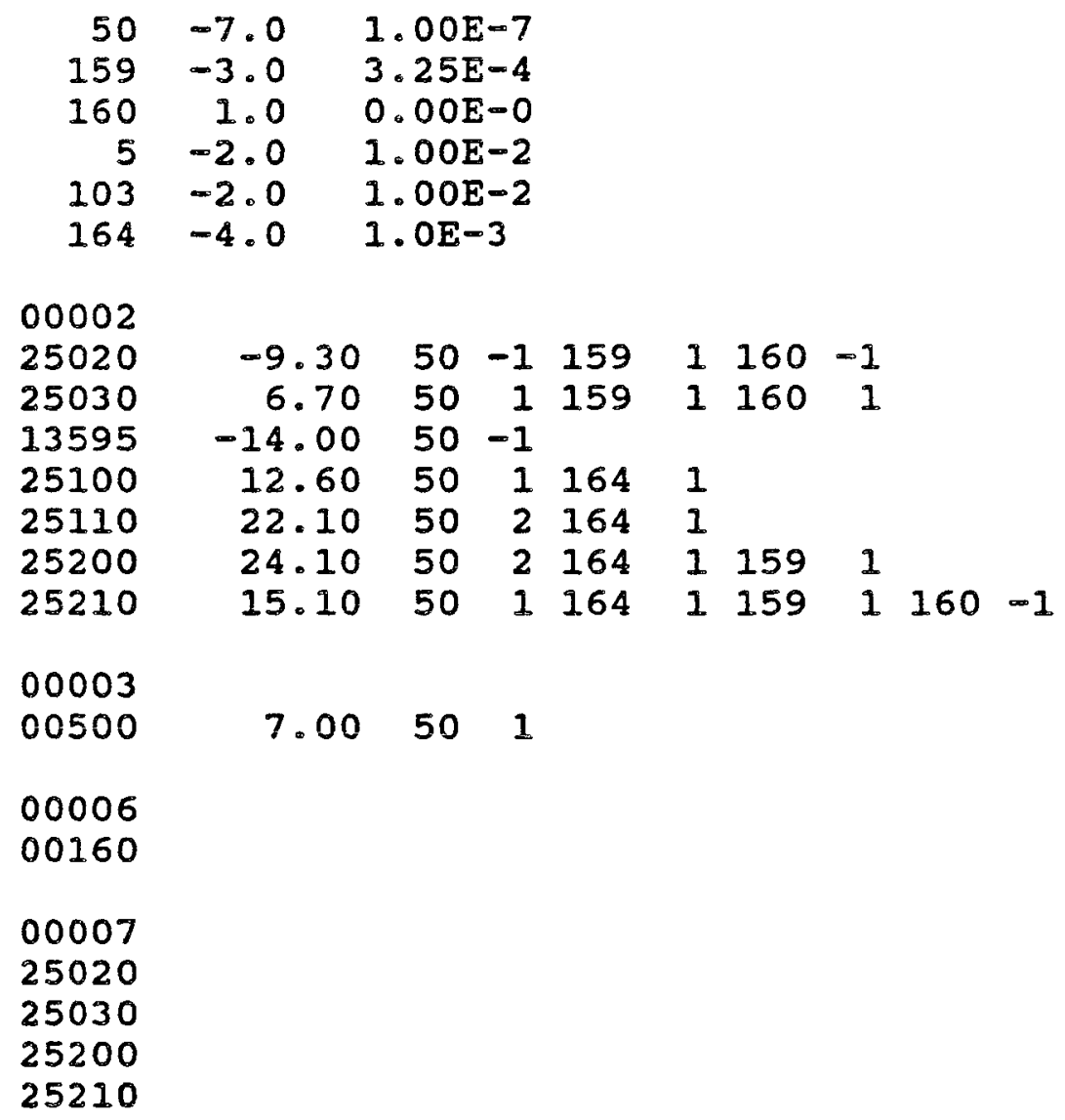




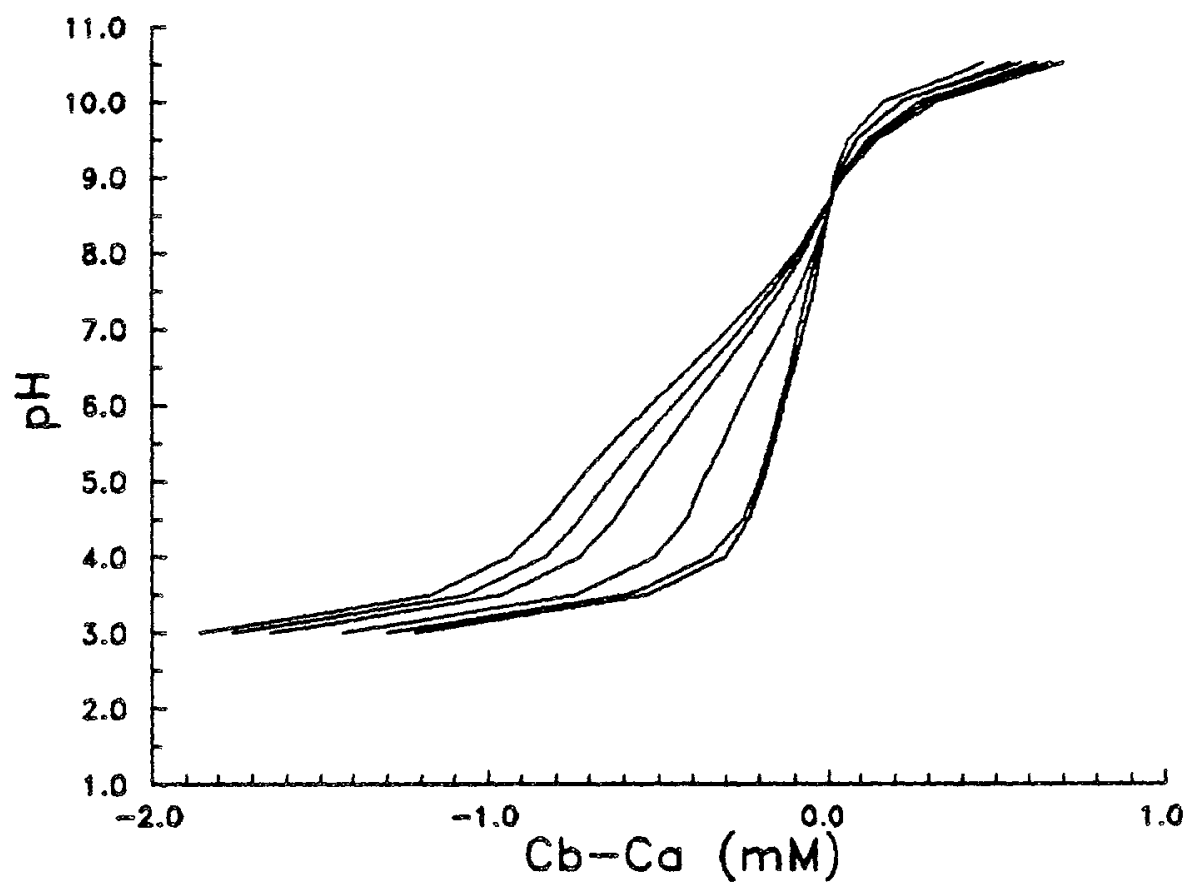

Figure $\mathrm{C}-1$ : Model runs $\mathrm{W} / \mathrm{variable}$ surface area for $\mathrm{Al}_{2} \mathrm{O}_{3}$ model parameters: $10 \mathrm{gL}-1$, capacitance $1.75 \mathrm{Fm}^{-2}, 1.3$ sites $\mathrm{nm}^{-2}$, $\mathrm{pK}^{\mathrm{s}}$ al 10.0 , $\mathrm{pK}^{\mathrm{S}} \mathrm{al}-6.7$, Left to Right (lower) $40,35,30$, $20,10,5 \mathrm{~m}^{2} \mathrm{~g}^{-1}$. 


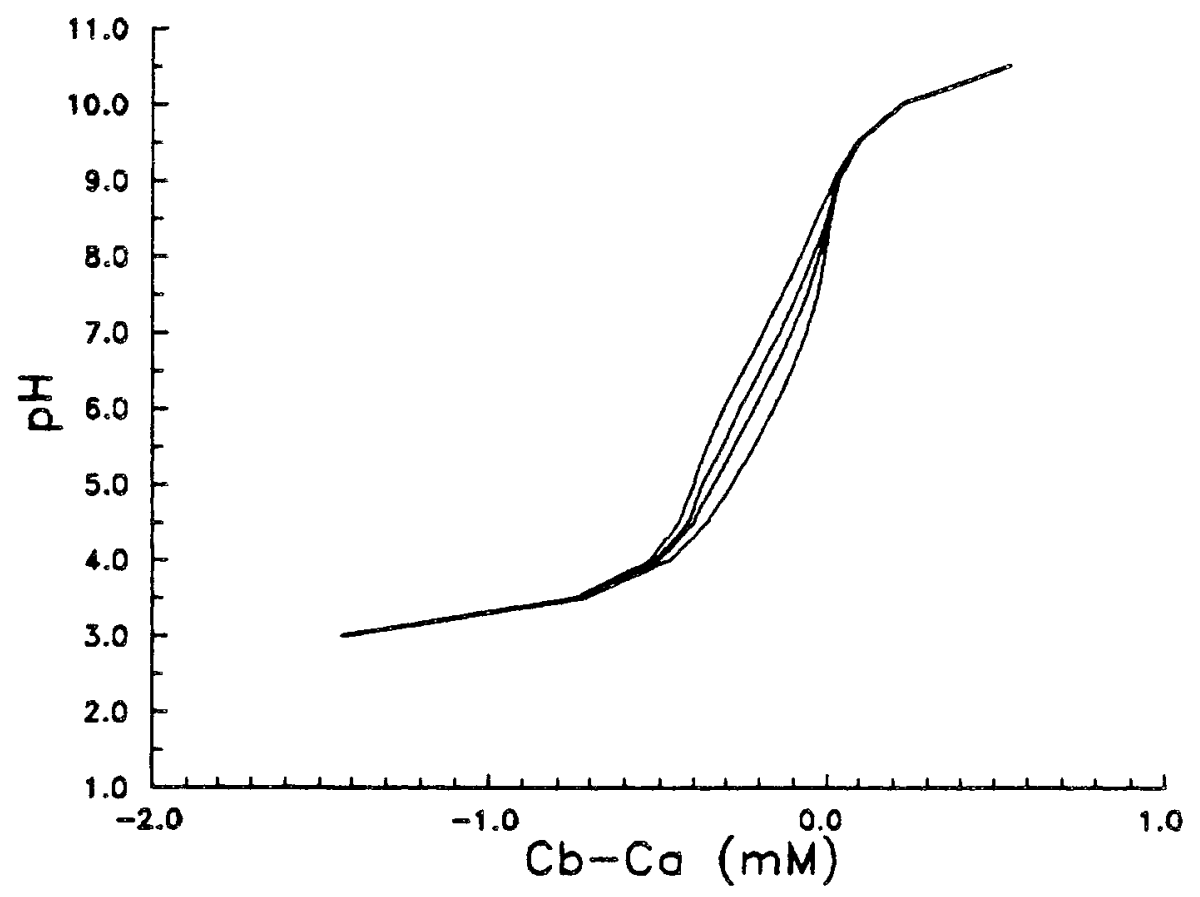

Figure C-2: Model runs w/variable pK's for $\mathrm{Al}_{2} \mathrm{O}_{3}$, model parameters: $10 \mathrm{gL}^{-1}, 15 \mathrm{~m}^{2} \mathrm{~g}^{-1}$, L to $\mathrm{R}-7.8,10 ;-7.4,10 ;-7.0,10 ;-6.5,10$. 


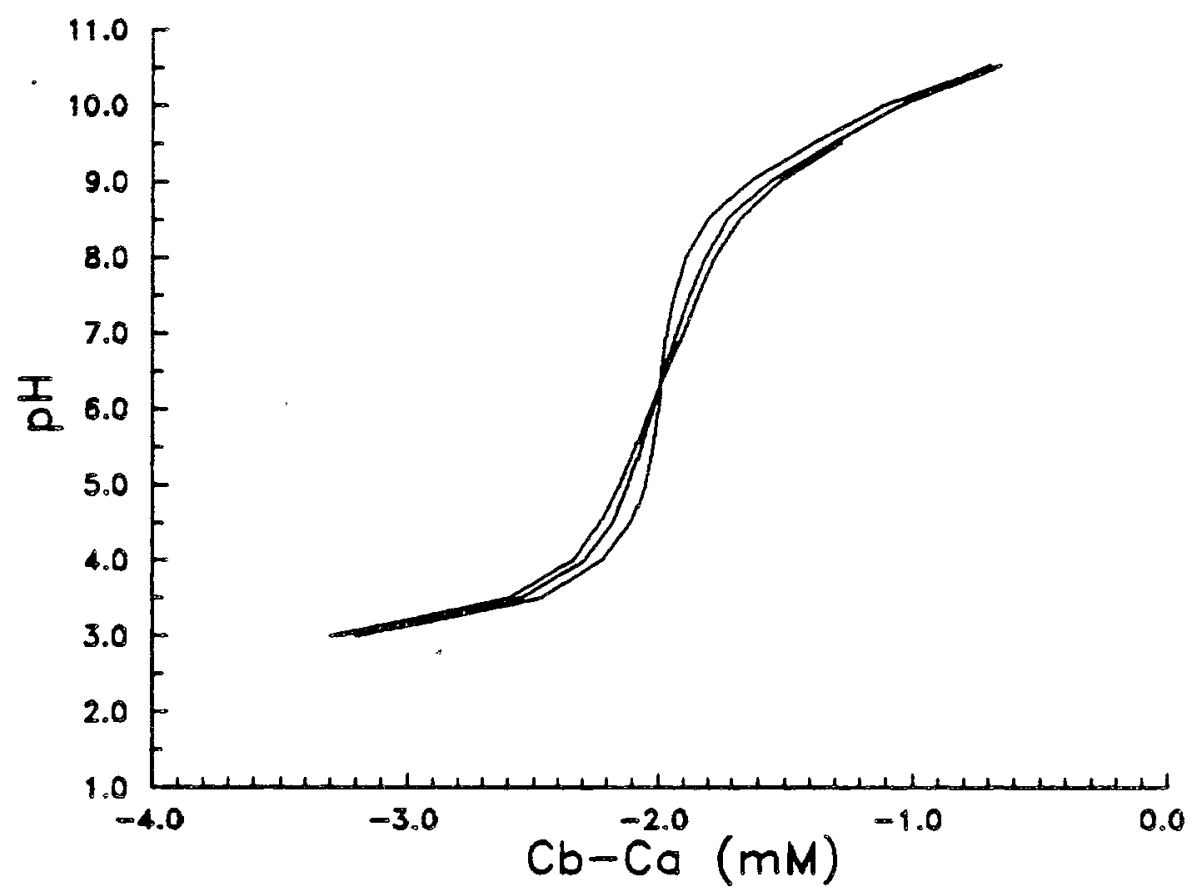

Figure $c-3:$ Model runs w/variable pK's for ligand exch. model parameters: $10 \mathrm{gL}^{-1}, 15 \mathrm{~m}^{2} \mathrm{~g}^{-1}$ capacitance $1.75 \mathrm{Fm}^{-2}, 1.3$ sites $\mathrm{nm}^{-2}$, $\mathrm{pK}^{\mathrm{S}} \mathrm{al} 9.3, \mathrm{pK}_{\mathrm{S}} \mathrm{al}-6.7$, L to $\mathrm{R}$ (top) for the Iigand exchange $\mathrm{pK}$ 's $5,-3 ; 4,-3 ; 3,-3$. 
REFERENCES CITED

Ali, W., O'Melia, C.R. and Edzwald (1984). Colloidal Stability of Particles in Lakes: Measurement and Significance. Water Sci. Technol., 17, 701-712.

Bales, R.C, Newkirk, D.D., and Hayward, S.B. (1984). Chrysotile Asbestos in California Surface Waters: From Upstream Rivers Through Water Treatment. I. Amer. Water Works Assn.. 76:5, 66-74.

Bales, R.C. Surface Chemical And Physical Behavior of Chrysotile Asbestos in Natural Waters and Water Treatment. Envir. Engr. Sci. Report AC-8-84, Calif. Inst. Technol., Pasadena, CA.

Birkner F.B. and J.J. Morgan (1968). Polymer flocculation kinetics of dilute colloidal suspensions. $\mathrm{J}$. Amer. Water Works Assn., 60, 175-191.

Bowers, A.R., and Huang C.P. (1984). Adsorption Characteristics of Polyacetic Amino Acid onto Hydrous $\alpha-\mathrm{Al}_{2} \mathrm{O}_{3}$. J. Colloid and Inter. Sci., 105, 197-205.

Brace, R. and Matijevic, E. (1973). Aluminum Hydrous Oxide Sols I, J. Inorg. Nucl. Chem., 35, 3691-3705.

Chowdhury, Z., Amy, G., and Bales, R., (in press). Chemical Coagulation of Submicron Particles, Proc. Amer. Water Works Assn. 1987 Annual Conf., Kansas City, MO, June 23-28.

Chowdhury (1988). Coagulation of submicron colloids in Water Treatment, University of Arizona, Tucson, Ph.D. dissertation.

Cornwall and Bishop (1983). Determining Velocity Gradients in Laboratory and Full-scale Systems, J. Amer. Water Works Assn., 9 , 470-475.

Edzwald, J.K., Upchurch, J.D. and O'Melia, C.R. (1974). Coagulation in Estuaries, Envir. Sci. Technol., 8 : 58-63.

Furlong, D.N., Freeman, P.A., and A.C. Lau, The Adsorption of Soluble Silica at Solid-Aqueous Solution

Interface. J. Colloid and Interface Sci., 80, 20-31. 


\section{REFERENCES CITED-Continued}

Gibbs, R.J. (1983) . Effect of Natural organic Coatings on the Coagulation of Particles, Envir. Sci. Technol., $17: 237-240$.

Hahn, H., and W. Stumm (1968). Kinetics of coagulation with hydrolyzed AI(III), J. Colloid and Interface

Sci. $28,134-144$.

Huang, C., and W. Stumm (1972). Specific Adsorption of Cations on Hydrous $\mathrm{Al}_{2} \mathrm{O}_{3}, \mathrm{~J}$. Colloid and Interface Sci., 43, 409-433.

Kummert, $R$. and stumm, $W(1980)$. The Surface complexation of Organic Acids on Hydrous $\mathrm{Al}_{2} \mathrm{O}_{3}, \mathrm{~J}$. Colloid Interface Sci. 72,373 .

Lai, R. Hudson, H., and J. Singley (1975). Velocity Gradient Calibration of Jar-Test Equipment, J. Amer. Water Works Assn., 10, 553-557.

Letterman, R.D., and P. Sricharoenchaikit (1982). Interaction of Hydrolyzed AI and Polyelectrolyte Coagulants, J. Envir. Engr. Div., 5, 883-899.

O'Melia, C.R. (1985). The Influence of Coagulation and Sedimentation on the Fate of Particles, Associated

Pollutants, and Nutrients in Lakes, Chemical Processes in Lakes, W. Stumm Ed., Wiley, 207-224.

O'Melia, C.R. (1980). Aquasols: Behavior of Small Particles in Aquatic Systems, Envir. Sci. Technol., 14, 1052-1050.

Osman-Sigg, G.K. (1982). Kolloidale und suspendierte Teilchen in nauturlichen Gewassern:

Partikelgrossenverteilung und Naturliche Koagulation in Zurichsee. Eidgenossischen Technischen Hochschule Zurich, Ph. D. dissertation number 6986.

Stumm W. and J.J. Morgan (1981). Aquatic Chemistry, 2nd ed. Wiley, New York.

Stumm. W., Kummert, R., and L. Sigg (1980). A Ligand Exchange Model for the Adsorption of Inorganic and organic Ligands at Hydrous oxide Interfaces, Croatica Chemica Acta, 53, 291-312.

Stumm, W. (1977). Chemical Interaction in Particle Separation, J.Envir. Sci. Technol., 11:1066-1069. 


\section{REFERENCES CITED-Continued}

Swift D.L. and S.K. Friedlander (1964). The coagulation of hydrosols by Brownian motion and laminar shear flow,

J. Colloid Science, 19, 621-647.

Vuceta, J. (1976). Adsorption of $\mathrm{Pb}(\mathrm{II})$ and $\mathrm{Cu}$ (II) on $\alpha$ quartz from Aqueous Solutions: Influence of pH,
Ionic Strength and complexing Ligands. Ph.D. Thesis, Calif. Inst. of Technol., Pasadena, CA

Westall, J., Zachary, J. L., and F. Morel (1976) . MINEQI A Computer Program for the Calculation of Chemical Equilibrium Composition of Aqueous Systems, Technical Note No. 18, Ralph M. Parsons Laboratory, M.I.T., Cambridge MA.

Westall, J. (1980). Chemical Equilibrium Including Adsorption on Charged Surfaces, in Adv. Chem. Series 189, M. Kavanaugh and J.O. Leckie, Ed., American Chemical society, Washington.

Wiese, G.R. and T.W. Healy (1975). Coagulation and Electrokinetic Behavior of $\mathrm{TiO}_{2}$ and $\mathrm{Al}_{2} \mathrm{O}_{3}$ Colloidal Dispersions, J. Colloid and Interface Sei., 51, 427433.

Young, J.R. (1981). A study of the Adsorption of $\mathrm{Ni}$ (II) onto an Amorphous Silica surface by Chemical and NMR Methods, Envir. Engr. Sci. Report AC-8-81, Calif. Inst. Technol., Pasadena, CA. 